Contract No.: $\quad$ 233-02-0056

MPR Reference No.: 8935-134

MATHEMATICA

Policy Research, Inc.

\title{
Implementation of the Building Strong Families Program
}

January 7, 2008

\author{
M. Robin Dion \\ Alan M. Hershey \\ Heather H. Zaveri \\ Sarah A. Avellar \\ Debra A. Strong \\ Timothy Silman \\ Ravaris Moore
}

Submitted to:

Submitted by:

U.S. Department of Health and Human Services

Mathematica Policy Research, Inc.

Administration for Children and Families

Office of Planning, Research, and Evaluation

370 L'Enfant Promenade, SW, 7th Floor, West

Washington, DC 20447

600 Maryland Ave., SW, Suite 550

Washington, DC 20024-2512

Telephone: (202) 484-9220

Facsimile: (202) 863-1763

Project Officers:

Nancye Campbell

Seth Chamberlain

Project Directors:

Alan Hershey

Barbara Devaney 



\section{A C K N OW L E D G M E N T S}

T

The findings described in this report result from the efforts of a great many individuals. They include staff at the Office of Planning, Research, and Evaluation (OPRE) at the Administration for Children and Families, U.S. Department of Health and Human Services, members of the Building Strong Families (BSF) technical workgroup and expert consultants, the research and technical assistance team, the BSF evaluation sites, the site sponsors and funders, the curriculum developers and trainers, and the participants themselves. Our thanks go especially to Nancye Campbell and Seth Chamberlain at OPRE, who continually provide excellent oversight and thoughtful guidance. The research, survey, and technical team contributed in various ways to this report. They include staff at five organizations: Mathematica Policy Research (Sarah Avellar, Barbara Devaney, Robin Dion, Alan Hershey, Glenn Jones, John Mamer, Shawn Marsh, Krisztina Marton, Sheena McConnell, Ravaris Moore, Timothy Silman, Debra Strong, Robert Wood, and Heather Zaveri); MDRC (Barbara Goldman, Chrishana Lloyd, Marilyn Price, and Rebecca Solow); Public Strategies (Courtney Harrison and Mary Myrick); Chapin Hall (Matt Stagner); and Decision Information Resources (Russell and Rosalind Jackson). At MPR, Daryl Hall carefully oversaw the editing process, and Donna Dorsey provided ongoing and consistent administrative support.

Without the creativity, energy, and tenacity of the BSF evaluation sites, this report would not have been possible. We applaud each of the teams at the seven sites, led by Sue Bullard, Cassandra Codes-Johnson, Rebecca Pena Hines, Joe Jones, Phyllis Kikendall, Carol McNally, Dena Morrison, Anita Odom, Becky Solis, Marty Temple, Akilah Thomas, Stefanie Toombs, and Carolyn Wiseheart. We also extend our gratitude to curriculum developers Julie and John Gottman; Pamela Jordan; Mary Ortwein and Bernard Guerney; and Pamela Wilson and their teams, who worked hard to design materials and provide their best guidance throughout the pilot and evaluation in response to the myriad challenges faced by sites. Anne Menard provided wise guidance in the development of site protocols for identifying and addressing domestic violence. Our deepest appreciation is reserved for the couples who agreed to participate in the BSF demonstration and evaluation.

The opinions and conclusions expressed herein are solely those of the authors and do not necessarily reflect the policies or positions of the Administration for Children and Families or the U.S. Department of Health and Human Services. 



\section{O N T E N T S}

EXECUTIVE SUMMARY. xi

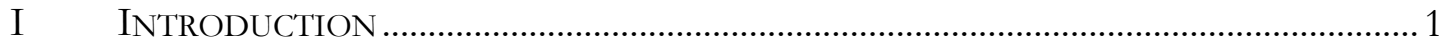

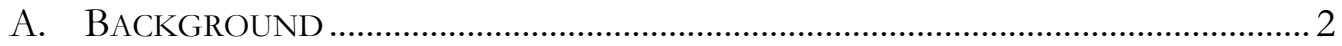

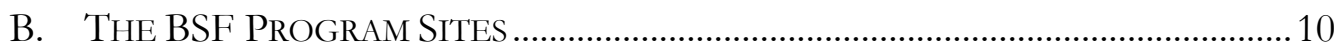

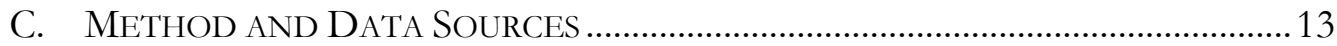

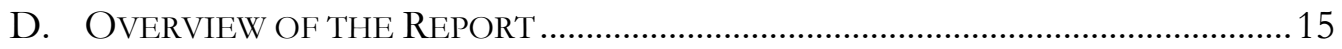

II Program Setting, DeVElopment, And ReSOURCES........................................... 17

A. Organizational Structure of BSF Programs .............................................18

B. BSF PROGRAM PlanNING AND DEVELOPMENT …..........................................23

C. Resources For Program Implementation ..................................................26

III SAMPLE ENROLLMENT AND CHARACTERISTICS ........................................................29

A. Identifying Sources of Potentially Eligible BSF Couples ...............29

B. Strategies for Recruiting Potentially Eligible Couples................... 34

C. EnRollment Progress TO Date ....................................................................46

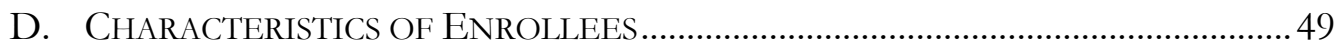


vi

$\begin{array}{lll}\text { Chapter } & \text { Page }\end{array}$

IV IMPLEMENTATION OF THE BSF MARRIAGE AND RELATIONSHIP

SKILLS PROGRAM COMPONENT .......................................................................................... 63

A. Preparation for Group Sessions ..................................................................... 63

B. ENCOURAging Initial ATtENDANCE AT GRoup SesSiOnS..............................69

C. Promoting Ongoing Group Attendance and Completion..................73

V IMPLEMENTATION OF THE BSF FAMILY COORDINATOR COMPONENT AND LINKAGES TO FAMILY SUPPORT SERVICES.........................................................79

A. Delivery of THE FAmily CoORdinator Component ...................................79

B. LINKING COUPLES TO FAMILY SUPPORT SERVICES …………………………...... 87

VI PARTICIPATION IN BSF ........................................................................................ 93

A. AtTENDANCE at MARRIAGE AND RELATIONSHIP SKILLS Group

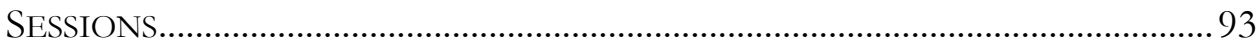

B. INDIVIDUAL CONTACT WitH FAMILY COORDINATORS AND OTHER

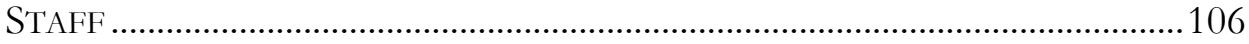

C. AsSESSMENT ANd REFERRALS TO FAMily Support SERVICES .......................109

VII COUPLes’ EXPERIENCES AND PerCePtions of THE BSF Program....................111

A. Participants' Reactions to BSF Services .................................................111

B. REASONS FOR NONPARTICIPATION ……………………………………….......120

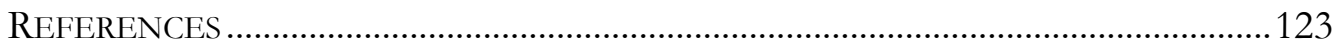

APPENDix A: SUMmARY OF BSF DEVELOPMENT AND IMPLEMENTATION BY SITE.................................................................................. 


\section{T A B L E S}

Table

Page

I.1 Key Features of Marriage and Relationship SKILLS CURricula USED AT BSF SITES 5

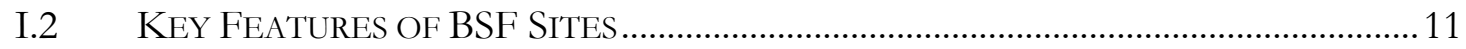

II.1 Potential Implementation Advantages of BSF Program SetTings ........19

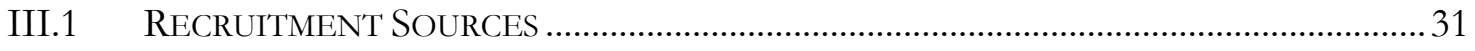

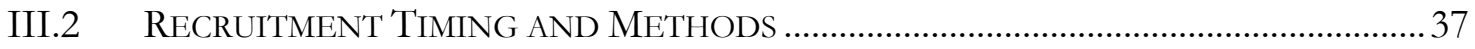

III.3 ReCruitment Practices That MAy CONTRIBUte to ENROLLMENT..................39

III.4 Number of Couples Enrolled by BSF Site And COHORT, Through

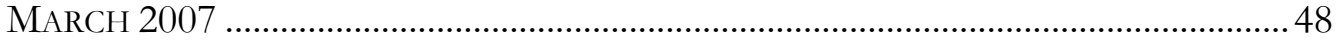

III.5 Average Monthly Enrollment At BSF Sites, By COHORT............................. 49

III.6 BASELINE CHARACTERISTICS OF BSF EVALUATION SAMPLE, BY GENDER ...........51

III.7 INDIVIDUAL-LEVEL BASELINE CHARACTERISTICS OF MOTHERS AND

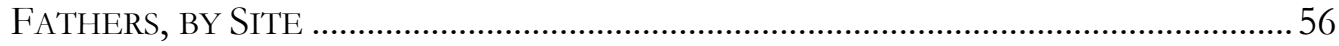

III.8 COUPLE-LEVEL CHARACTERISTICS, BY RACE/ETHNICITY ....................................... 61

IV.1 PRACTICES TO ENCOURAGE INITIAL GROUP ATTENDANCE .................................... 71

IV.2 Practices TO ENCOURAgE Ongoing Group AtTENDANCE ............................... 74

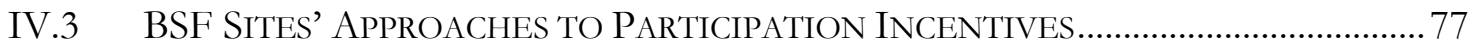


viii

Table

Page

V.1 STAFFING THE BSF FAMILY COORDINATOR COMPONENT

V.2 Site Plans for Primary Mode, Frequency, and Average Length

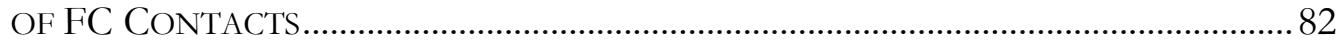

V.3 REINFORCING MARRIAGE AND RELATIONSHIP SKILLS .......................................... 85

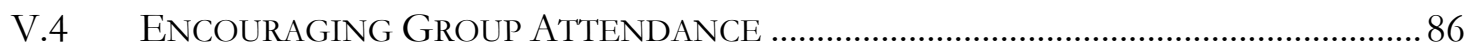

V.5 STAFF AND LOCATION FOR CONDUCTING ASSESSMENTS ......................................... 88

VI.1 Percentage of BSF Program COUPLes Initiating Group ATTENDANCE THROUGH JANUARY 31, 2007

VI.2 Average Number of Hours Attended Group Sessions, Among INITIATORS

VI.3 Percentage of Curriculum ReCEIVED by Program Group........................... 99

VI.4 INDIVIDUAL-LEVEL BASELINE CHARACTERISTICS OF BSF TREATMENT GROUP, BY ATTENDANCE STATUS

VI.5 COuple-LeVEl Baseline Characteristics of TreatMent Group, By ATTENDANCE STATUS 105

VI.6 CONTACTS WITH PROGRAM STAFF OUTSIDE GROUP SESSIONS 108 


\section{F I G U R E S}

Figure

Page

I.1 The BuILding Strong Families Program Model ............................................... 4

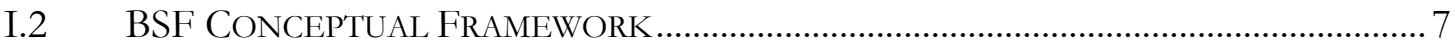

VI.1 Percentage of Couples Receiving Instruction In TOPIC Areas-By

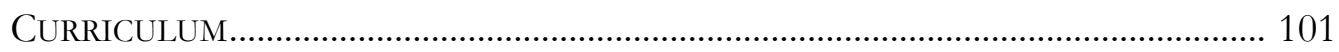

VI.2 PERCENTAge OF COUPLES RECEIVING INSTRUCTION IN CURRICULUM TOPIC

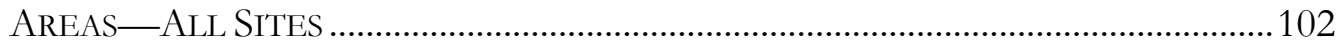





\section{EXE C U T I VE S U M M A R Y}

$\mathrm{B}$ uilding Strong Families (BSF) is a large-scale demonstration of marriage and relationship education programs for low-income, romantically involved, unmarried couples who are expecting or recently had a child together. It is also a rigorous evaluation of the programs' effectiveness. The entire project is sponsored by the Administration for Children and Families, U.S. Department of Health and Human Services. BSF was motivated by findings from the 20-city Fragile Families and Child Well-Being Study which showed that at the time of their child's birth, many unmarried couples have high hopes for marriage, but few couples succeed in that goal (Carlson, McLanahan, and England 2004). BSF aims to learn whether well-designed interventions can help interested unmarried parents strengthen their relationships and, if they choose to wed, achieve their aspirations for a healthy marriage.

The BSF evaluation relies on a rigorous longitudinal research design, with random assignment of eligible couples to either a program or control group. Data are collected at three points: baseline, 15 months after enrollment, and when each BSF child is three years old. The evaluation will examine the impact of BSF on the quality of couple relationships, the decision to marry, family outcomes, and children's well-being. The first impact findings are expected to be available in 2009, but much has already been learned about the implementation of the intervention program.

This executive summary highlights the key findings from an implementation analysis of BSF's seven program sites. The implementation analysis focuses on the programs' design, development, and operations during the first six to 14 months of the evaluation. ${ }^{1}$ It also documents recruitment and enrollment practices, describes the characteristics of enrolled couples, provides data on program participation, and summarizes the experiences of participant couples in the program group. Information for the report draws on qualitative data from comprehensive site visits to each BSF location in the fall-winter of 2006, information from ongoing monitoring efforts, and structured data recorded in each

${ }^{1}$ Although sites had staggered startup dates from June 2005-June 2006, most of the information in this report was collected around the same time period (fall/winter 2006). Consequently, when the information was collected, some sites had more operational experience than others. 
xii

program's management information system. Although the evaluation is still going on and these findings are based on only one stage in the evolution of the BSF programs, they reveal the challenges and successes involved in operating programs for low-income unmarried couples, and also provide context for understanding later analyses of BSF impacts on couples and their children.

\section{Sites Were Guided by a Common Program Model}

To ensure a reasonable degree of consistency across sites, BSF programs were guided by a common set of eligibility criteria and a specific intervention model. Although participation in the program and study was entirely voluntary, eligibility criteria called for couples to have a biologically-related child under the age of three months, or to be expecting a child. In addition, couples had to be either unmarried but romantically involved, or married after the conception of the child that made them eligible for the program. Each member of the couple had to be at least 18 years old and speak a language in which BSF was offered, English or Spanish. Only couples who were not involved in domestic violence were eligible for BSF.

The BSF intervention model included three required components: group instruction in marriage and relationship skills, individual-level program support from "family coordinators," and referrals to additional family services as needed (summarized in Figure 1). Nevertheless, sites were also given the flexibility to develop a program that worked in their local and organizational context.

Figure 1. The Building Strong Families Program Model

\begin{tabular}{|c|c|c|}
\hline $\begin{array}{l}\text { Individual-Level } \\
\text { Support from } \\
\text { Family } \\
\text { Coordinators }\end{array}$ & $\begin{array}{c}\text { Core Component: } \\
\text { Group Sessions in Marriage and } \\
\text { Relationship Skills* }\end{array}$ & $\begin{array}{l}\text { Assessment and } \\
\text { Referral to } \\
\text { Family Support } \\
\text { Services }\end{array}$ \\
\hline $\begin{array}{l}\text { Encouragement } \\
\text { for program } \\
\text { participation } \\
\text { Reinforcement of } \\
\text { marriage and } \\
\text { relationship } \\
\text { skills } \\
\text { Ongoing } \\
\text { emotional } \\
\text { support } \\
\text { Assessment and } \\
\text { referral to } \\
\text { support services }\end{array}$ & $\begin{array}{l}\text { Communication } \\
\text { Conflict management } \\
\text { Affection, intimacy, trust, commitment } \\
\text { Considering marriage } \\
\text { The transition to parenthood } \\
\text { Parent-infant relationships } \\
\text { Children by prior partners } \\
\text { Stress and postpartum depression } \\
\text { Family finances }\end{array}$ & $\begin{array}{l}\text { Education } \\
\text { Employment } \\
\text { Parenting } \\
\text { Physical and } \\
\text { mental health } \\
\text { Child care } \\
\text { Legal issues } \\
\text { Substance } \\
\text { abuse } \\
\text { Domestic } \\
\text { violence } \\
\text { assistance }\end{array}$ \\
\hline
\end{tabular}

*Sample of topics included in marriage and relationship skills curricula. 
Group Sessions in Marriage and Relationship Skills. The central component of BSF programs is group-based education in the skills shown through empirical research to be associated with a healthy marriage. This core element of the BSF program is intended to be intensive, comprehensive, and long-term, to help promote internalization of the skills and information. The curricula that guide the group sessions cover topics common to many relationship and marriage education programs, such as communication and conflict management skills; ways to build fondness, affection, and emotional intimacy; managing how parenthood can affect couple relationships and marriage; enhancing parent-infant relationships, especially the influence of fathers, and recognizing the signs of relationship meltdown. BSF curricula also address specific topics that research suggests are of particular importance in the healthy development of unmarried-parent relationships in low-income families, including the development of mutual trust and commitment, consideration of marriage, management of complex family relationships that may include children from prior relationships, and working together as a financial team.

For the group sessions, each site was free to select any curriculum that met the requirements of the BSF program. ${ }^{2}$ Each of the sites selected one of three research-based curricula adapted specifically for the BSF target population: Loving Couples, Loving Children (LCLC), developed by Drs. John and Julie Gottman; Love's Cradle (LC), developed by Mary Ortwein and Dr. Bernard Guerney; and the Becoming Parents Program for Low-Income, LowLiteracy Couples (BPP), developed by Dr. Pamela Jordan. Prior to adaptation, these curricula had shown positive impacts on couples' relationships in samples of mostly married, middleincome, typically white couples. The adaptations for BSF included adding new topics to address issues specific to low-income unmarried couples as described above, as well as changes to the reading level and cultural sensitivity represented in curriculum materials, reducing the amount of lecture, and increasing group discussions and hands-on activities.

Each curriculum is about 30 to 42 hours in length, and was provided in weekly segments that take from one and a half months to six months, depending on format. Five BSF sites implemented the LCLC curriculum, which is typically provided in weekly 2-hour modules over 5 to 6 months (42 total hours). The recommended group size for LCLC sessions is 4 to 6 couples (8 to 12 individuals). One site implemented the adapted 30-hour BPP curriculum and offered two formats: 3-hour weekly sessions for 10 weeks or 5-hour weekly sessions for 6 weeks. Group size typically ranged from 10 to 15 couples. The final BSF site implemented LC, which was most often provided in 2-hour weekly modules for 5 to 6 months and aimed to include 6 to 8 couples per group.

${ }^{2}$ To ensure there would be a reasonable degree of consistency across programs for the evaluation and still provide local sites with some flexibility and choice, curriculum criteria were established in the BSF Program Model Guidelines (Hershey et al. 2004). Guidance was included on the desired intensity and duration, instructional format, and specific topics to be covered. Sites were encouraged to select a curriculum with a strong research base. 
xiv

Individual Support Through Family Coordinators. To help couples address the often complex challenges in their lives, the program model called for each BSF family to be assigned a staff member who would meet individually with the couple. These family coordinators (FCs) were expected to identify families' needs, provide linkages to support services, encourage BSF program participation and completion, and reinforce marriage and relationship skills learned during group sessions. Each BSF site was free to define the frequency, duration, and mode of FC meetings with couples.

Connection to Family Support Services. Personal and family challenges can impede the progress of unmarried couples as they work to form and sustain stable and healthy relationships and marriages. Most communities have existing resources targeting lowincome families, but parents may not be aware of or know how to access these services. For these reasons, the third component of the BSF model is linkages to family support services. The model called on sites to ensure that FCs had at their disposal information about services available in the community, such as employment and education programs, mental health and substance abuse treatment, and child care and housing resources, and to train them to assess family members and provide referrals to appropriate services.

\section{THE BSF SITES}

The aim of the BSF project is to assess the effectiveness of well-implemented programs. To be part of the evaluation, sites had to complete a pilot phase and demonstrate their ability to (1) effectively implement the BSF program consistent with the model guidelines, (2) recruit enough couples to meet sample size targets, and (3) comply with evaluation requirements such as consent procedures and baseline form administration. Seven sites, briefly described below, participated in the pilot period and were selected for inclusion in the evaluation.

- Atlanta, Georgia: Georgia Building Strong Families. The Health Policy Center at Georgia State University (GSU) and the Latin American Association, a nonprofit community-based organization, serve BSF couples in Atlanta. GSU leads the site, conducts all outreach and recruitment, and serves Englishspeaking couples. The Latin American Association serves Spanish-speaking couples.

- Baltimore, Maryland: Baltimore Building Strong Families. The Center for Fathers, Families, and Workforce Development (CFWD; now known as the Center for Urban Families) is a community-based organization for low-income families in Baltimore. CFWD expanded from primarily providing employment and responsible fatherhood services to offering a workshop-based co-parenting program to low-income parents, which inspired them to offer BSF.

- Baton Rouge, Louisiana: Family Road Building Strong Families. Family Road of Greater Baton Rouge, a non-profit organization, focuses on the needs of low-income expectant and new parents. Through community partnerships, parents can access childbirth education, fatherhood programs, parenting classes, 
money management, counseling, and home visiting for at-risk mothers and children on-site. With existing services for new mothers and fathers, BSF's couples-based program was a natural addition.

- Florida: Healthy Families Plus. Healthy Families Florida, a home visiting program to prevent child abuse for at-risk parents run by The Ounce of Prevention Fund of Florida, integrated BSF services with Healthy Families, an intensive home-visiting program to prevent child abuse and neglect. Two counties, Broward (Fort Lauderdale) and Orange (Orlando), offer the integrated program.

- Indiana: Healthy Couples, Healthy Families Program. Like Florida, Indiana embedded BSF in its existing Healthy Families home visiting service. Three counties (from seven separate locations) offer the combined program. ${ }^{3}$ A non-state agency with the largest Healthy Families caseload in the state, SCAN, Inc. coordinates the program.

- Oklahoma: Family Expectations. Family Expectations grew out of the Oklahoma Marriage Initiative, which is managed by Public Strategies, Inc. under contract from Oklahoma Department of Human Services. The site offers BSF to low-income unmarried couples, and similar services to low-income married couples as part of another demonstration.

- Texas: Building Strong Families Texas. Former Healthy Families programs in two Texas locations, Houston and San Angelo, transformed their home visiting services by offering BSF only to unmarried couples meeting BSF eligibility criteria.

\section{SITES IMPLEMENTED BSF IN VARIED ORGANIZATIONAL FRAMEWORKS}

The BSF sites have demonstrated that the program model can be implemented in a variety of organizational contexts. The sites took three different implementation approaches. Baton Rouge and Baltimore added BSF as a new program with its own staff under their existing multi-program umbrellas. Florida, Indiana, and Texas used existing staff infrastructure to integrate BSF into their Healthy Families home visiting services. Atlanta and Oklahoma City developed BSF operations from the ground up by hiring new staff and establishing new infrastructure for service delivery.

Sites adopted these implementation approaches because they offered specific advantages within the existing environment, such as an infrastructure on which to build, or a center-based facility with which low-income families were already familiar. Each site, however, had to confront challenges inherent in their chosen approach. For example, when

3 During the pilot period, Indiana operated BSF in four counties. Due to low enrollment, full implementation occurred in three counties. 
integrating BSF into Healthy Families, sites faced the challenge of reconciling a longestablished service delivery approach and procedures with the new goals and operational demands of BSF. Sites that did not build on a pre-existing staff infrastructure required more time and effort to create certain BSF components such as the family coordinator, but were free of constraints associated with pre-existing procedures and sometimes competing goals. Unlike other sites, the two that developed from the ground up had to identify and forge relationships with local family support services to be able to link couples. All sites, regardless of organizational setting, had to hire at least some new staff or retain contract staff to lead the group sessions. Importantly, all sites had to learn how to recruit and work with couples - a new concept in the delivery of social services for low-income parents.

\section{Recruitment Outcomes SHow That BSF SucCeEded IN GaINING THE INTEREST of Couples, Not Just Individual PaRENTs}

Prior to BSF, it was not known whether voluntary marriage education programs could attract large numbers of low-income, culturally diverse unmarried couples. As of March 31, 2007, BSF sites had enrolled 2,684 couples (5,368 individual parents). Monthly enrollment varied across sites, from 20 to 43 couples on average. Data from the most recent six months of enrollment in which all sites had reached "steady state" (October 1, 2006 to March 31, 2007) indicate that the seven BSF sites together were enrolling an average of about 210 couples per month.

\section{Enrollment Was the Product of Complex Factors Related to Recruitment Practices, Site Context, and Management Control}

Many factors affected success in recruitment. Recruiting practices undoubtedly played a role, but they very likely interacted with other factors such as size of the community in which recruitment occurs, length of the site's experience, organizational capacity and staffing changes, and continued access to a steady source of potentially eligible couples. The enrollment pace was quite variable across and within sites, reflecting temporary disruptions often due to staff turnover which affected the site's resources for and focus on recruitment. Enrollment increased when programs secured more overall program resources and devoted greater resources to recruitment, or identified new recruitment sources or strategies to identify eligible couples. Long experience did not necessarily lead to pre-eminence in recruitment; sites that started earliest were sometimes outstripped in enrollment success by later start-up sites. Breakthroughs in recruitment methods-which were specific to sitesseem more instrumental in achieving high enrollment than simply the accumulation of experience.

\section{WHO ENROLLS IN BSF?}

BSF is a new kind of voluntary program, and little was known about the couples it would attract. Although couples must meet eligibility criteria related to marital and relationship status and age of their child, it was unclear beyond that who would be interested in the program. Using data collected at intake from mothers and fathers, we can construct a portrait of the demographic characteristics, economic well-being, personal attitudes, and 
feelings about their relationship, for the 2,684 couples enrolled from the start of the evaluation through March 31, 2007.

Individuals who enrolled in BSF were young, often had children from prior relationships, and represent the diverse populations served by the site organizations. Over half the recruited sample members were African American; about one-quarter were of Hispanic origin, and about 14 percent were non-Hispanic white. Study participants were typically in their mid-twenties, and had two children, on average (one of which was the BSF child). Although having children by other partners was common, the BSF child was the couple's first child together for nearly half of the sample.

Most enrollees had a high school education, and current work experience, but individual earnings were often low. Slightly more than 66 percent of both men and women had at least a high school degree. More than three-quarters of men were working at baseline, but only about one-quarter of women were employed (a finding most likely related to the eligibility requirement that women be pregnant or within three months of delivering a child). More than three-quarters of women and 93 percent of men reported some earnings in the year prior to enrollment. Earnings were low for most, with half of men and twothirds of women reporting earnings below $\$ 15,000$ in the year prior to enrollment. More than 80 percent of women in the sample received some sort of public assistance for themselves or their children, such as Medicaid, SCHIP, or the Special Supplemental Nutrition Program for Women, Infants, and Children (WIC), but few (10 percent) were receiving Temporary Assistance for Needy Families (TANF).

Most couples were cohabiting at intake and had high hopes for marrying each other. More than 70 percent of the enrolled couples were unmarried cohabiters. The average couple reported knowing each other for more than three years and most believed their chances of marrying one another were high. Most respondents reported believing that marriage is ideal for children, but also saw single parenthood as adequate. A measure of relationship quality suggested that, on average, relationships were good.

Outside social support was high, attendance at religious services modest, and the prevalence of serious mental illness low at baseline. The vast majority of respondents indicated they had sources of social support, such as people who could provide emergency child care or loan them $\$ 100$. The average frequency of attendance at religious services during the prior 12 months was reported by both men and women to be a few times a year. A measure of distress found that only a few men or women (less than 10 percent) had clinical characteristics associated with serious mental health problems.

\section{The Maternal Health Care System Was a Frequent Source of Potentially Eligible COUPLES}

BSF programs had to enroll unmarried couples during the short "window" of pregnancy and up to three months after the birth of their baby. This narrow window challenged sites to identify avenues through which their own staff or staff of other organizations could come into contact with the target population and implement an efficient 
xviii

outreach and intake process. Although many recruitment sources were identified, the maternal health care system was the most common, since it is a frequent destination for expectant couples and new parents. The majority of sites recruited from prenatal clinics and birthing hospitals, and most used multiple sources within this system. In addition to hospitals and clinics, some sites also recruited through a range of social service providers, including WIC, Head Start, Catholic Charities, Medicaid, TANF, and local community based organizations.

Some sites supplemented such targeted referral sources with broad outreach methods. These sites believed broad outreach was important because it informed the community about BSF, could help the site meet its recruitment targets, and gave evidence of the organization's commitment to the community. Typical outreach strategies included public service announcements, street outreach, mass mailings, and community events and presentations. Some BSF participants learned of the program through word of mouth.

\section{Recruitment Success Seemed Most Likely When First Contact Was in Person and Both Parents Were Approached Together}

BSF sites were required to enroll couples rather than individual parents, but to ensure confidentiality of their responses, each member of the couples had to complete intake forms separately. Sites developed strategies for efficiently recruiting couples, identified staff who were able to quickly build rapport, and learned to present BSF in an appealing manner to couples.

Initiating contact in-person at locations frequented by potentially eligible parents came to be a common strategy. Although a minority of sites conducted telephone outreach by calling couples who were likely to be eligible, most sites relied heavily on a direct in-person approach. Outreach staff often stationed themselves at locations frequented by potentially eligible parents, such as clinics and hospitals that serve low-income parents. Passive approaches, such as expecting couples to call in as a result of posters or flyers distributed to the general public, were not relied on as a major source of recruitment.

The most expeditious enrollment method was to conduct outreach and intake in one step with both members of the couple present. Because eligible couples could be "lost" before there was an opportunity to conduct intake with one partner and then the other in a later encounter, sites increasingly strove to conduct intake with both parents simultaneously. When joint enrollment was not possible, sites aimed to streamline outreach and intake to a single encounter with each parent. Generally the fewer contacts needed to complete intake with both parents, the more likely it was that an eligible couple would be enrolled.

To convey that BSF is for couples, some sites believed that recruitment staff should be male-female teams. Two sites used a mixed-gender team approach. Atlanta had four male and two female staff members who were stationed at the hospital clinic where most recruiting occurred, and they spontaneously formed two-person outreach teams when a pregnant woman and her partner appeared. They believed rapport with couples developed 
more easily, because each member of the couple had someone of their own gender to whom they could relate. Baton Rouge recruited male and female outreach workers. As a team, they jointly made presentations about the program to groups of expectant mothers, and conducted intake, pairing the male worker with the male member of the couple when present. Other sites deployed individual staff, male or female, usually in keeping with existing procedures or organizational constraints.

During recruitment, outreach staff emphasized services to enhance couple relationships and marriage and expressed enthusiasm for BSF. Especially in the beginning, many sites expected that the potential benefits for children would be an important motivator for couples to enroll in BSF. This was true in many cases. However, in experimenting with recruitment messages, a few sites reported that some couples seemed even more motivated by messages that focus on the potential benefits to the couple themselves. Some parents explained that although they were aware of many services intended to benefit their child, BSF was the only program they had encountered that was intended to focus on the parents' relationship, and they valued this unique feature.

Domestic violence screening was an important element during intake and also later, as couples participated in BSF. Identifying couples experiencing domestic violence was a major concern for BSF sites, as they recognized the possibility that if a couple was experiencing domestic violence, participating in group-based marriage and relationship skills education could aggravate the situation and increase risk. In consultation with local or statelevel domestic violence coalitions or national experts, sites developed protocols and screening procedures. Couples who did not pass the screening at intake were excluded from $\mathrm{BSF}$ and were connected with alternative services to ensure safety. Couples who passed the screening and entered the program continued to be monitored for signs of domestic violence during the full period of their program participation.

\section{All Sites Successfully Implemented the Core MarRiage and Relationship SKILLS COMPONENT}

According to the BSF model, group sessions on marriage and relationship skills for couples - rather than individual parents - were to be the centerpiece of the intervention. The organizations sponsoring BSF were breaking new ground, since large-scale, group-based help with relationships for low-income couples was not common before BSF. Sites therefore had to learn what kinds of individuals made the best group facilitators, identify what program formats would work for the schedules of most low-income couples, and determine what programmatic features would be necessary to encourage long-term attendance and completion.

Group sessions were generally led by at least one lead facilitator and a cofacilitator, usually a male and female. Sites uniformly believed that mixed gender teams were important to convey the sense that the program is intended for both men and women, and to give all participants someone of their own gender with whom to relate. 
Lead facilitators usually had a bachelor's or master's degree in psychology, counseling, family therapy, education, public health or a similar discipline. Although sites differed in their preferences for background and experience, most required that the lead facilitator have at least a bachelor's degree. In about half the locations, the lead facilitators had master's degrees. Co-facilitators and "coaches" (staff who provide individual assistance to couples as they practice communication skills during group sessions) were often someone from the community, a family coordinator, or other individual with perhaps less education and experience but who had the ability to relate well to the couples being served. Although a few locations used some existing staff, most sites hired new staff or used contract staff to fill lead facilitator and co-facilitator positions.

Sites frequently sought group facilitators with experience working with low-income children and families or facilitating groups, though not necessarily couples' groups. Some sites looked for personal experience with marriage or parenting. Several particularly valued individuals who were married, because they could draw on that experience during group facilitation. When a group facilitator pair was married to each other, they could also function as role models.

All group facilitators and co-facilitators attended intensive curriculum training; many also received expert supervision for an extended period. Curriculum training required 3-5 full days, with substantial opportunity for hands-on practice facilitating groups and teaching the material. In most cases, training was provided by the curriculum developers, especially during the first year or so of operations. Eventually, other persons who were certified by the developer provided training as sites expanded or replaced staff. Following training, each curriculum developer offered subsequent technical assistance or supervision, although the extent of this supervision varied significantly by curriculum.

Sites made arrangements to prevent potential barriers to group attendance. Most of the organizations sponsoring BSF already had long experience working with low-income families (though not usually couples) and were aware of issues that could impede their participation in the group sessions. They aimed to identify locations for group sessions that were already known to the low-income community or that were easily accessible and familyfriendly. They offered bus tokens or gas vouchers, or used a program van to pick up participants. Some sites offered on-site child care during group sessions, while others reimbursed couples for this care. All sites held sessions outside of standard business hours, and ensured that both facilitators and space were available evenings and weekends.

\section{Achieving High Levels of Ongoing Participation Presented Challenges}

Once groups began, sites found that not everyone who enrolled and agreed to attend actually carried through on their stated intentions. Across all sites, 61 percent of enrolled couples attended at least one group session. Although a range of reasons were given for nonparticipation, staff at many sites thought the most common explanation was changes in the work schedules of participants. The work schedules of these low-income couples often appeared to be unstable, complicating both the initial scheduling and ongoing attendance at group sessions. Although all sites offered group sessions during evenings and weekends 
when couples were more likely to be available, participants frequently obtained new employment (especially mothers, who often went back to work after recovering from childbirth), lost jobs and gained jobs with a schedule that conflicted with that of the group sessions, or had work with hours that varied from week to week. Other reasons for nonattendance included family illness or a lack of time. Although site staff recognized that some absences would be unavoidable, they nevertheless found a range of strategies to get couples started and encourage as much attendance as possible.

Actively encouraging couples to initiate attendance became an important priority. While sites learned that not all couples would attend group sessions, they also noticed that couples who attended once tended to return for more sessions. To encourage initial group participation and avoid loss of interest, sites tried to engage couples in some form of BSF activity between enrollment and the first group session. For example, some held orientation sessions to demonstrate what the group sessions would be like, or arranged "meet and greet" events to which all enrolled couples were invited. In some sites, family coordinators or group facilitators met with couples prior to the first scheduled group session either in the couple's home or the program office. One location invited couples already participating in BSF to the initial session of other groups to provide firsthand testimony of their experiences in the program.

BSF sites were energetic and creative in encouraging ongoing group attendance throughout the curriculum cycle. They made reminder calls about upcoming group sessions, contacted couples to follow up on absences, and in some cases covered missed curriculum material in make-up sessions. Ongoing social activities (such as "date nights" or holiday events) were hosted to foster a sense of friendship and belonging; and celebrations were held to honor engagements and weddings, as well as attendance milestones or completion. Sites also learned that offering group sessions in a comfortable setting encouraged ongoing attendance, especially for pregnant women who often needed to elevate their feet at the end of a long day. Despite these measures, couples often became unable to attend their regularly scheduled group due to changes in their personal schedules. To address this issue, flexibility became important and led some sites to allow couples to transfer between groups.

Almost all BSF sites offered some sort of incentive for participation. In most cases, these incentives were in the form of gift certificates or baby items. The emphasis that sites placed on incentives varied substantially across sites. Some viewed incentives as a primary tool for encouraging attendance and actively promoted them, while other sites provided incentives only intermittently as an unexpected reward for participating.

\section{Although Not All Couples Attended Group Sessions, Those Who Did Got a SUBSTANTIAL "DOSE"}

A basic measure of participation in BSF is the percentage of couples that attended one or more sessions of the core marriage and relationship skills groups. Across all sites, 61 percent of the early program sample attended BSF group sessions one or more times (Table 1). Rates of initial attendance varied widely across program sites, from 40 to 80 
xxii

percent. Although lower than hoped, the rate at which couples ever attend BSF group sessions is similar to that reported by evaluators of standard marriage education interventions with middle-class couples. ${ }^{4}$

Averaged across sites, couples who initiated attendance participated in about 21 hours of group sessions. This is about half the total number of hours offered at most sites. The overall average obscures substantial variation across sites, which ranged from 13 to 29 hours. There is no basis for judging at this point what dosage is sufficient to achieve impacts on couples and children, but the average of 21 hours exceeds the dosage maximum in other marriage education programs, including those that have demonstrated positive impacts on couple relationships and marriage albeit with more advantaged populations (Markman et al. 1993; Guerney et al. 1981; Russell et al. 1984). Of course, the average BSF dosage of 21 hours was only received by those couples who initiated attendance, so the average dosage across the entire program group including those who never attended is lower.

Table 1. Participation in BSF Program Activities

\begin{tabular}{|c|c|c|c|c|c|}
\hline & $\begin{array}{l}\text { Percentage of } \\
\text { Program } \\
\text { Group } \\
\text { Initiating } \\
\text { Group } \\
\text { Attendance }\end{array}$ & $\begin{array}{l}\text { Average } \\
\text { Number of } \\
\text { Total Hours } \\
\text { Attended } \\
\text { Group } \\
\text { Sessions, } \\
\text { Among } \\
\text { Initiators }\end{array}$ & $\begin{array}{l}\text { Percentage of } \\
\text { Program } \\
\text { Group Ever } \\
\text { Contacted by } \\
\text { Staff Outside } \\
\text { of Group }\end{array}$ & $\begin{array}{l}\text { Average } \\
\text { Number of } \\
\text { Monthly } \\
\text { Contacts Per } \\
\text { Program } \\
\text { Group Couple }\end{array}$ & $\begin{array}{l}\text { Percentage of } \\
\text { Program } \\
\text { Group } \\
\text { Couples Who } \\
\text { Received a } \\
\text { Referral to } \\
\text { Support } \\
\text { Services }\end{array}$ \\
\hline Total & 61 & 21 & $\mathrm{~N} / \mathrm{A}$ & $\mathrm{N} / \mathrm{A}$ & $\mathrm{N} / \mathrm{A}$ \\
\hline $\begin{array}{c}\text { Atlanta } \\
\text { GSU } \\
\text { LAA }\end{array}$ & $\begin{array}{l}79 \\
70\end{array}$ & $\begin{array}{l}22 \\
29\end{array}$ & $\begin{array}{l}82 \\
96\end{array}$ & $\begin{array}{l}2 \\
1\end{array}$ & $\begin{array}{c}3 \\
26\end{array}$ \\
\hline Baltimore & 61 & 19 & 100 & 2 & 27 \\
\hline Baton Rouge & 64 & 22 & 98 & 2 & 25 \\
\hline $\begin{array}{l}\text { Florida } \\
\text { Broward County } \\
\text { Orange County }\end{array}$ & $\begin{array}{l}65 \\
61\end{array}$ & $\begin{array}{l}13 \\
16\end{array}$ & $\begin{array}{l}84 \\
91\end{array}$ & $\begin{array}{l}4 \\
5\end{array}$ & $\begin{array}{l}62 \\
75\end{array}$ \\
\hline $\begin{array}{l}\text { Indiana } \\
\text { Allen County } \\
\text { Lake County } \\
\text { Marion County }\end{array}$ & $\begin{array}{l}50 \\
50 \\
40\end{array}$ & $\begin{array}{l}26 \\
19 \\
28\end{array}$ & $\begin{array}{c}100 \\
91 \\
100\end{array}$ & $\begin{array}{l}8 \\
4 \\
4\end{array}$ & $\begin{array}{l}64 \\
76 \\
87\end{array}$ \\
\hline Oklahoma & 80 & 24 & 100 & 4 & 61 \\
\hline $\begin{array}{l}\text { Texas } \\
\text { Houston } \\
\text { San Angelo }\end{array}$ & $\begin{array}{l}43 \\
57\end{array}$ & $\begin{array}{l}20 \\
25\end{array}$ & $\begin{array}{l}100 \\
100\end{array}$ & $\begin{array}{l}4 \\
5\end{array}$ & $\begin{array}{l}56 \\
40\end{array}$ \\
\hline
\end{tabular}

N/A: Variation in data structure across sites prevents the calculation of a total across sites.

${ }^{4}$ A report on the experimental evaluation of the Prevention and Relationship Enhancement Program (PREP) indicated that 50 percent of the couples who were assigned to receive the intervention did not participate at all (Markman et al. 1993), compared to 39 percent in BSF. Other researchers have anecdotally reported similar rates of no-shows. 


\section{IMPLEMENTATION OF THE FAMILY COORDINATOR COMPONENT VARIED}

Given latitude in implementing the Family Coordinator (FC) component, sites took different paths. They adopted different approaches to FC staffing, the intensity of FC contacts, and the content covered in meetings between FCs and couples. Nevertheless, the rate at which site staff had at least some contact with couples outside groups was generally high (Table 1), with some variation in the frequency of contact reflecting the sites' approaches to family coordinator role.

Contacts with family coordinators at Healthy Families sites were structured, frequent, and in-person, though not always focused on the couple. Three of the seven BSF sites used Healthy Families home visitors to fulfill the FC role. These home visiting programs already had policies and infrastructure in place to support frequent home visits, which were typically held on a weekly basis in the beginning, but gradually decreased in frequency over time. The average number of monthly contacts made by FCs in these sites ranged from 4 to 8 . The main role of the HF home visitor was to provide information about parenting and child development during the visits. The BSF FC role was added to these existing responsibilities of the home visitors, so most FC contacts were through home visits. The proportion of each home visit that was focused on the couple relationship (compared to parenting material) varied significantly by site, location, home visitor, and family. In many cases, the couple-focus was limited to reminders to the parents of upcoming group sessions, though some home visitors worked to help couples review relationship skills learned in groups. Some home visits addressed only Healthy Families protocols and did not include any BSF-related information or support for couple relationships. Many home visits in the Healthy Families sites were conducted only with mothers, who were more likely to be available during the regular workday hours of Healthy Families home visitors.

Contacts with family coordinators at non-Healthy Families sites were generally less frequent but tended to be more focused on couple content. Other sites often combined the FC role with other BSF roles, such as outreach workers or group cofacilitators, in order to create staffing efficiencies. Although some conducted limited home visits, these were not usually on a regular or frequent schedule. Most contact was made by phone with a lesser amount in-person at the program site or another location. Regardless of contact mode, some sites felt the frequency of contact between FCs and couples should be determined by each couple's level of need rather than a fixed schedule, to avoid overburdening families for whom contact outside of group sessions was not needed. Others believed that regular contact was important, and scheduled frequent contacts by telephone, through office visits, and in other ways (such as before or after group sessions).

The content and duration of contacts with FCs varied across sites. FCs at most sites used contacts to encourage group participation and to determine whether the couples were experiencing any barriers to attendance. More than half of the BSF locations also made concerted efforts to have their FCs reinforce marriage and relationship skills (though some only recently began to do so). To do this effectively, sites arranged special training for FC staff by the developer of their group curriculum. Two sites used FC meetings as systematic opportunities to follow up on needs, assessments and referrals, and the family's stated goals. 
xxiv

\section{ASSESSMENTS AND REFERRALS TO SUPPORT SERVICES}

The third component of the BSF model called for referrals to be made, as needed, to services available in the community. These services were intended to help couples address issues such as unemployment, housing instability, and substance abuse. Both the emphasis on and approach to assessments and referral varied from site to site.

Needs assessments were comprehensive and structured at some sites, and less formal at other sites. Family coordinators conducted most assessments, although in some cases group facilitators or intake staff were also involved. Most Healthy Families sites conducted a comprehensive assessment of the mother's needs prior to enrollment, in keeping with these sites' standard practice. Some Healthy Families locations also assessed the father's needs. Other sites conducted assessments with couples during an initial home or office visit. These initial assessments often produced a plan and priorities for addressing a couple's needs and identifying short- and long-term goals. The needs assessment and resulting plan guided staff in providing referrals for services. Program staff suggested resources to the couple and provided contact information, sometimes including the name of a specific contact person.

About half of all program group couples, across all sites, received a recorded referral to family support services. The extent of referrals is likely greater than the data suggest, as staff often informally mentioned services or provided brochures to couples. ${ }^{5}$

\section{The Average Cost per Program Group Couple Is Estimated at \$11,100}

During the planning phase, sites developed budgets for a full implementation of all BSF model components. From these budgets, we estimate an average per-couple cost of about $\$ 11,100$ (ranging from approximately $\$ 8,840$ to $\$ 14,170$ across sites). The average anticipated costs differ across implementation approaches. Costs averaged across the three sites that modified an existing home-visiting program are about $\$ 12,100$. For the two sites that added BSF to the services of a multi-program agency, the average budgeted cost per couple was approximately $\$ 10,100$. The budgeted costs across the remaining two sites, which established a new entity with BSF as its sole service, averaged roughly $\$ 10,000$ per couple. These costs include staff labor, materials and supports for participants, and costs related to the evaluation.

\section{Participating Couples Valued Their Experience}

Program participants view the BSF program as a positive experience. Focus groups with a random sample of program group participants explored their expectations of BSF, reactions to the group sessions, reasons for attending or missing sessions, and perceptions of

5 Because sites varied in coding practices, estimates of referrals are imprecise. Results on the extent of referrals likely understate the frequency that couples were linked with services, since staff did not always record informally provided referrals in the BSF management information system. 
the program's benefits. Overall, couples described their relationships prior to enrollment as burdened by problems with communication and trust, and difficulties managing conflict and anger. After hearing about BSF, couples hoped that participating in the program would strengthen their relationship, improve communication, and bring them closer. Many described initial concerns and hesitation about participating, but these concerns disappeared after experiencing a few group sessions. Couples cited group discussions, hands-on exercises, and other couples as the most useful elements of group. Participants talked about how the program helped them learn to handle conflict and control their anger, which benefited their relationship as a couple and even in their relationships with children and others in their lives. 



\section{H A P T E R I}

\section{N T R O D U C T I O N}

The Building Strong Families (BSF) project is a large-scale program demonstration and rigorous evaluation to learn whether well-designed interventions can help interested

romantically involved unmarried parents build stronger relationships and fulfill their aspirations for a healthy marriage if they choose to wed. The central question of the evaluation is whether interventions can succeed in helping these parents improve their couple relationships, enter into and sustain healthy marriages, and enhance the well-being of their children. Sponsored by the Administration for Children and Families (ACF) at the U.S. Department of Health and Human Services (DHHS), the project has been underway since late 2002 and involves programs operating in seven sites. This report analyzes the implementation of the BSF program in these sites and presents information on their development, operations and lessons learned, and provides context for the future analysis of program impacts on couples and their children. Specifically, the report addresses the following questions:

- What is the context in which programs are implemented?

- How are participants identified as eligible for BSF and then enrolled in the program?

- What are the characteristics of couples that choose to enroll in BSF?

- How is the BSF model put into operation at local sites?

- To what extent do enrolled couples attend and complete BSF?

- What is the experience of couples enrolled in the BSF program?

- What are the lessons learned that may be useful for other similar programs?

This chapter first describes the background of the BSF project, including how it originated, the conceptual framework and program model that guides the intervention design, the evaluation plan, and an overview of the seven sites. The chapter continues with 
an explanation of the analysis method and data sources for this report and concludes with a description of the report's organization.

\section{A. BACKGROUND}

BSF was designed to address a policy question that arose in response to emerging research on unmarried parent families suggesting that at the time of their child's birth many are romantically involved and hope to marry but few actually achieve that goal (Carlson, McLanahan, and England 2004; Carlson, McLanahan, England, and Devaney 2005). Prior to BSF, ACF conducted a study to explore the needs and circumstances of such families and consider what types of interventions might be useful for them. This research culminated in a conceptual framework developed by Mathematica Policy Research (MPR) describing how such programs might be implemented and evaluated (Dion et al. 2003). Efforts were also made to identify intervention programs that address relationships and marriage with lowincome, unmarried couples starting with the birth of their child. The purpose of identifying such programs was to evaluate their stage of implementation and readiness for and interest in a rigorous evaluation of program impacts. However, these efforts found that such programs were practically non-existent at that time (Dion and Strong 2004).

The absence of such programs meant that in order to address the policy question of interest-whether well-designed interventions can help unmarried parents achieve their aspirations for a healthy relationship and stable marriage-an intervention model had to first be conceived and programs created. To that end, ACF, through MPR, designed a program model based on the conceptual framework previously developed, and sought local organizations willing to implement the model. Programs were selected for the evaluation based on how well they implemented the model during a pilot period. This section describes the research and policy concerns that motivated the BSF project, the model and conceptual framework that were developed to guide it, and the evaluation that is underway to test the programs' effectiveness.

\section{BSF Emerged from Research on Families and the Interest of Policy Leaders}

Research on family structure in the United States has given rise to a growing concern about the prevalence and consequences of nonmarital childbearing. The number of births to unmarried women increased in 2003 to its highest level ever recorded in national statistics (Martin et al. 2005), and the proportion of births to unmarried women reached 34.6 percent, continuing an upward trend observed since the late 1990s. Although many children of single parents do well, research shows that on average they are at greater risk of living in poverty and developing social, behavioral, and academic problems compared with children growing up with their married biological parents (McLanahan and Sandefur 1994; Amato 2001).

In the early 2000s, research findings began to emerge suggesting that there may be opportunities to address this important policy concern. Findings from the 20-city Fragile Families and Child Wellbeing Study showed that despite common socioeconomic and other challenges, the great majority of unwed parents are romantically involved at the time of their child's birth, and have high hopes for marriage and a stable future together. Nevertheless,

\section{I: Introduction}


the study also showed that many couples split up, with only a small fraction married one year later, and less than one-fifth of the couples married three years later (Carlson et al. 2004; Carlson, et al. 2005). These findings served as the impetus for the conceptualization of a project that could test whether programs serving this population could help couples reach their goal of building a strong family (Dion et al. 2003).

In response to broad changes in family structure, policymakers began to take action and recently enacted policies and allocated funding to encourage the development and testing of programs supporting healthy family formation and marriage. The landmark 1996 welfare reform legislation encouraged states to use their block grants to encourage the formation of two-parent families and marriage. Within a few years, a Healthy Marriage Initiative was declared by President Bush, who gave lead authority for the initiative to ACF. In 2006, Congress approved $\$ 150$ million per year in grants to organizations, communities, and states to develop, implement, and evaluate healthy marriage and responsible fatherhood programs. Thus, although the conceptualization of the BSF project had its origins in research prior to the Healthy Marriage Initiative, it has become a critical component of this broad policy effort.

\section{BSF Programs Were Expected to Follow a Common Model Grounded in Research}

Prior to program implementation, the BSF research team developed a set of model guidelines that all program sites were expected to follow (Hershey et al. 2004). The guidelines were created to ensure a reasonable degree of consistency across sites and improve the chances of detecting impacts should they occur. They provided prospective BSF sites with research-based information about unmarried parents and their circumstances, identified the target population, and specified an intervention model that included three main components and one optional feature. The guidelines also provided sites with ideas for developing and implementing their programs, including such aspects as recruitment and retention, context and setting, service delivery options, instructional formats, and staffing issues. Despite this guidance, sites had considerable flexibility in operationalizing the program model to suit local needs, contexts, and organizational capacities. For example, each site was free to develop an organizational structure, identify recruitment sources and strategies, shape delivery of the main components, and choose its own marriage and relationship skills curriculum — as long as the curriculum met certain basic requirements.

The three main components of the BSF program model include weekly group instruction in marriage and relationship skills, individual-level program support from "family coordinators," and referrals to additional family services as needed (summarized in Figure I.1).

Group Sessions on Marriage and Relationship Skills. The core and essential component of BSF programs is group-based education in the skills found by research to be essential to a healthy marriage. Because changing relationships is not expected to be a minor undertaking, particularly among low-income couples who may be experiencing high levels of stress, this component is intended to be intensive and long-term. The curricula chosen by the sites involve up to 42 hours of instruction and are provided over a sustained period of 
time up to six months. The sustained delivery of instruction is expected to help promote internalization of the skills and information.

Figure I.1. The Building Strong Families Program Model

\begin{tabular}{|c|c|c|}
\hline $\begin{array}{l}\text { Individual-Level Support } \\
\text { from Family } \\
\text { Coordinators }\end{array}$ & $\begin{array}{l}\text { Core Component } \\
\text { Group Sessions in Marriage and } \\
\text { Relationship Skills* }\end{array}$ & $\begin{array}{l}\text { Assessment and } \\
\text { Referral to } \\
\text { Family Support } \\
\text { Services }\end{array}$ \\
\hline \multirow{9}{*}{$\begin{array}{l}\text { Encouragement for } \\
\text { program participatio } \\
\text { Reinforcement of } \\
\text { marriage and } \\
\text { relationship skills } \\
\text { Ongoing emotional } \\
\text { support } \\
\text { Assessment and } \\
\text { referral to support } \\
\text { services }\end{array}$} & Communication & Education \\
\hline & Conflict management & Employment \\
\hline & Affection, intimacy, trust, commitment & Parenting \\
\hline & Considering marriage & Physical and \\
\hline & The transition to parenthood & mental health \\
\hline & Parent-infant relationships & Child care \\
\hline & Children by prior partners & Legal issues \\
\hline & Stress and postpartum depression & $\begin{array}{l}\text { Substance } \\
\text { abuse }\end{array}$ \\
\hline & Family finances & $\begin{array}{l}\text { Domestic } \\
\text { violence } \\
\text { assistance }\end{array}$ \\
\hline
\end{tabular}

*Sample of topics included in marriage and relationship skills curricula.

The BSF model guidelines called for curriculum content to cover specific topics common to many relationship education programs: communication and conflict management skills; ways to build fondness, affection, and emotional intimacy; managing how parenthood can affect couple relationships and marriage; enhancing parent-infant relationships, especially the influence of fathers, and recognizing the signs of relationship meltdown. To address other topics that research suggests are central in the development of unmarried-parent relationships and movement toward marriage, BSF curricula were to include material and information on marriage, managing complex family relationships, building mutual trust and commitment, managing stress and emotions, and managing and communicating about family finances (Hershey et al. 2004).

Prior to BSF, almost all existing relationship skills curricula were written for married or engaged couples, and used most frequently with middle-income, typically white couples. In contrast, the BSF target population is unmarried, low-income, culturally diverse couples expecting a baby or the biological parents of a newborn. Because of the target population's circumstances and needs, the research team stimulated a curriculum development effort to adapt and supplement existing curricula for the BSF target population. Three research-based curricula that had shown positive impacts on couples' relationships and whose developers were interested in modifying the material for BSF couples were identified (Table I.1). The adapted curricula are: Loving Couples, Loving Children, developed by Drs. John and Julie Gottman; Love's Cradle, developed by Mary Ortwein and Dr. Bernard Guerney; and the

\section{I: Introduction}


Becoming Parents Program for Low-Income, Low-Literacy Couples, developed by Dr. Pamela Jordan (called Becoming Parents Program in this report).

Table I.1. Key Features of Marriage and Relationship Skills Curricula Used at BSF Sites

\begin{tabular}{|c|c|c|c|}
\hline & $\begin{array}{l}\text { Loving Couples, } \\
\text { Loving Children }\end{array}$ & Love's Cradle & $\begin{array}{l}\text { Becoming Parents for } \\
\text { Low-Income, Low- } \\
\text { Literacy Couples }\end{array}$ \\
\hline Developers & $\begin{array}{l}\text { John and Julie } \\
\text { Gottman }\end{array}$ & $\begin{array}{l}\text { Mary Ortwein and } \\
\text { Bernard Guerney }\end{array}$ & Pamela Jordan \\
\hline Original curriculum & Bringing Baby Home & $\begin{array}{l}\text { Relationship } \\
\text { Enhancement }\end{array}$ & $\begin{array}{l}\text { Becoming Parents } \\
\text { Program }\end{array}$ \\
\hline $\begin{array}{l}\text { Length of training for } \\
\text { group leaders }\end{array}$ & $\begin{array}{l}5 \text { days, about } 40 \\
\text { hours }\end{array}$ & $\begin{array}{l}2 \text { two-day sessions, } \\
\text { about } 32 \text { hours }\end{array}$ & $\begin{array}{l}4 \text { days, about } 32 \\
\text { hours }\end{array}$ \\
\hline $\begin{array}{l}\text { Recommended } \\
\text { minimum qualifications } \\
\text { for group leaders }\end{array}$ & $\begin{array}{l}\text { Master's degree and } \\
\text { experience working } \\
\text { with groups or } \\
\text { couples }\end{array}$ & $\begin{array}{l}\text { Master's degree or } 5 \\
\text { years experience with } \\
\text { population }\end{array}$ & $\begin{array}{l}\text { Master's degree and } \\
\text { experience working } \\
\text { with groups or } \\
\text { couples }\end{array}$ \\
\hline $\begin{array}{l}\text { Recommended group } \\
\text { size }\end{array}$ & 4-6 couples & 6-8 couples & 10-15 couples \\
\hline Total curriculum hours & 42 hours & 42 hours & 30 hours \\
\hline Length of sessions & 2 hours & 2 hours & 3 to 5 hours \\
\hline Frequency of sessions & Weekly & Weekly & Weekly \\
\hline
\end{tabular}

These three curricula retained most of their original substance and emphasis on skill building, but were modified in some important ways. Prior to the BSF pilot phase, focus groups with the target population indicated that many unmarried parents had negative experiences with educational systems and did not want to be lectured at or told what to do. As a result, the modified curricula, to varying degrees, minimize didactic methods and use a more experiential approach, allowing couples to share and learn from their own and others' experiences. To make the material more useful to couples with lower levels of education, the curricula are written at a fifth grade level and incorporate concrete, culturally relevant examples instead of abstract or more general concepts. The adaptation of each of the three original curricula included supplementation of material focused on topics shown by previous research to be particularly important for the BSF target population. These included information on the benefits and challenges of marriage, strategies for building trust and commitment, dealing with children and partners from previous relationships, and communicating about finances. Two of the three adapted curricula (Love's Cradle and the Becoming Parents Program) incorporated material on these topics from supplementary modules developed by a team of experts in low-income families and marriage (Wilson et al. 2005). The third curriculum, Loving Couples Loving Children, developed its own material on these topics. 
Family Coordinators. Prior research with low-income families shows that unmarried parents often have complex and challenging lives that may contribute to relationship problems and impede their ability to participate in and complete the BSF program. To address this issue, each BSF family is assigned a staff member known as a family coordinator whose role is to meet with couples on an individual basis. Family coordinators (FCs) are expected to identify and address families' needs and provide emotional support and encouragement for program participation. Their activities include:

- Conduct initial and ongoing assessments of each family member's needs.

- Link family members to existing services most appropriate for their needs.

- Encourage initial and ongoing BSF program participation and completion.

- Provide sustained emotional support as couples make key life decisions.

- Reinforce the healthy relationship and marital skills being taught in group sessions

Although the family coordinator role varies somewhat across sites, staff filling this role are expected to be knowledgeable about services to address employment and education needs, mental health or substance abuse issues, domestic violence, or problems with child care, transportation or housing. At some sites, the FC role is integrated with individual instruction in parenting and child development, as part of a home visiting program. Across sites, there is considerable variation in how frequently and for how long the couples meet with their family coordinators.

Family Support Services. Unmarried parents may face personal and family challenges that can impede their ability to form and sustain stable and healthy marriages-for example, limited education and employment skills, depression or other mental health conditions, or problems obtaining stable housing. Most areas have existing community resources to help low-income families address these issues, but parents may not be aware of how to access them. FC's assess BSF families for their needs and provide referrals to such services. In some sites, these or other services are available in-house through the organization that sponsors BSF; others link families to services that are external to the core program. Depending on need and local availability, BSF families may be referred to the following types of services:

- Parenting education

- Employment services, including job skills and job placement

- General education, including GED classes, ESL, or community college

- Mental health or counseling services

\section{I: Introduction}


- Child care

- Services to address domestic violence

- Legal assistance

- $\quad$ Food Stamps, Medicaid, WIC, SCHIP

- Transportation

\section{A Conceptual Framework Guided the Research and Program Design}

BSF is intended to affect the quality of couple relationships, their decision to marry, and their general well-being. However, many factors are likely to influence these outcomes, including the nature of the intervention, the rate at which couples participate, and the various needs and circumstances of couples that enroll. Figure I.2 illustrates the conceptual framework that guided design of the intervention and the evaluation outcomes to be assessed. It highlights the important linkages among the background characteristics of couples, services offered by BSF and couples' participation in them, and the expected program outcomes - marital status and quality of couple relationships, family outcomes, and child well-being.

Figure 1.2: BSF Conceptual Framework

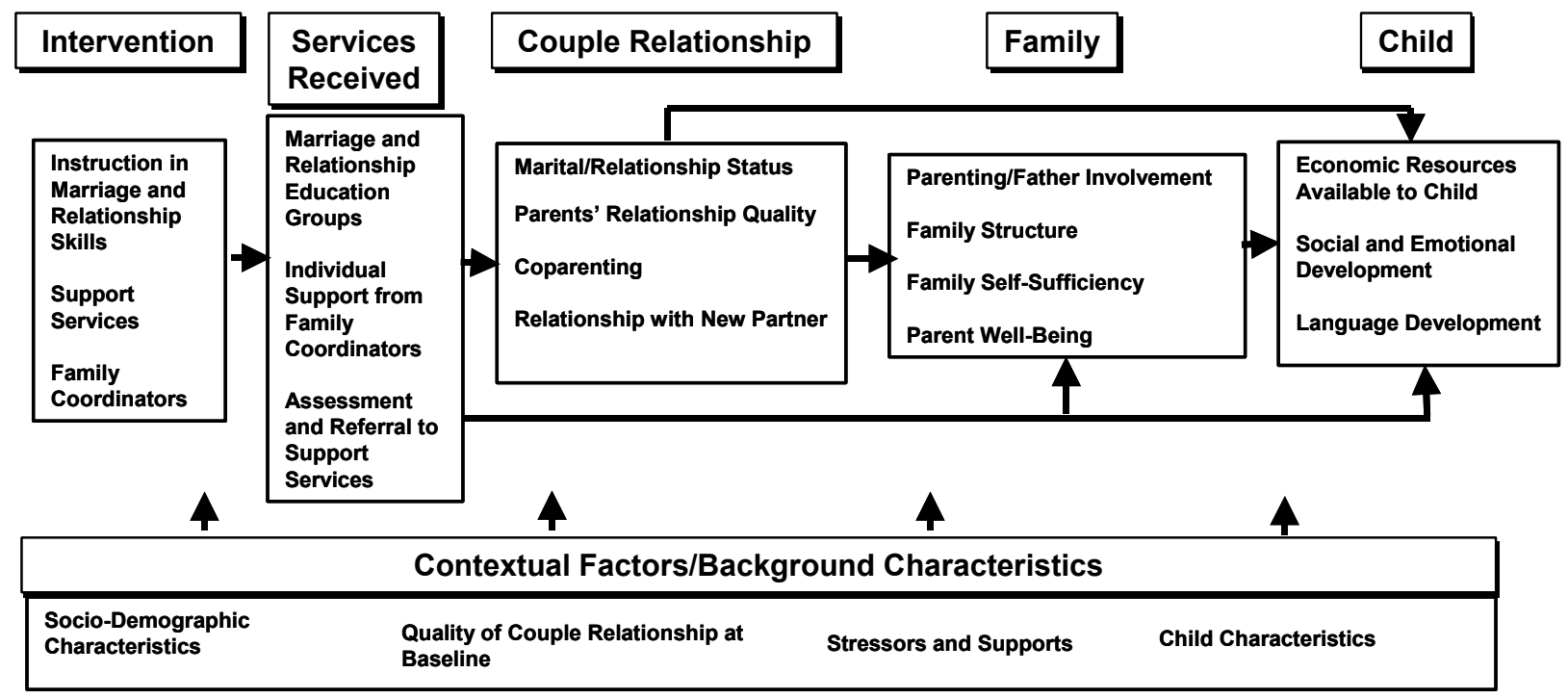

Contextual Factors/Background Characteristics. Couples enter BSF with a wide range of characteristics and circumstances. They vary in whether they have children from previous relationships, their level of employment, attitudes toward marriage, parenting skills, cultural factors, and physical and mental health. These factors can have important and direct effects on their relationships, family and child outcomes. The use of a random assignment 
design for the BSF impact analysis, however, will ensure that these factors are equally distributed on average in the program and control groups and thus any difference in outcomes between the two groups can be attributed to the program and not other factors. However, these factors could affect whether couples who are offered the BSF services actually participate, and thus the likelihood that impacts will be large enough to be detected and found significant.

Effect of Services on Outcomes. BSF services received may have direct or indirect effects in each of the main outcome domains. The marriage education services as well as the individual-level contact and family support services may have direct impacts in all three outcome areas. BSF services may also, by improving the quality of parental relationships, indirectly lead to healthy marriages, better family outcomes, and improved child well-being.

\section{The BSF Evaluation Relies on a Rigorous Longitudinal Research Design}

The two main purposes of the BSF evaluation are to determine whether well-designed interventions can be successfully implemented, and whether they can help interested and romantically involved unmarried parents achieve their aspirations for a strong relationship and, depending on their choices, a healthy marriage. Ultimately, the healthy marriages that result are expected to enhance the well-being of couples' children. The primary research questions to be addressed by the evaluation are:

- How is BSF implemented? How is the program model implemented at each site? What were the challenges in their implementation and how were they overcome? What aspects of the program are important for its replication? What are the lessons learned? What program characteristics and features may be linked to the effectiveness of the program?

- What services are received by experimental group couples? ${ }^{6}$ Do couples enrolled in the experimental group attend the marriage and relationship skills education sessions? What is the typical program dosage-i.e., how much do couples attend and how often do they complete the full program? Do the FCs meet regularly with their assigned couples? To what family support services are couples referred?

- Does BSF improve outcomes for families? What is the impact of BSF on parents' relationships, the decision to marry, family outcomes, and children's well-being? Does BSF work better for some families than for others; what types of BSF programs work best; and how does BSF work?

The implementation analysis that is the subject of this report addresses the first two of these three sets of questions. It examines the development and operations of the program

'The phrases “experimental group," "program group," "treatment group," and "intervention group" are used interchangeably throughout this report.

\section{I: Introduction}


model in local sites and reports on the type and intensity of services received by enrolled couples. Further implementation analysis, based on data collected about a year after the first round, will assess whether programs have changed and, if so, how.

The impact analysis referred to in the third set of questions uses a rigorous experimental design with longitudinal follow-up. ${ }^{7}$ In each of the BSF programs, eligible couples are randomly assigned to either a group that receives the BSF intervention, or a control group that does not. The control group is eligible to receive other services in the community. Estimates of impacts will be based on a comparison of outcomes for the BSF intervention group and the control group. Data on outcomes are to be measured twice: 15 months after random assignment, and when the BSF child reaches 3 years of age. Outcomes include:

Status and Quality of the Couple Relationship. The key outcomes related to the parents' relationship include marriage, relationship status and stability, living arrangements, attitudes toward marriage, quality of the relationship, co-parenting, and whether there is a relationship with a new partner.

Family Outcomes. These outcomes are related to how the family is structured and functions. They include parenting behavior and father involvement, living arrangements of the child, the self-sufficiency of the family, and parental well-being.

Child Outcomes. The ultimate aim of BSF is to improve child development and wellbeing. Thus, collecting data on child outcomes will be an important part of the impact analysis. The child outcomes of most interest include the child's socio-emotional and language development and economic resources available to the child, as these are most likely to be affected by the intervention.

Data collected at baseline support description of the sample's characteristics and other analytical purposes: analysis of subgroups; including covariates in regressions; matching couples for nonexperimental analyses; and adjustment for survey non-response. Baseline data include demographic and socioeconomic characteristics as well as information on the couple's relationship, family structure, attitudes about marriage, mental health, social support, and religiosity.

BSF Eligibility. To ensure that the evaluation is focused on a specific target population, eligibility for BSF is assessed through a structured checklist completed by intake staff for each parent in the couple. To be eligible for BSF, both the mother and father must report being:

- Expectant biological parents or the biological parents of a baby age 3 months or younger

- In a romantic relationship with each other

${ }^{7}$ The results of the impact analysis will be presented in future reports. 
- At least 18 years old

- Unmarried, or married since conception of the baby

- Available to participate in BSF, and able to speak and understand a language in which BSF is offered (English or Spanish)

- Not engaged in domestic violence that could be aggravated by participation in $\mathrm{BSF}$

Although income is not an explicit eligibility criterion, BSF participants were expected to be low-income for two main reasons. First, unmarried parents have lower average incomes and education, and are at greater risk of living in poverty than married biological parents (McLanahan and Sandefur 1994; Carlson 2004; Amato 2001). Second, by design, most BSF programs operate in communities that are largely low income.

\section{B. The BSF Program Sites}

Because the goal of the evaluation is to assess the effectiveness of well-implemented programs, the BSF sites were selected through a process that involved both technical assistance and scrutiny of their implementation progress and capacity. The research team communicated with many organizations and agencies interested in implementing the BSF model; the team also provided information and guidance to people in areas throughout the country. After working with a large number of potential sites, the field was narrowed to seven sites that seemed the most promising. These sites developed detailed plans for implementation. An intensive program design period helped these sites systematically consider and plan for such operational needs as recruitment sources, staffing structure, domestic violence screening, a management information system (MIS), and curriculum selection and training.

As each site completed its program planning, it moved into a pilot phase that lasted between three and nine months, depending on the site. Throughout this phase, the research team closely and regularly monitored each site's operational progress and provided assistance as needed. At the end of the pilot, each site was assessed for its suitability to be part of the evaluation. To be included in the evaluation, a site needed to meet three main criteria: (1) effective implementation of the BSF program in a way that was faithful to the program model; (2) demonstrated ability to recruit enough couples to meet sample size targets; and (3) ability to comply with the requirements of the evaluation, including administering the consent and baseline information forms. All seven sites in the pilot met the criteria and were chosen to be in the evaluation.

\section{BSF Sites Operate at 12 Locations in 7 States}

The seven demonstration sites operate in the following areas: Atlanta, Georgia (two locations); Baton Rouge, Louisiana; Baltimore, Maryland; Florida (two counties); Indiana (three counties); Oklahoma City; and Texas (two cities). All sites were located in large urban

\section{I: Introduction}


areas with the exception of San Angelo, Texas, which is a small city surrounded by a rural area. The characteristics of sites varied in a number of aspects, particularly in the organizational structure in which BSF was implemented, characteristics of the population served, and the chosen marriage and relationship skills curriculum. Three of the sites built upon their Healthy Families programs, an intervention for preventing child abuse and neglect through intensive home visits that has been implemented in 35 states. Table I.2 summarizes these similarities and differences across sites.

Table I.2. Key Features of BSF Sites

\begin{tabular}{|c|c|c|c|c|}
\hline Pilot Site & $\begin{array}{c}\text { Host } \\
\text { Organization }\end{array}$ & $\begin{array}{c}\text { Primary } \\
\text { Recruitment } \\
\text { Sources }\end{array}$ & $\begin{array}{c}\text { Race/Ethnicity of } \\
\text { Main Population } \\
\text { Served }\end{array}$ & $\begin{array}{l}\text { Timing of } \\
\text { Recruitment } \\
\text { for Most } \\
\text { Couples }\end{array}$ \\
\hline Atlanta, Georgia & $\begin{array}{l}\text { Georgia State } \\
\text { University; Latin } \\
\text { American } \\
\text { Association }\end{array}$ & $\begin{array}{l}\text { Prenatal clinic at } \\
\text { major public } \\
\text { health hospital }\end{array}$ & $\begin{array}{l}\text { African American } \\
\text { and Hispanic }\end{array}$ & Prenatal \\
\hline $\begin{array}{l}\text { Baltimore, } \\
\text { Maryland }\end{array}$ & $\begin{array}{l}\text { Center for } \\
\text { Fathers, } \\
\text { Families and } \\
\text { Workforce } \\
\text { Development }\end{array}$ & $\begin{array}{l}\text { Local hospitals, } \\
\text { prenatal clinics }\end{array}$ & African American & $\begin{array}{l}\text { Prenatal and } \\
\text { postnatal }\end{array}$ \\
\hline $\begin{array}{l}\text { Baton Rouge, } \\
\text { Louisiana }\end{array}$ & $\begin{array}{l}\text { Family Road of } \\
\text { Greater Baton } \\
\text { Rouge }\end{array}$ & $\begin{array}{l}\text { Prenatal } \\
\text { program for low- } \\
\text { income women }\end{array}$ & African American & Prenatal \\
\hline $\begin{array}{l}\text { Florida: Orange } \\
\text { and Broward } \\
\text { counties }\end{array}$ & $\begin{array}{l}\text { Healthy Families } \\
\text { Florida }\end{array}$ & $\begin{array}{l}\text { Maternity wards } \\
\text { of area hospitals }\end{array}$ & $\begin{array}{l}\text { African American } \\
\text { and Hispanic }\end{array}$ & Postnatal \\
\hline $\begin{array}{l}\text { Indiana: Allen, } \\
\text { Marion, and Lake } \\
\text { counties }\end{array}$ & $\begin{array}{l}\text { Healthy Families } \\
\text { Indiana }\end{array}$ & $\begin{array}{l}\text { Referrals from } \\
\text { WIC, hospitals } \\
\text { and clinics }\end{array}$ & $\begin{array}{l}\text { White and African } \\
\text { American }\end{array}$ & $\begin{array}{l}\text { Prenatal and } \\
\text { postnatal }\end{array}$ \\
\hline $\begin{array}{l}\text { Oklahoma City, } \\
\text { Oklahoma }\end{array}$ & $\begin{array}{l}\text { Public } \\
\text { Strategies, Inc. }\end{array}$ & $\begin{array}{l}\text { Hospitals, health } \\
\text { care clinics, } \\
\text { direct marketing }\end{array}$ & White & Prenatal \\
\hline $\begin{array}{l}\text { Texas: San } \\
\text { Angelo and } \\
\text { Houston }\end{array}$ & $\begin{array}{l}\text { Healthy Families } \\
\text { San Angelo and } \\
\text { Houston }\end{array}$ & $\begin{array}{l}\text { Maternity wards } \\
\text { of hospitals; } \\
\text { public health } \\
\text { clinics }\end{array}$ & Hispanic & $\begin{array}{l}\text { Prenatal and } \\
\text { postnatal }\end{array}$ \\
\hline
\end{tabular}

Atlanta, Georgia: Georgia Building Strong Families. The Health Policy Center at Georgia State University (GSU) and the Latin American Association serve BSF couples in Atlanta. The GSU Health Policy Center is the lead agency for the site and is responsible for managing the program and conducting all outreach to potential participants, as well as providing services for English-speaking couples. The Latin American Association, a nonprofit community organization, delivers BSF services to Spanish-speaking couples, 
including a fatherhood program. Prenatal couples are primarily recruited from Grady Memorial Hospital, the largest hospital in Georgia and public hospital for Atlanta. The site began its pilot in July 2005 and began enrolling its evaluation sample in December 2005.

Baltimore, Maryland: Baltimore Building Strong Families. The Center for Fathers, Families, and Workforce Development (CFWD), a community-based organization in Baltimore, operates this BSF program. The original focus of CFWD was on fathers, and the agency provided employment services and responsible fatherhood programs to lowincome men. More recently, CFWD expanded its services to a workshop-based coparenting program for low-income parents, which inspired the site to become involved in BSF. The site uses both hospital- and clinic-based outreach, recruiting from six hospitals and clinics in the Baltimore area. This site began a pilot in September 2005, and shortly thereafter began enrolling couples for the evaluation (December 2005).

Baton Rouge, Louisiana: Family Road Building Strong Families. Family Road of Greater Baton Rouge is a non-profit organization that provides access to a wide array of services for expectant and new parents. Through its coalitions with community organizations and extensive network of partners, Family Road is a "one-stop shop" of social services. These include childbirth education, fatherhood programming, parenting and child development classes, money management, job placement, counseling, home visiting for atrisk mothers and children, as well as a range of other programs for parents. Many BSF couples are recruited from the Better Beginnings program, which meets at Family Road and links Medicaid-eligible pregnant women to prenatal and pediatric services. Others are recruited from outreach contacts, such as health units and WIC clinics. The Baton Rouge site began its pilot in April 2005; enrollment for the evaluation began in November 2005.

Florida: Healthy Families Plus. Healthy Families Florida is a state-level program run by The Ounce of Prevention Fund of Florida, with local sites throughout the state. This site integrated BSF services into its Healthy Families program, which is designed to prevent child abuse and neglect through intensive home-visiting for up to five years after a child's birth. The integrated Healthy Families and BSF program, Healthy Families Plus, is offered in two counties: Orange (Orlando) and Broward (Ft. Lauderdale). The majority of BSF participants are recruited from the maternity wards of local birthing hospitals as part of the routine intake procedure for Healthy Families. Both locations prescreen potential couples through information provided by the hospitals. The Orange County location was one of the first to begin a pilot in February 2005; it began enrolling evaluation sample, in June 2005. The Broward location began enrolling evaluation sample six months later, in December 2005.

Indiana: Healthy Couples, Healthy Families Program. Indiana also integrates BSF into its existing statewide Healthy Families program. Seven local Healthy Families programs offer BSF-known as Healthy Couples, Healthy Families — in three areas: (1) four in Marion County (Indianapolis), (2) one in Allen County (Fort Wayne), and (3) two in Lake County (Gary). The Healthy Couples, Healthy Families program is coordinated by SCAN, Inc., a non-state agency in Allen County that has the state's largest Healthy Families caseload. The Indiana locations employ different recruitment sources, including birthing hospitals, social service agencies, prenatal care centers, and the WIC program. Indiana

\section{I: Introduction}


began enrolling couples for its pilot in February 2005; enrollment for the evaluation sample began in January 2006.

Oklahoma: Family Expectations. Family Expectations grew out of the Oklahoma Marriage Initiative, and was developed from the ground up by Public Strategies, Inc., under contract to the Oklahoma Department of Human Services. Unlike other sites, the BSF groups are open to both unmarried and married couples, which the site believes may encourage unmarried couples to marry (data for only the unmarried couples are used in BSF evaluation analyses, to be consistent with other sites). Recruitment occurs through a variety of sources, including a local hospital, physician offices and clinics, and mailers to women receiving Medicaid. Intake occurs at the Public Strategies' office or at referral locations. Oklahoma began its pilot program in August 2005; enrollment for the BSF evaluation began in June 2006.

Texas: Building Strong Families, Texas. The two Texas locations, San Angelo and Houston, transformed their Healthy Families programs into BSF programs, serving only couples who meet BSF eligibility requirements. ${ }^{8}$ For San Angelo, initial contact is made with families at the hospital at the time of the child's birth, and if the family is amenable, staff obtain consent-to-contact forms. Intake is then typically conducted later, usually in the couple's home. The Houston location accepts referrals from a multitude of sources. In addition, staff contact parents and conduct screening over the phone using lists of patients provided by city health clinics and the local child support agency. More recently, Houston began to station staff in the waiting rooms of four city public health clinics to obtain consent-to-contact forms. Enrollment for the pilot program in Texas began in February 2005; with full random assignment beginning in July 2005.

\section{Method ANd Data Sources}

The findings described in this report rely on multiple data collection efforts, including both qualitative and quantitative sources. Qualitative data were collected in the field through two-person visits to all 12 program locations, with each visit lasting several days. Quantitative data recorded in each program's MIS were also collected and analyzed, including recruitment and baseline information for all enrollees, and data on program participation for those assigned to receive the intervention.

- Enrollment and Program Participation Data. Each BSF program maintained electronic records of enrollment and participation in program activities, including attendance at curriculum group sessions and meetings with family coordinators. Four of the sites used a web-based MIS developed expressly for BSF (Atlanta, Baltimore, Baton Rouge, and Texas), providing the research team with immediate access to data on program operations. The three remaining sites

${ }^{8}$ Although the Texas programs use the Healthy Families (HF) name and their programs were similar to the national HF model of home visiting prior to BSF, they were not certified as Healthy Families programs. Unlike some HF programs, the Texas programs integrated a strong fatherhood component. 
(Florida, Indiana, and Oklahoma) chose to record data in their previously existing systems, transmitting data to the research team on a regular basis.

- Baseline Survey Data. As part of the required evaluation activities, site staff entered data collected at baseline into their MIS for transmittal to the research team. These data include information on the background characteristics of couples including each parent's socioeconomic status, family structure, and attitudes about marriage, the quality of their couple relationship, mental health and social support.

- Interviews with Program Staff. Research staff traveled to each of the 12 BSF locations to conduct in-person, semi-structured interviews with program staff at each level, including managers and supervisors, intake and outreach workers, staff at recruitment sources, group facilitators, and family coordinators. The results of these interviews were recorded in a standardized template.

- Direct Observation of Operations and Records Review. While on site, research staff also directly observed program operations including the recruitment process, group sessions with BSF couples and facilitators, and meetings between family coordinators and couples. Observations were recorded on a standardized checklist. In addition, the team reviewed records and documentation of operations.

- Focus Groups with Program Participants. At each BSF site at least one but usually two focus groups were held with a randomly selected sample of BSF couples who had participated in at least three of five group sessions. A total of 145 intervention group members-mothers and fathers-participated in the 13 focus groups.

- Telephone Interviews with Non-Participants. To understand why some enrolled couples did not attend group sessions, brief telephone interviews were held with a randomly selected group of enrollees at each site. The couples selected for these interviews had enrolled but either never attended a session or attended only once or twice. A total of 36 telephone interviews were conducted, at least four per site.

Several guiding principles were used to ensure a systematic and objective approach to analysis and inference, particularly with regard to site visits. First, the goals and research questions for the implementation analysis were clearly stated and imparted to all research staff involved. Second, a set of protocols, checklists, and other tools were developed to ensure that the same information was collected for each site. Staff who had not previously visited each site or provided technical assistance support for its implementation were designated as site visitors to ensure objectivity. Third, all sites were observed through the same analytical lens, with site visitors reporting their detailed results using standardized templates and checklists that had previously been developed for this purpose. Their reports were reviewed by each program's "site coordinator" who had monitored program operations

\section{I: Introduction}


over a sustained period of time, as a check on accuracy and interpretation. Any lingering questions of fact were followed up with site staff. Each report was then coded along a range of implementation dimensions, facilitating comparison of the same operational practices across sites and locations.

To complement the information gathered through qualitative methods, we analyzed each site's MIS data in four areas: enrollment, participation in group sessions, contact with family coordinators, and referrals to family support services. Each analysis uses the full sample of couples enrolled through March 31, 2007, or a subset depending on the particular research question being addressed and limitations of the available data. For example, to examine the extent to which couples attend and complete group sessions, we restricted the sample to a subset of couples enrolled early enough that their attendance could be observed over a period somewhat longer than the standard schedule of sessions, since some couples are not immediately matched with a group that meets when they could attend. The sample was therefore restricted, for most sites, to couples for whom a minimum of eight months of attendance experience could be observed. In Oklahoma, however, data only needed to be restricted to a four-month observation period, because that site scheduled sessions so that participants could complete the curriculum within a 6 - to 10 -week period.

In contrast, contacts with family coordinators, although often regularly scheduled, were not usually driven by the BSF curriculum or other material that was expected to be completed, so we might have examined data over the full period that each couple was enrolled. Nevertheless, there was substantial variation across sites in the duration of family coordinator services, with some providing contact for as long as three years, and others providing access to family coordinators only during the time that couples were expected to attend the group sessions and shortly thereafter. To provide a consistent measure of family coordinator contact and intensity across sites, we examined data for contacts with family coordinators for up to eight months after random assignment, with adjustments for those who had been enrolled less than that period.

Using all this information about implementation, we created site profiles. These profiles draw on information from the site visit interviews and operations, MIS data, and discussions with participants and nonparticipants (Appendix A). Information was organized on a site-by-site basis along several key dimensions of implementation: recruitment and enrollment, core group sessions, family support services, and contact with family coordinators.

\section{OVERVIEW OF THE REPORT}

The remaining chapters of this report focus on the context and organizational structure of sites, practices related to outreach and program enrollment, implementation of the BSF model components, participation in BSF activities, and experiences and perceptions of intervention group members.

- Chapter II: Program Setting, Development, and Resources. This chapter describes the various approaches sites took to developing their BSF programs, 
the organizational context and setting of each site, the resources required for implementation, and the main challenges they faced in early development.

- Chapter III: Sample Enrollment and Characteristics. This chapter documents the recruitment sources BSF sites relied on to identify potentially eligible couples, and the enrollment practices they adopted. It also reports on the enrollment progress sites have made to date and provides a description of the background characteristics of the enrolled sample within and across sites.

- Chapter IV: Implementation of the BSF Marriage and Relationship Skills Program Component. This chapter describes how each site offered ongoing group sessions to couples. It discusses the process sites went through to prepare to deliver sessions and the strategies used to encourage initial and ongoing attendance.

- Chapter V: Implementation of the BSF Family Coordinator Component and Linkages to Family Support Services. This chapter describes how each site operationalized two of the three main components of the BSF program model: the family coordinator component, and the family support services, including the practices used and challenges encountered.

- Chapter VI: Participation in BSF. Data on attendance at the marriage and relationship skills sessions, frequency of contact with family coordinators, and rate of referrals to family support services are reported in this chapter.

- Chapter VII: Couples' Experiences and Perceptions of the BSF Program. This chapter provides insight into the motivations couples have for enrolling in $\mathrm{BSF}$, their reasons for attending or missing group sessions, and their perceptions of the effect of the program on their relationships. 


\section{H A P T E R I I}

\section{PROGRAM SETTING, DEVELOPMEN T, A N D R E S O U R C E S}

L ike previous generations of social service programs, BSF aims to improve child and family well-being. Unlike traditional approaches, however, it does so by working with both mothers and fathers together as a couple, to help them strengthen their relationship and prepare for a healthy marriage. Customary social services such as assessments, referrals, and direct services to meet employment, health, parenting and other individual and family needs, though not the main focus, are also an important part of the BSF program model.

While prior research guided development of the BSF model, little was known about what program and organizational settings would be suitable for providing marriage and relationship skills education for unwed expectant and new parents in a social services context. Doing so was such a new concept that there were no organizations with the existing capacity to address all facets of BSF. Social services organizations typically had little or no experience working with couples or talking with clients about their personal relationships or the topic of marriage. Counseling centers providing marriage or relationship skills education had little experience attracting or serving a low-income population or linking clients to social services. Earlier studies had confirmed that programs serving low income groups and addressing relationships were rare (Dion and Strong 2004; Dion et al. 2003).

Examining how participating sites got BSF off the ground is a useful first step towards understanding the implementation experiences described in this report. It also provides insights for others interested in developing similar programs. This chapter describes the types of program and organizational settings into which BSF was embedded, and the advantages and challenges experienced in each. We discuss why sites were initially interested in BSF, and which approaches to planning and organizing programs made implementation easier. Finally, we consider program budgets and the level of resources necessary to staff BSF and operate its core component, marriage and relationship skills education. 
Key Findings on Program Setting, Planning, and Resources

- Sites created BSF programs using three organizational approaches: (1) modifying an existing program, (2) adding a new program in a multiprogram agency, or (3) establishing a new entity with BSF as its sole agenda. Each approach proved workable, but had advantages and disadvantages.

- Most sites were motivated by research on the importance of marriage for children and adults, and a desire to help couples in their relationships. Many built community support by drawing in multiple stakeholders to help plan their programs.

- Relative to other sites, implementation went more smoothly at sites that, during the early planning period, solicited input from existing staff members who would be part of the BSF program.

- Over the life of the program, including pilot and evaluation periods, site budgets for BSF program operations ranged from about $\$ 8,840$ to $\$ 14,170$ per couple, with an average approximate cost of $\$ 11,100$ (including evaluation costs).

- The average budgeted cost per couple included items such as transportation, child care, participation incentives, social activities, curriculum materials, and staff training. Together, these items represented between $\$ 575$ and $\$ 950$ of the per-couple cost.

\section{A. Organizational Structure of BSF Programs}

To participate in BSF, interested organizations had to integrate marriage and relationship-strengthening and social service activities "under one roof." To do this, the seven evaluation sites used one of three general approaches to establish workable BSF service delivery settings. Three sites modified an existing home visiting program for new atrisk parents. Community-based organizations in two sites added BSF as a new program under their existing multi-program umbrellas. Two sites built BSF operations from the ground up by developing totally new staff structures and procedures. Advantages (Table II.1) and disadvantages of each approach emerged during pilot operations and continue to affect sites to some degree. 
Table II.1. Potential Implementation Advantages of BSF Program Settings

\begin{tabular}{|c|c|c|c|c|c|c|c|}
\hline & \multicolumn{3}{|c|}{$\begin{array}{l}\text { BSF Integrated with Existing } \\
\text { Home Visiting Program }\end{array}$} & \multicolumn{2}{|c|}{$\begin{array}{l}\text { BSF Embedded } \\
\text { as New Program } \\
\text { within Multi- } \\
\text { program Agency }\end{array}$} & \multicolumn{2}{|c|}{$\begin{array}{l}\text { BSF Established } \\
\text { as Sole Focus of } \\
\text { New Entity }\end{array}$} \\
\hline & $\mathrm{FL}$ & IN & TX & LA & MD & $\mathrm{GA}$ & OK \\
\hline $\begin{array}{l}\text { Existing Intake } \\
\text { And Service } \\
\text { Delivery Staff }\end{array}$ & $\checkmark$ & $\checkmark$ & $\checkmark$ & & $\checkmark$ & & \\
\hline $\begin{array}{l}\text { Existing Home } \\
\text { Visit System and } \\
\text { Tools }\end{array}$ & $\checkmark$ & $\checkmark$ & $\checkmark$ & & & & \\
\hline $\begin{array}{l}\text { Facilities for Group } \\
\text { Services }\end{array}$ & & & $\checkmark$ & $\checkmark$ & $\checkmark$ & & $\checkmark$ \\
\hline $\begin{array}{l}\text { Existing Access to } \\
\text { Local Family } \\
\text { Support Services }\end{array}$ & $\checkmark$ & $\checkmark$ & $\checkmark$ & $\checkmark$ & $\checkmark$ & & \\
\hline $\begin{array}{l}\text { Existing Source } \\
\text { of Couples in the } \\
\text { BSF Target } \\
\text { Population }\end{array}$ & $\checkmark$ & $\checkmark$ & $\checkmark$ & $\checkmark$ & & & \\
\hline $\begin{array}{l}\text { Already } \\
\text { Established } \\
\text { Presence in } \\
\text { Low-Income } \\
\text { Community }\end{array}$ & $\checkmark$ & $\checkmark$ & $\checkmark$ & $\checkmark$ & $\checkmark$ & & \\
\hline $\begin{array}{l}\text { Experience with } \\
\text { Low-Income } \\
\text { Parents }\end{array}$ & $\checkmark$ & $\checkmark$ & $\checkmark$ & $\checkmark$ & $\checkmark$ & & \\
\hline $\begin{array}{l}\text { Experience } \\
\text { Recruiting and } \\
\text { Serving Fathers }\end{array}$ & & & $\checkmark$ & $\checkmark$ & $\checkmark$ & & \\
\hline $\begin{array}{l}\text { No Potentially } \\
\text { Competing Goals, } \\
\text { Program, Policies, } \\
\text { or Procedures }\end{array}$ & & & & & & $\checkmark$ & $\checkmark$ \\
\hline
\end{tabular}

\section{Three Sites Modified an Existing Program}

The Florida, Indiana, and Texas sites grafted BSF components onto the recruitment procedures, organizational practices, and service delivery systems of local home visiting programs designed to reduce the risk of child abuse and neglect among low-income and disadvantaged families. The strategy of integrating BSF into existing home visiting programs 
(called "Healthy Families") took advantage of existing infrastructure." The site agencies already had staff devoted to outreach and intake, procedures for conducting assessments and linking clients to needed services, and an ongoing home visit component conducted by specialized staff using a well-established parenting curriculum. Programs had ongoing connections with birthing hospitals from which they already were recruiting Healthy Families participants. The site agency in one of the two Texas locations had earlier added a fatherhood component to their Healthy Families program and so already had several male staff and an agenda of father-related activities. Some adjustments were still necessary, however. The other Texas location and the Florida and Indiana sites made an effort to hire male staff to complement their mostly female staff. Sites trained female staff, accustomed to working with mothers and babies, to increase their comfort with and focus on fathers.

\section{Two Sites Added BSF to the Services of a Multi-Program Organization}

In Baltimore and Baton Rouge, local community based organizations created BSF alongside an array of services they were already offering to low income families. In contrast to the approach taken by the home visiting programs, these organizations chose not to integrate BSF into one of their existing programs. Instead, they developed BSF-specific policies and procedures, and hired and trained new staff to operate BSF-offering it as an addition to the menu of services they offered. The organizations that hosted BSF in these sites had experience providing a variety of family services related to employment, parenting, prenatal care, child safety, and WIC enrollment, for example, to low-income families, either directly or through "one-stop" access or referrals. They had facilities at well-known locations that were accessible and convenient for their target groups. Both operated programs to encourage responsible fatherhood, so they already had male staff and experience recruiting fathers and providing them with center-based activities. Baton Rouge conducted Medicaid enrollment and hosted regular Medicaid-related classes that brought 30 or more expectant mothers, sometimes with their partners, directly to their door each week-a promising recruiting stream for BSF.

\section{Two Sites Established a New Entity with BSF as Its Sole Service}

The two remaining sites, Atlanta and Oklahoma, implemented the program model by developing new program infrastructure devoted solely to BSF. This entailed hiring all program staff and establishing procedures and policies from scratch, although both sites were able to hire staff experienced in key administrative and program functions. They also partnered with existing organizations for administrative oversight and support, or to assist in providing BSF program services. While creating new infrastructure did require a significant investment of planning time and resources, it also gave sites flexibility in hiring staff with the most appropriate backgrounds, setting goals and priorities, and developing recruiting

"All three sites used the name "Healthy Families" for their program. Sites in Florida and Indiana follow a national program model launched by Prevent Child Abuse America. Sites in Texas use a similar approach but are not affiliated with the national program or Prevent Child Abuse America. 
sources. Rather than making compromises to integrate BSF with existing practices or programs, leaders in these sites could chart a path focused only on BSF goals.

\section{Each Implementation Approach Had Both Strengths and Challenges}

Sites adopted their implementation approach because it offered specific advantages, such as an existing infrastructure or an established and well-known center-based facility, or because building from the ground up was the only way to get started. Each site, however, had to confront specific challenges regardless of the chosen approach. Sometimes these were broad implementation challenges that applied to all approaches, while others were specific to the approach taken. Sites that modified an existing program had to confront issues related to integrating services. Shifting the focus of existing services, establishing family coordinator roles, and making linkages to support services challenged several sites, at least initially. Although new staff hired specifically for BSF tended to feel comfortable addressing marriage and relationships, some existing staff members were sometimes a little more uncertain, though their comfort increased over time.

Healthy Families sites faced the challenge of integrating their existing service operations with BSF operations. In sites where BSF was integrated into Healthy Families programs (Florida, Indiana, and Texas), program leaders saw BSF as compatible with the Healthy Families goal of reducing child abuse and neglect. In practice, integrating the BSF mission to support healthy relationships and marriage required compromises and choices which, in some BSF Healthy Families locations, were more difficult and took more time to achieve than anticipated. Some of the Healthy Families sites continued to offer their traditional program, which served mostly single parents but could also accommodate couples, as well as an "enhanced" model for couples that included the special BSF components. Because of the evaluation, eligible couples who wanted to receive BSF services risked being assigned to the control group and receiving no services. This factor created dilemmas for intake staff and prospective enrollees at some locations. Intake staff were sometimes reluctant to submit BSF-eligible couples for random assignment, preferring to avoid the possibility they would not receive services, and enrolled them instead in the traditional but more limited program.

Other issues arose not from the evaluation context but from the adjustment required to focus on the group sessions that are the core of the BSF program model. Some Healthy Families locations were initially hesitant to make group-based instruction in marriage and relationship skills the centerpiece of their program, out of concern that couples would be unwilling to attend group workshops until they had a strong connection to the home visiting component. One site consciously delayed placing newly recruited couples into group sessions due to concerns couples would resist attending groups, but over time they learned that interest in the group sessions was often highest when couples were newly enrolled.

Implementing BSF in Healthy Families sites also meant that existing staff had to adjust to serving couples rather than mothers and their children. To work with fathers and integrate BSF topics and procedures into their programs, some long-established assessment and home visiting procedures had to be modified. One typical modification was that home 
visits needed to be scheduled when both members of the couple were available, such as in the evenings. That shift required a change in staff deployment practices, which some staff had not expected, and in a few cases was not possible. With primarily female staff, these sites were also faced with how to avoid the impression during outreach and intake that the program is intended primarily for mothers, rather than couples.

More time and effort were needed to create the family coordinator role at sites that did not build on a pre-existing staff infrastructure. Where there were no preexisting staff working with families, sites had to create the family coordinator role. The Healthy Families sites already had well-established roles for home visitors and a structured child development curriculum that gave them regular, defined agendas for home visits. Sites that added BSF services to an existing multi-program agency had to develop the staff capability and a system for working with couples one-on-one. At such sites the roles for family coordinators were not fully defined until implementation was well under way, and it took some time even after BSF operations began for them to develop procedures and materials to support their roles. Sites that built BSF programs from the ground up-Atlanta and Oklahoma-faced similar challenges, since they had no existing case management or home visiting models to build on. Both types of sites at first defined the family coordinator role mainly as supporting and encouraging group attendance, along with making referrals to needed services. However they later added more responsibilities, such as conducting assessments or reinforcing lessons and topics covered during group sessions.

Sites developing from the ground up had to forge relationships with local family support services. Sites that created an infrastructure for BSF from the ground up had no existing relationships with local family support services to which they could refer participants. These sites had to find local community resources, create partnerships, and develop procedures for making referrals to them. In some cases, the result was a mix of new referral networks and services developed in-house by the BSF program. Oklahoma sought out providers of employment, mental health, substance abuse, housing assistance, and other services for referrals, but also developed in-house resources, such as fatherhood services, to fill gaps. In Atlanta, GSU staff developed a list of local resources to which they could make referrals, mostly by providing BSF participants with contact information. The organization serving Spanish-speaking couples in Atlanta offered many services in-house, including a fatherhood program. It also had connections with other external providers and often made direct contacts with them to coordinate referrals for their BSF couples.

All sites had to learn to recruit and work with couples. No BSF sites had much prior experience working with couples-only Baltimore had done so in a co-parenting program it piloted. ${ }^{10}$ Therefore each site had to develop the capacity and procedures for meeting with couples rather than individual parents. Sites that had experience working with mothers or fathers separately had to adapt their existing practices and "mindsets." For instance, sites with little or no prior experience working with fathers needed to build

${ }^{10}$ The organization sponsoring the Oklahoma site, Public Strategies, was able to draw on its experience managing the Oklahoma Marriage Initiative, but had not directly provided services itself until BSF. 
awareness among staff of the importance of fathers to families and to their children, and increase staff comfort working with men. Home visiting staff accustomed to working with new mothers had to develop specific ways to include men in home visit activities and encourage them to participate. Sites that had operated fatherhood programs found their experience recruiting men useful, but still had to revise their approaches to solicit both partners, determine their eligibility, and complete enrollment.

Addressing relationships and marriage was a new concept for most sites. None of the BSF sites except Oklahoma had prior experience with marriage and relationship skills training or discussing issues related to marriage. Feeling comfortable with these topics was important for all BSF staff, from intake workers who were the initial "face" of the program, to group facilitators and family coordinators who worked with participating couples-but some staff members had to adapt more than others to this new focus. Most group facilitators were newly hired specifically for BSF, and therefore had clearly defined expectations and intensive training to address relationships and marriage. On the other hand, existing home visitors and outreach staff were a little more uncertain, especially with respect to marriage. While they seemed comfortable discussing marriage when couples themselves raised it, some were less confident about raising the topic themselves. This was mainly due to initial concerns that doing so might be perceived as pushing couples toward marriage. As they developed ways to discuss marriage in different contexts, and learned that participants were interested in the topic, sites became more proactive about addressing marriage, though at some sites a few staff members continued to resist doing so because of persistent concerns about appearing to denigrate single parents. Generally BSF program staff had positive views on marriage regardless of their own marital status, recognized that couples were interested in the topic, and found that acknowledging the efforts of single parents was not inconsistent with helping couples explore marriage.

\section{B. BSF Program Planning and Development}

BSF is pioneering a program model in an emerging policy field that has been the subject of some controversy, but the BSF site organizations were eager to participate. What drew them to try the BSF model and participate in the evaluation? How did they engage their states or communities and staff in exploring and ultimately implementing the program? How did their approaches to planning and organizing their programs affect BSF implementation? Sites were generally motivated by the idea of working with couples on their relationships, especially as a way to promote child well-being, but they recognized the need to gain support for entering this new policy area, and drew in other stakeholders to explore and plan BSF, often including front-line staff if BSF was being integrated into existing agencies or programs.

\section{Many Sites Saw Working on Marriage and Relationships as a Logical Extension of Services for Low-Income Parents}

Most of the organizations sponsoring BSF had served low-income mothers or fathers separately, and felt that working with couples was the next logical step for their services. One site had prior experience with couples' groups as part of a co-parenting program, and 
was interested in more programming to address couple issues. Others had programs for low-income mothers, such as childbirth preparation, and services for low-income fathers, focused on responsible fatherhood, but had no program for the parents as a couple. Sites approached BSF in different ways, but most felt that stabilizing unwed families could benefit children and communities and was consistent with existing organizational missions. For example:

- Community and organization leaders were becoming aware of emerging research showing positive associations between marriage and improved child outcomes.

- Policymakers in some states had explored legislation such as covenant marriage and programs to improve relationship skills and increase awareness of the benefits of marriage, and were interested in adding a targeted program with specific services to their healthy marriage agenda.

- Organizations welcomed BSF as a way to build capacity to address relationship issues, since clients sometimes requested relationship advice from program staff. Several sites conducted brief surveys of their existing clients, many of whom reported they were in romantic relationships and would be interested in taking part together in a program to strengthen that relationship.

- Some organization leaders recognized a growing interest in healthy marriage among policymakers and felt that adding healthy marriage and relationship education services to their existing programs would improve agency access to funds, thereby enhancing program and agency sustainability.

\section{Sites Collaborated with Stakeholders in Step-by-Step Planning}

The BSF host organizations saw relationships and healthy marriage as a new program frontier that needed careful exploration and the support of partners. In a few sites, most of the planning was done by and within the organization that would operate BSF, but most sites also involved other local stakeholders in varying combinations: community and civic leaders, advocates, other service providers, representatives of nonprofit, faith, public, or other key sectors, and sometimes experts from area universities. This collaboration, in addition to building local buy-in, also helped identify and develop recruitment sources and potential providers of family support services. Sometimes state- or national-level entities participated - generally where interest in BSF originated at the state level, when state funding was sought, or when the site organization was part of a national service network. For example, two of the Healthy Families organizations worked with Healthy Families America, their national credentialing body, to obtain input and approval for programmatic changes needed to implement BSF.

In all sites, exploration and planning began up to a year before pilot operations commenced. During this time, sites typically established ongoing planning groups representing the collaborative partners mentioned above. These groups conducted a step-

\section{II: Program Setting, Development, and Resources}


by-step process to evaluate (1) interest among key groups and their constituents in addressing marriage and relationships, (2) potential recruiting sources, (3) the general outline of the program, including target groups, funding needs and sources, (4) whether and how current programs might be adapted to include BSF services, and (5) organizations with the capacity to implement the program, or locations where services could be offered. All sites had to explore funding issues. ${ }^{11}$

\section{Getting Input from Existing Staff Was a Priority for Some Sites}

Although it was not always possible due to various organizational constraints, when sites were able to involve existing staff in early planning and build their buy-in, they tended to respond more positively during program implementation.

Getting program staff involved in planning seemed to build buy-in. The two sites that added BSF to an existing multi-services agency included their staff in exploration and planning. For example, even before exploring BSF interest within the larger community, the Baltimore site convened an internal workgroup of staff to discuss marriage, relationships, and staff attitudes toward programming in this area. In sites that modified an existing program, however, front line staff were sometimes less involved, mainly due to some structural barriers. In one site, it was difficult to assemble front-line staff to participate in planning meetings, because the meetings interrupted field operations and reduced reimbursements tied directly to delivery of "units" of intake and ongoing services. In some cases, centralized planning had to be completed before local site agencies were selected; once local agencies became involved the process was too far along to give front line staff much opportunity to weigh in. In a few sites where that was the case, some staff initially balked at the increased paperwork that came with the evaluation, such as obtaining consent and collecting baseline information, had difficulty adjusting to the need to schedule client meetings when both parents were available, or expressed discomfort with adding a marriage and relationship focus to their existing services. Staff who had earlier input into the decision to implement BSF seemed less troubled by these challenges.

Sites that built programs from the ground-up avoided these problems. By definition their planning had to be "top-down," but when hiring began, people who were unsure or unsupportive of the program's goals and focus either did not apply, or withdrew from consideration. When hiring new BSF staff, these sites generally described program goals and asked applicants directly whether they felt comfortable and supportive of BSF's objectives and approach as part of the interview process. Many sites took a similar approach when replacing existing BSF or agency staff if positions turned over.

${ }^{11}$ When outreach to attract interested BSF sites began in 2003, it was expected that healthy marriage grant funds proposed as part of TANF reauthorization would soon be available. Due to delays in congressional reauthorization (which ultimately occurred in 2006), some interested sites needed to solicit funds from a variety of sources to support planning and early implementation. Efforts to obtain such funding extended BSF planning longer than initially expected. 


\section{Complexity in Organizational Structure Sometimes Made Implementation More Challenging}

Sites that were able to keep the BSF program's administrative control and management within a single organization had fewer implementation difficulties than those with more complex arrangements. For example, sites led by a single community-based organization, like Baltimore and Baton Rouge, or those that had a fair degree of autonomy, such as Oklahoma, had more opportunity to be flexible and responsive to implementation challenges that arose. Yet the reality is that mobilizing complex bureaucratic structures to deliver programs like BSF can be both practical and desirable. This was the case with several other sites, who faced the challenge of dealing with multiple layers of administration and oversight. For example, some sites subcontracted out parts of their BSF services, while others were funded or authorized by a centralized state agency or a designate that provided ongoing direction and feedback on implementation and operations. Although necessary for overseeing contractual obligations, this feedback was not always aligned with BSF's goals and priorities and could create confusion or reduce the site's ability to quickly make decisions and act on them. These more complex site organizational structures ultimately succeeded in implementing BSF, but faced more challenges in doing so.

\section{RESOURCES FOR PROgRAM IMPLEMENTATION}

Total budgeted costs for the BSF program ranged from about $\$ 8,840$ to $\$ 14,170$ per couple, with a mean cost of $\$ 11,100 .^{12}$ The average anticipated costs differed across implementation approaches. Costs averaged across the three sites that modified an existing program were $\$ 12,100$. For the two sites that added BSF to the services of a multi-program agency, the average cost per couple was $\$ 10,100$. The costs averaged across the remaining two sites that established a new entity with BSF as its sole service was $\$ 10,000$ per couple. ${ }^{13}$ These budgets reflect staff labor, materials and supports for participants, and costs related to the evaluation.

\section{The Goal of Testing Well-Implemented Programs Affected Staff Structures and Program Budgets}

The BSF evaluation asks whether a well-implemented program can help interested and romantically involved unmarried parents build stronger relationships and fulfill their aspirations for a healthy marriage if they so choose. Because the quality of implementation

${ }^{12}$ These figures include BSF program costs as well as the sites' support for the evaluation. Sites had to recruit twice as many couples as they served, since half were assigned to a control group. Site staff also administered baseline data collection forms for the evaluation as part of their intake process.

${ }^{13}$ The budget documents examined for this report reflect actual costs incurred during the pilot and early implementation phases (through 2006) for most sites, and estimated costs for 2007 and beyond based on this experience, so they are not merely hypothetical. Readers should keep in mind that actual costs sites experience over time may be somewhat higher or lower, and may be distributed differently, than indicated in the budgets we reviewed. For example, budgets do not reflect in-kind contributions or the value of services provided to BSF participants by outside agencies, such as employment services. 
was a primary concern sites were asked to propose realistic budgets that ensured full implementation of the BSF model in all of its components. Most important for achieving this was an adequate staffing structure that reflected BSF model guidelines, as adjusted for local priorities and needs.

Each site employed staff to fulfill three primary BSF functions. The main staff functions required to implement BSF were: (1) recruiting and enrolling participants, (2) facilitating group sessions, and (3) working with couples one-on-one. ${ }^{14}$ To perform these functions, sites structured staff positions and responsibilities somewhat differently, depending on existing practices and on local preferences.

- Sites hired outreach and intake workers to recruit and enroll couples into the study. In a few sites, responsibility for identifying eligible couples and enrolling them in BSF was split between two positions. For example, outreach workers might visit new mothers in local hospitals to identify eligible couples, and then hand off the case to an intake worker who would try to meet with the parents to assess eligibility and enroll them.

- While most sites hired or contracted with dedicated facilitators to guide and supervise group sessions, in some sites program directors or other staff members served as facilitators, co-facilitators, or coaches for some or all group sessions.

- Sites employed family coordinators to work individually with couples. Their planned caseloads varied across sites from as few as 10 to 50 or more, depending on how frequent and/or intensive their connections with couples would be. Sites that mandated ongoing weekly or monthly home visits (the Healthy Families sites) kept family coordinator caseloads lower because these staff were required not only to fulfill the FC role but also to deliver a parenting and child development curriculum. Some sites split up the functions of the family coordinator role across multiple BSF staff positions.

In addition to fulfilling functions that were common across sites, some sites also added specialized staff to work with fathers or to provide counseling or other relationship support to couples. Texas, Oklahoma, and Indiana employed fatherhood specialists who sometimes helped with outreach, partnered with female family coordinators as needed to help them work with fathers, and sometimes ran special activities for participating fathers. Louisiana and Maryland each contracted with a counselor or therapist to provide short-term help to couples facing particular relationship challenges. IV.

${ }^{14}$ Staffing approaches for specific program components are described in more detail in Chapters III and 


\section{Costs for BSF's Core Component Included Various Supports for Participants}

In addition to program staff, sites needed to cover other costs of the BSF core group sessions. To implement the weekly group sessions, sites provided child care and offered transportation for attending couples, and served meals and/or refreshments prior to or during the sessions, depending on their length and when they occurred. Some held small celebrations at group sessions, such as for engagements and birthdays, or held graduations or occasional "meet and greet" activities. All sites and locations except one (San Angelo) budgeted for and offered incentives for group attendance, though the level of incentives varied greatly. (San Angelo did provide small gifts to participants such as movie tickets or door prizes, but these were not necessarily tied to participation.) Baltimore and Oklahoma also provided other supports to help couples continue attending groups and participating in other ways, in the form of emergency assistance and resources for addressing basic needs. The planned cost per couple for these supports ranged from $\$ 575$ to $\$ 947$ across most sites. ${ }^{15}$

Sites also incurred costs for purchasing and using their selected curriculum. These costs ranged from as little as $\$ 35$ to as much as $\$ 555$ per couple, and averaged $\$ 272$. Costs varied depending largely on whether curriculum developers provided ongoing training, feedback, and support to sites, or whether training was mostly a one-time activity with minimal or no subsequent followup. Total costs for all participation support, including these curriculum training and materials costs, represented between 7.8 and 11.6 percent of total BSF costs across six of the seven evaluation sites.

\section{Some Costs Were Related to Participation in the Evaluation}

Participating in the evaluation increased costs for all sites compared to what they would otherwise have been. Most notably, to support random assignment, sites needed to recruit twice as many couples as they could serve. In addition, as part of the enrollment process, staff needed to obtain informed consent, complete confidentiality agreements, and collect baseline information from both mothers and fathers. It is difficult to estimate the proportion of costs that stem strictly from the evaluation. Once random assignment ends, budgeted costs will decline somewhat-for example, although all sites plan to continue enrollment after random assignment ends, the number of enrollment staff positions will be reduced. Once the evaluation phase of the BSF program ends, sites could conceivably implement further cost reductions, such as cutbacks in the extent to which sites collect case management information in their MIS files, their attendance at conferences, or outlays on curriculum licenses, materials, training, and supervision.

${ }^{15}$ One site budgeted a substantially higher amount for participation costs compared to other sites; however, this appeared to reflect differences in how the site classified costs in their budget rather than higher planned expenditures for supporting group sessions. Consequently, we excluded that site from the range of percentages reported for participation costs. 


\section{H A P T E R I I I}

\section{SAMPLE E N R OLLME N T A N D C H A R A C T E R I S T I C S}

$\mathrm{s}$ pioneers in implementing programs for low-income unmarried couples, the
organizations sponsoring BSF faced numerous practical issues. Where were they
most likely to find couples who fit the BSF eligibility criteria? How would they go about recruiting them? What messages would appeal to them? Would they be able to enroll enough couples to be a viable evaluation site? What kinds of couples were likely to enroll? What kinds of strengths and challenges would the couples bring to the program?

Issues relating to enrollment are a concern in an evaluation but also in "real-world" programs. In the BSF evaluation, it has been essential for sites to reach enrollment targets to ensure that the evaluation estimates of program impacts are statistically sound. Operators of ongoing programs face similar pressures, because they are attractive as investments of public funds only if they can fill their programs and make efficient use of their resources.

The BSF sites demonstrated creativity, flexibility, and persistence in addressing issues pertaining to enrollment. They developed and refined strategies and ultimately succeeded in identifying and recruiting large numbers of couples for the study. The couples who agreed to enroll fit the eligibility criteria and yet had substantial diversity in their background characteristics. The first part of this chapter describes how and where sites found eligible couples and details their recruitment sources and practices, including the challenges they encountered and the strategies they used to address them. The second part of this chapter reports on the extent to which the BSF sites have enrolled couples in the study and the factors that appear to have affected enrollment success, and documents the characteristics of couples enrolled.

\section{A. Identifying Sources of Potentially Eligible BSF Couples}

The "time window" in which BSF seeks to enroll couples is short. Unmarried couples are only eligible to enroll during pregnancy or up to three months after the birth of their baby. The narrow window for recruitment, and the very specific eligibility criteria couples had to meet, challenged sites to identify avenues through which their own staff or staff of other organizations could have regular contact with the target population and pursue an efficient outreach and intake process. In some cases, this meant building partnerships that 
enabled BSF staff to access potentially eligible couples. Ultimately, sites developed partnerships with a diverse set of organizations within the maternal health care and social service systems.

KEY FINDINGS ON BSF RECRUITMENT SOURCES

- All BSF sites recruited at least in part through the maternal health care system, which yielded a substantial number of potentially eligible couples.

- Multiple recruitment sources were usually necessary; sites could not simply rely on couples to apply, or other agencies to refer, as their sole recruitment strategy.

- Some sites supplemented targeted recruitment with broad outreach efforts such as public service announcements, "street outreach," and personal referrals.

- All BSF sites nurtured their partnerships with recruitment sources.

\section{The Maternal Health Care System Was the Most Common Source for BSF Recruitment}

The maternal health care system made sense for the obvious reason that it is a common destination for pregnant women and their partners. The maternal health care system contributed to recruitment through prenatal clinics and birthing hospitals in nine of the BSF locations. Some site locations also partnered with social service programs within the maternal health care system, such as WIC or local programs that assist pregnant women in accessing Medicaid for prenatal care and delivery.

Nevertheless, only a few BSF locations relied on a single recruitment source. Ten BSF locations identified multiple organizations for recruitment, involving either several entities of the same type (such as multiple local hospitals) or several types of organizations (such as a mix of clinics, hospitals, or social services programs). As indicated in Table III.1, only four locations focused their recruitment on a single category, such as hospitals or clinics. The remaining locations adopted a more diverse approach that involved multiple categories. Atlanta was the only BSF site that came to focus its recruitment effort primarily on one source, a busy prenatal clinic in a major inner-city hospital. ${ }^{16}$ The size of the hospital and large number of uninsured, pregnant women it served made it feasible for the Atlanta site to rely on this single source. Other sites did not have a single source in their community that could yield a sufficient number of potentially eligible couples. Instead, they developed

${ }^{16}$ Other recruitment sources included community public health centers and prenatal clinics for Spanishspeaking women, although these were mostly active during the pilot period. 
relationships with multiple organizations to ensure they recruited a sufficient number of couples.

Table III.1. Recruitment Sources

\begin{tabular}{|c|c|c|c|c|c|c|c|}
\hline & $\begin{array}{l}\text { Birthing } \\
\text { Hospital }\end{array}$ & $\begin{array}{l}\text { Prenatal } \\
\text { Clinic }\end{array}$ & $\begin{array}{l}\text { Public } \\
\text { Health } \\
\text { Clinic }\end{array}$ & $\begin{array}{l}\text { Social } \\
\text { Service } \\
\text { Program }\end{array}$ & $\begin{array}{c}\text { Public } \\
\text { Service } \\
\text { Announce- } \\
\text { ment }\end{array}$ & $\begin{array}{c}\text { Street } \\
\text { Outreach }\end{array}$ & $\begin{array}{c}\text { Personal } \\
\text { Referral/ } \\
\text { Word of } \\
\text { Mouth }\end{array}$ \\
\hline $\begin{array}{c}\text { Atlanta } \\
\text { GSU } \\
\text { LAA }\end{array}$ & & $\begin{array}{l}\checkmark \\
\checkmark\end{array}$ & & & & & \\
\hline Baltimore & & $\checkmark$ & & $\checkmark$ & & $\checkmark$ & \\
\hline Baton Rouge & & & $\checkmark$ & $\checkmark$ & $\checkmark$ & & \\
\hline $\begin{array}{l}\text { Florida } \\
\text { Broward County } \\
\text { Orange County }\end{array}$ & $\begin{array}{l}\checkmark \\
\checkmark\end{array}$ & & & & & & $\checkmark$ \\
\hline $\begin{array}{l}\text { Indiana } \\
\text { Allen County } \\
\text { Lake County } \\
\text { Marion County }\end{array}$ & $\begin{array}{l}\checkmark \\
\checkmark \\
\checkmark\end{array}$ & & & $\checkmark$ & & & \\
\hline Oklahoma & $\checkmark$ & $\checkmark$ & $\checkmark$ & $\checkmark$ & $\checkmark$ & & $\checkmark$ \\
\hline $\begin{array}{l}\text { Texas } \\
\text { Houston } \\
\text { San Angelo }\end{array}$ & $\begin{array}{l}\checkmark \\
\checkmark\end{array}$ & $\checkmark$ & $\checkmark$ & & & & \\
\hline
\end{tabular}

Birthing Hospitals. Four BSF sites worked with birthing hospitals to recruit couples. Hospitals gave BSF staff access to mothers shortly after they delivered. This source was most common in sites that already offered Healthy Families services. Under long-standing agreements allowing Healthy Families recruitment, these sites were permitted to review a mother's chart, and were thus able to prescreen for some BSF eligibility requirements, such as age or marital status. Several of the sites that targeted birthing hospitals developed relationships with multiple hospitals in their community. For example, Broward County, Florida conducts recruitment at five hospitals and Orange County in three hospitals.

Prenatal Clinics. Three sites, Atlanta, Baltimore, and Oklahoma, identified prenatal clinics as recruitment sources. BSF staff made contact with mothers and couples as they attended prenatal care appointments. Atlanta partnered with a large downtown public health hospital with two prenatal clinics. Baltimore developed relationships with six hospitals throughout the city; each runs pre- and/or post-natal clinics where BSF staff could access potentially eligible couples. Focusing on prenatal recruitment options was essential for the Oklahoma site, which at least initially aimed to have all couples complete the marriage and 
relationship skills curriculum prior to the birth of the baby. Oklahoma identified both public and private prenatal clinics at local hospitals, health clinics, and doctors' offices.

Public Health Clinics. Two locations, Houston and Oklahoma, developed partnerships with local public health clinics. These organizations served a similar population as the prenatal clinics, though they provided a wider array of services. Houston arranged to have a table in the clinic waiting room where BSF staff could talk with clients coming in for their appointments. Oklahoma developed a referral procedure: clinic staff identified and referred potentially eligible couples to the BSF program, which then contacted the couples for intake assessment.

Social Services Programs. After birthing hospitals, the next most common type of recruitment organization was social service programs. BSF sites identified a range of social service programs as recruitment sources, including WIC, Head Start, Catholic Charities, TANF, and local community-based organizations.

\section{In a Few Sites, Broad Outreach Methods Supplemented Targeted Recruitment}

To supplement recruitment efforts through organizations serving a concentration of likely BSF-eligible couples, four of the BSF sites used broad outreach methods to identify potentially eligible couples. These methods included public service announcements, street outreach, and personal referrals or word of mouth (Table III.1). No site relied on broad outreach to identify a large percentage of their potentially eligible couples, yet the sites using broad outreach felt it was an important element of their strategy. In the view of site leaders, these broad outreach methods were useful because they informed the community about the new BSF program, helped the site meet its recruitment target, and gave evidence of the organization's commitment to the community.

Public Service Announcements and Direct Mailings. Two sites, Baton Rouge and Oklahoma, used public service announcements or direct mailings. Through radio spots, sites advertised for BSF and highlighted eligibility criteria. A radio announcement in Oklahoma was produced after program staff spoke with radio station staff about an unrelated topic, but got the station management interested in BSF to the point that they offered to run a free announcement describing the program. The announcements increased program visibility, although they do not appear to have generated a large number of BSF applicants. However, Oklahoma's direct mail strategy has generated considerable response, according to program managers.

Street Outreach. The BSF site in Baltimore used street outreach as one of their recruitment strategies. CFWD, the host organization, has a history of identifying and recruiting participants for its fatherhood program by approaching men on the street and speaking about its programs and services. CFWD adapted this technique into its BSF recruitment by focusing on couples, as part of its ongoing commitment to connecting with and serving the population in Baltimore City.

Personal Referrals/Word of Mouth. The sites in Broward County, Florida, and Oklahoma used personal referrals and word of mouth to increase recruitment. Personal 
referrals came from participating couples or even program staff. The Family Expectations leadership in Oklahoma encouraged staff to refer potentially eligible couples, and provided them with brightly colored business cards with the message "Having or just had a baby? Then check out Family Expectations." The cards included contact information for the program to encourage potentially eligible couples to call. As another strategy, Oklahoma included messages, such as "Know someone who is having or just had a baby?" on their mailers to currently participating couples to encourage referrals. They also provided incentives to participating couples, if a referred couple followed through with an intake assessment.

\section{To Ensure a Steady Flow of Potential Recruits, Sites Nurtured Partnerships with Community Organizations}

Many BSF recruitment sources were community based organizations with which sites developed partnerships. In some cases, sites had pre-existing relationships with organizations that they built upon for BSF. In other cases, sites developed new relationships.

BSF staff built relationships with senior management at identified recruitment sources. Particularly in large organizations, such as hospitals, BSF staff initially spoke with upper management to gain entry into the organization for recruitment purposes. Early conversations focused on orienting the organization to BSF and broadly discussing how the organization could support BSF's recruitment efforts.

Baltimore staff found it useful, in building relationships with senior management at six hospitals, to present information on how the BSF program could benefit the organization. For example, they described not only the potential benefit to children when their parents stay together and marry, but also the potential cost savings for the health care organization when the couple's relationship is maintained.

Sites and recruitment sources negotiated arrangements for working together. After gaining the interest and support of upper management, BSF staff worked with the organization to develop a strategy for how the site and recruitment organization would work together. Upper management often delegated this planning to their staff. BSF sites and these staff considered issues like how and when contact between BSF staff and clients would happen, how client confidentiality would be maintained, and what training the organization's staff would receive on BSF. After negotiating the details, BSF introduced its staff who would be stationed at or frequent the organization's location for recruitment purposes.

BSF sites often arranged to station staff at recruitment source locations and developed procedures for receiving referrals. Detailed planning led BSF sites to develop arrangements with recruitment sources that involved directly stationing BSF staff at the recruitment source. Alternatively, they sometimes arranged with staff at these source agencies to refer potentially eligible couples to BSF. Using a combination of these approaches was a frequent solution, because BSF staff could not always maintain a constant presence at the recruitment source. 
All BSF sites arranged for at least part-time stationing of BSF staff at one or more of their recruitment sources. Sites viewed stationing staff at the organization as ideal, because it facilitated direct contact between BSF and potentially eligible couples and minimized the burden placed on staff at the recruitment source. Through direct contact, BSF staff ensured that couples received accurate initial messages and, in some cases, enabled them to complete all intake steps during an initial contact. Sites worked with the recruitment source to identify days and times when BSF staff could be present. The selected times aligned with times that potentially eligible couples would likely be on-site. For example, if a prenatal clinic operated three mornings a week, the site arranged for BSF staff to be present during at least some of this time.

To supplement their own on-site presence, BSF site staff developed procedures for the recruitment source agencies to refer potentially eligible couples to BSF. A common approach was to provide the recruitment source with a form on which couples completed a brief set of pre-screening questions and provided consent for BSF to directly contact them. Couples completed the form and staff at the recruitment source delivered it to BSF. This procedure was not possible at all recruitment sources, however, because agency staff were often so overwhelmed with existing responsibilities that they couldn't take on even this minor task.

Sites received referrals from diverse organizations. BSF staff in Marion County, Indiana, Baton Rouge, and Oklahoma received referrals from the WIC program. In addition to WIC, Oklahoma received referrals from prenatal clinics, public health clinics, doctor's offices, the Department of Human Services, and other social service providers. Houston at first received lists of potentially eligible BSF couples from city health clinics, which they used to contact and screen prospective participants. Although the clinics stopped providing the lists for privacy reasons, the site receives lists of potentially eligible couples from social workers at a local hospital and from the State Attorney General's Child Support Office.

\section{B. Strategies for Recruiting Potentially Eligible Couples}

The details of enrollment at all BSF sites had to closely align with the research design, but each site could design its enrollment process to fit with its organizational structure and recruitment sources. All sites complied with research requirements, but variation in how couples were identified, approached, and enrolled may have affected how many couples they could enroll in the study. This section describes how sites went about enrolling couples in $\mathrm{BSF}$, how the process varied across sites, and specific practices that may have affected the likelihood that a couple would enroll in BSF. One issue of particular concern was how BSF programs could avoid inappropriately serving couples with serious domestic violence problems, so this section concludes with a description of the procedures sites used to detect and address domestic violence during intake and participation. 
Key Findings on EnRollment Process, Practices, And Progress

- After an early learning curve, BSF sites are enrolling sample at a steady pace. Combined, BSF sites enrolled over 2,600 couples at the end of March 2007.

- Sites were challenged by the need to enroll two people (a couple) for each BSF case. The most expeditious enrollment method was to conduct outreach and intake in one meeting with both members of the couple present.

- Success in enrollment often required sites to be flexible and opportunistic Outreach and intake were conducted on location at agencies, hospitals, clinics, and in couples' homes. Sometimes it was most practical to simply engage interest during the first contact, making an appointment to go through the full intake process later.

- Most sites described the BSF group sessions as the primary program feature during the initial outreach contact.

- To avoid the impression that BSF was for mothers only or fathers only and to send the message that the program is for couples, some sites favored recruitment teams including both male and female staff.

- All BSF sites developed a plan for detecting and addressing domestic violence during intake and after program enrollment. After beginning BSF implementation, several sites reassessed their protocols, leading them to seek assistance from experts and revise their screening or monitoring policies.

- BSF has attracted culturally diverse, mostly young, low-income couples. Many have children, by the same or a former partner, prior to enrolling in BSF. Most couples have known each other for some time and live together. While most are economically disadvantaged, many work and have a high school education and social support. Marriage aspirations are high.

\section{To Enroll in BSF, Both Members of Each Couple Had to Meet Eligibility Requirements and Provide Consent}

All BSF sites were required to complete the same intake steps with each member of the couple, although they had flexibility in how they structured the steps.

1. Identify Potentially Eligible Couples. As described in the previous section, sites identified prospective participants by working with recruitment sources that had ongoing contact with the target population. 
2. Determine BSF Eligibility. BSF staff met with potential participants to screen for BSF eligibility, using a brief checklist, and meeting separately with mothers and fathers. As part of this eligibility process, staff screened potential participants for domestic violence.

3. Describe Program and Obtain Consent for Study. All eligible and interested couples completed a formal informed consent process to ensure that they understood that BSF is part of a research study. Each parent signed a consent form, after BSF staff described the program and its services and determined if the individual was interested.

4. Complete Study Baseline Forms. BSF staff administered a brief baseline data form and another form on which participants provided contact information on several friends and relatives. The contact information was intended to help the evaluation team locate sample members for follow-up surveys, but it aligned closely with forms already used by site organizations to collect emergency contact information.

\section{Approach to Identifying Potentially Eligible Couples Varied Across Sites}

Sites diverged in the timing and methods of their first contacts with couples. Sites' approaches arose in part out of their organizational structures and in part from existing practices and preferences at some sites. Some of the variation observed in the number of couples recruited may be at least partially explained by these differences in enrollment approach.

Sites identified potential enrollees during the prenatal period, the postnatal period, or both. Sites could enroll couples during the pregnancy or within three months of delivery. Six locations completed at least some of their recruitment during the prenatal period and eight locations completed at least some of their recruitment during the postnatal period (Table III.2). About a quarter of sites recruited during both periods.

Three sites conducted all or most of their enrollment during the prenatal period. In two instances they did so of the nature of their main recruitment source, and in one case because prenatal recruitment was consistent with the focus of their chosen curriculum. Atlanta focused on prenatal enrollment because their primary recruitment source, prenatal clinics at a large hospital, provided all the couples the site needed to recruit. Originally, Baton Rouge recruited a large percentage of their couples through a group-oriented program at Family Road for newly pregnant, Medicaid-eligible women. Over time, Baton Rouge diversified their recruitment to include referrals from several social service organizations and health units, but continued to focus on expecting couples. Oklahoma was more purposeful in choosing to recruit prenatal couples, because the Becoming Parents Program curriculum they chose is specifically designed for prenatal couples.

The BSF programs integrated into Healthy Families programs conducted recruitment soon after the birth of the baby, identifying mothers in the maternity wards of local hospitals. In Florida and Indiana this was the preferred approach because it fit with the way

\section{III: Sample Enrollment and Characteristics}


the Healthy Families programs already recruited. In San Angelo, although the Healthy Families program was transformed into BSF and there was no continuing recruitment for a distinct Healthy Families program, the site used its pre-existing arrangements with local hospitals to identify new mothers eligible for BSF.

Table III.2. Recruitment Timing and Methods

\begin{tabular}{|c|c|c|c|c|}
\hline & \multicolumn{2}{|c|}{ Timing of Recruitment } & \multicolumn{2}{|c|}{$\begin{array}{l}\text { Methods for Initially Identifying } \\
\text { Potentially Eligible Coupes }\end{array}$} \\
\hline & $\begin{array}{l}\text { During } \\
\text { Pregnancy }\end{array}$ & $\begin{array}{l}\text { After Baby's } \\
\text { Birth }\end{array}$ & $\begin{array}{l}\text { Program Directly } \\
\text { Approaches } \\
\text { Couples }\end{array}$ & $\begin{array}{l}\text { Respond to } \\
\text { Referrals }\end{array}$ \\
\hline \multicolumn{5}{|l|}{ Atlanta } \\
\hline GSU & $\checkmark$ & & $\checkmark$ & \\
\hline LAA & $\checkmark$ & & $\checkmark$ & \\
\hline Baltimore & $\checkmark$ & $\checkmark$ & $\checkmark$ & $\checkmark$ \\
\hline Baton Rouge & $\checkmark$ & & $\checkmark$ & $\checkmark$ \\
\hline \multicolumn{5}{|l|}{ Florida } \\
\hline Broward County & & $\checkmark$ & $\checkmark$ & $\checkmark$ \\
\hline Orange County & & $\checkmark$ & $\checkmark$ & \\
\hline \multicolumn{5}{|l|}{ Indiana } \\
\hline Allen County & & $\checkmark$ & $\checkmark$ & $\checkmark$ \\
\hline Lake County & & $\checkmark$ & $\checkmark$ & $\checkmark$ \\
\hline Marion County & $\checkmark$ & $\checkmark$ & $\checkmark$ & $\checkmark$ \\
\hline Oklahoma & $\checkmark$ & & $\checkmark$ & $\checkmark$ \\
\hline \multicolumn{5}{|l|}{ Texas } \\
\hline San Angelo & & $\checkmark$ & $\checkmark$ & \\
\hline Houston & $\checkmark$ & $\checkmark$ & $\checkmark$ & $\checkmark$ \\
\hline
\end{tabular}

Note: Represents primary method of recruitment in place at the time information was collected for this report. Some sites have expanded or broadened their strategies since then.

To ensure they recruited enough couples, several locations (Baltimore, Houston, and Marion County in Indiana) conducted both pre- and postnatal recruitment. These locations did not have partnerships with organizations focused on either expecting couples or new parents that appeared able to generate enough couples to meet the sites' enrollment targets. Instead, they developed partnerships with several community organizations that regularly interacted with potentially eligible couples, including couples both before and after the birth of their child.

Couples often learned of BSF through a direct in-person encounter with BSF staff, but that was not always possible. In all BSF locations, the first contact in which potentially eligible couples learned about the BSF program was, in many cases, when they were approached in person by BSF staff. Usually these contacts were with BSF staff stationed at recruitment sources such as hospitals or prenatal clinics, but sometimes BSF 
staff approached them in public places like neighborhood sidewalks and shopping malls. Most sites used this initial interaction to describe the BSF program and solicit interest. If they met with an expression of interest, staff would complete the intake process on the spot or make an appointment.

Sometimes, however, the initial contact was not with BSF staff directly. In some cases the site's arrangement with a recruitment source precluded direct involvement of BSF staff in this first contact. In eight locations, as a result, BSF staff were often responding to referrals from other organizations. When they made contact with the parent or both partners by telephone, the BSF staff's major objective was to build rapport, describe BSF, screen for eligibility, and schedule a full intake. Some individuals expressed nervousness or were unsure of their interest when first contacted, and staff sometimes had to make numerous contacts before they could schedule and actually complete an intake appointment.

\section{With Two Persons (a Couple) to Recruit for Every Case, Simplifying the Enrollment Process Was Essential}

The need to engage the interest, consent, and commitment of a couple posed specific practical challenges to efficient recruitment, and how these challenges were addressed had implications for success in recruitment and enrollment. It took time to engage the interest of parents, assess their eligibility, and enroll them in the study, and the circumstances of the initial encounter with outreach staff often dictated whether there was adequate time or sufficient staff to complete all these steps at once. Sometimes, the outreach worker's first encounter was with one partner, not both. For these reasons, follow-up appointments to complete intake with one or both partners were often necessary. It appears that the greater the number of separate encounters to complete intake with both partners, the more likely it was that the couple might drop out of the enrollment process. Thus, sites strove to find ways to streamline the recruitment process wherever possible. Table III.3 reviews several program practices that may affect recruitment and enrollment.

Enrollment seemed more likely when both parents were present at the initial contact. It appears that approaching parents together, when possible, makes it more likely that both parents will be assessed for eligibility and enrolled. One explanation for this is that this process does not rely on one partner explaining BSF to the other, which could introduce misinformation or skepticism. Sometimes eligible women told site staff that they had talked with their partners about the program but "he wasn't interested." In such cases, sites typically offered to have a staff member contact the partner to explain the program-but often the partner had already made up his mind and was not open to solicitations from the program. Some sites found that the partners of eligible women simply avoided being contacted by the program for eligibility assessment. 
Table III.3. Recruitment Practices That May Contribute to Enrollment

\begin{tabular}{|c|c|c|c|c|c|c|}
\hline Site & $\begin{array}{l}\text { Both Parents } \\
\text { Usually Present at } \\
\text { Initial Contact }\end{array}$ & $\begin{array}{l}\text { Single Point of } \\
\text { Contact for All } \\
\text { Intake Steps }\end{array}$ & $\begin{array}{c}\text { Mixed Gender } \\
\text { Recruitment Teams }\end{array}$ & $\begin{array}{l}\text { Couple Not } \\
\text { Required to Enroll } \\
\text { in Additional } \\
\text { Services }\end{array}$ & $\begin{array}{c}\text { Staff Describe BSF } \\
\text { as the Primary } \\
\text { Service }\end{array}$ & $\begin{array}{l}\text { Staff Emphasize the } \\
\text { Couple Relationship }\end{array}$ \\
\hline \multicolumn{7}{|l|}{ Atlanta } \\
\hline GSU & $\checkmark$ & $\checkmark$ & $\checkmark$ & $\checkmark$ & $\checkmark$ & $\checkmark$ \\
\hline LAA & $\checkmark$ & $\checkmark$ & $\checkmark$ & $\checkmark$ & $\checkmark$ & $\checkmark$ \\
\hline Baltimore & & & & $\checkmark$ & $\checkmark$ & $\checkmark$ \\
\hline Baton Rouge & & & $\checkmark$ & $\checkmark$ & $\checkmark$ & $\checkmark$ \\
\hline \multicolumn{7}{|l|}{ Florida } \\
\hline Broward County & & $\checkmark$ & & & & $\checkmark$ \\
\hline Orange County & & $\checkmark$ & & & & $\checkmark$ \\
\hline \multicolumn{7}{|l|}{ Indiana } \\
\hline Allen County & & $\checkmark$ & & & & \\
\hline \multirow{2}{*}{\multicolumn{7}{|c|}{$\begin{array}{l}\text { Lake County } \\
\text { Marion County }\end{array}$}} \\
\hline & & & & & & \\
\hline Oklahoma & & $\checkmark$ & & $\checkmark$ & $\checkmark$ & $\checkmark$ \\
\hline \multicolumn{7}{|l|}{ Texas } \\
\hline Houston & & $\checkmark$ & & & & \\
\hline San Angelo & & & & & & $\checkmark$ \\
\hline
\end{tabular}

Note: Sites with a checkmark were determined to have conducted the recruitment practice always, almost always, or most of the time. Sites without a checkmark either never used the practice, or used the practice sometimes or rarely. 

Another, more obvious, advantage of approaching couples when they are together is that it can be difficult to find a time to schedule the second partner's intake, and interest can diminish if a long period elapses after the first parent's completion of intake. Sites that approached one parent and then followed up with the other parent generally had to work harder to locate and engage the second partner's interest and gain consent to be assessed for eligibility.

In Atlanta, BSF staff developed an efficient recruitment approach based on the observed importance of a two-partner initial contact. BSF in Atlanta stations a team of male and female outreach staff at the prenatal clinic, who focus their efforts on approaching couples waiting together for an appointment. By having multiple staff on location at the same time, BSF workers can complete all intake steps while the couple waits for their appointment, between prenatal exams and other screening tests, or immediately following appointments. This process has two advantages: it avoids setting up a situation in which one partner is informed but the other is not, and avoids the need to schedule follow-up contacts to complete intake. It is an efficient process that eliminates the risk that no-shows will derail a couple on the way to enrollment.

Sites increasingly strove to conduct intake with both parents simultaneously, even if not in an initial contact. Several locations placed a high priority on conducting intake with both parents in a single contact. Atlanta encouraged staff to complete all intake steps in a single encounter, typically with both members of the couple present. When it was not possible to complete all the steps at the clinic, an appointment was made to finish the process during a home visit with both parents. Oklahoma and Houston followed a similar approach, although initial contact with a couple was often made in response to a referral. After contacting potentially eligible individuals, staff at these sites described the program by telephone and attempted to schedule intake at a time when both parents could attend.

Other sites also strove to meet with both parents to conduct intake. In Baltimore, staff often received referrals in the form of a "consent to contact" and telephoned the individuals to schedule an intake appointment with both parents. San Angelo staff approached newlydelivered mothers in the maternity ward about the program and screened them for eligibility and interest. There, too, BSF staff followed up and tried to schedule an intake meeting that both the mother and father were expected to attend.

If a joint enrollment session was not possible, it was still useful to complete initial contact and all of the intake steps in a single encounter with each parent. It was generally the case that the fewer contacts necessary to complete intake with both parents, the more likely it was that an eligible couple would be enrolled. If separate intake sessions with the two parents were inevitable, it was particularly important to complete intake with each in the fewest possible contacts. It also appeared that having a single staff person complete all outreach and intake steps for the couple was more effective than having couples interact with multiple outreach or intake staff. 
In four locations staff usually completed all of the intake steps with one parent, often the mother, in one encounter. Some of the Healthy Families locations (Broward County and Orange County in Florida, and Allen County in Indiana) tried to complete intake with the mother while she was in the maternity ward. Fathers were not often in attendance at the hospital when intake staff were present, which meant that staff then needed to locate him and schedule an intake. Similarly, when Baton Rouge identified interested and eligible mothers, and sometimes couples, during a group-oriented program for expectant mothers, staff tried to complete a full intake with one or both members of the couple immediately following the program presentation.

Some sites learned that complicated enrollment processes involving multiple steps and staff were likely to limit enrollment. Two locations in Indiana had separate outreach and intake procedures for their Healthy Families program and for BSF. First a mother was contacted in response to a referral for Healthy Families or as a result of a screening of hospital records. During this contact, Healthy Families staff conducted an eligibility assessment for their program and screened the mother for BSF eligibility. Sometimes, but not always, BSF was briefly mentioned during this encounter as one of many available programs. If eligible, the mother was later contacted by BSF staff to schedule another appointment for BSF intake, sometimes with a different staff member. Staff attempted to schedule the BSF intake appointment with both mother and father, but they were not always able to do so, which meant that a further appointment was needed to conduct intake with the father. This multi-step, multi-staff process was clearly more difficult than the approach followed in Florida where BSF intake was integrated into the process for the host program, Healthy Families, and conducted by a single staff member.

\section{Mixed-Gender Recruitment Teams Could Put Couples at Ease but Was Not Considered Essential by All Sites}

Some sites felt that recruitment staff, as the "face" of the program, should be malefemale teams to convey the message that the program is for couples, rather than individual parents or mostly mothers. Other sites deployed individual staff, male or female, usually in keeping with existing procedures or organizational constraints, although in other cases reflecting the site's staffing philosophy.

Two sites fostered a mixed-gender team approach. Atlanta had six outreach/intake staff-four men and two women-who stationed themselves at the hospital clinic where most recruiting occurred, and spontaneously formed two-person teams. Rapport with couples developed easily, because each member of the couple had someone of their own gender to talk to. This seemed to be especially helpful when staff described the program, perhaps because parents often wondered "whose side" the program might be on. Once the program was described and the couple indicated their willingness to be assessed for eligibility, the staff team conducted intake, typically with each partner's intake done by the staff of the same gender. 
Baton Rouge consciously recruited male and female outreach workers and encouraged them to work together as a team. They jointly made presentations about the program to groups of expectant mothers visiting the center for other purposes, and conducted intake, pairing the male worker with the male member of the couple when present. These teams also made outreach presentations to staff and potentially eligible individuals at social service organizations.

The remaining BSF sites arranged for individual staff to complete intake for both members of a couple. Sometimes these were male, sometimes female workers. Baltimore and Oklahoma employed both male and female staff who worked independently on outreach and intake. In the Healthy Families sites (Florida, Indiana, and Texas), female staff did most recruitment. In some cases male staff, who worked with fathers already in the program or served as group co-facilitators, assisted with enrollment when female intake staff had difficulty connecting with a father. One program, however, remained skeptical about the added value in deploying two-person teams.

\section{The Content and Enthusiasm of Recruitment Messages May Affect Recruitment Success}

How staff describe the BSF program and study to potentially eligible couples may influence their willingness to be assessed for eligibility and, if eligible, to seriously consider entering the study. The messages involved in the initial presentation of the program and the enthusiasm with which they are presented might also affect later participation among couples who are found eligible and agree to enroll. BSF offers many potential benefits and program staff could highlight different aspects during recruitment, although the main focus was expected to be on the services to enhance couple relationships and marriage.

Most outreach messages focused on the couple relationship, but some emphasized benefits to children. During outreach, staff could focus on the couple relationship, the individual parent, the child, or some combination. Seven of the BSF locations emphasized the importance of nurturing the couple relationship and highlighted how BSF supported this relationship. Sites emphasized the couple relationship by describing BSF as a program for people who care about their relationship and want to make it better, or who want to explore marriage. Others focused on the effects of the couple relationship on children, explaining "what is best for your baby is the two of you" (mother and father), or connecting the couple's relationship to the health of their baby. Variations in emphasis may be connected to differences in the motivations of couples at different sites. For example, Atlanta found that its African American couples were most likely to respond to messages that appealed to their desires to improve their couple relationship. In sites with large numbers of Hispanic families, such as the Texas sites, messages focused on the benefits to children resonated best.

In recruitment, stand-alone BSF programs (Atlanta, Baltimore, Baton Rouge, and Oklahoma) focused on the couples' group sessions and described meetings with a family coordinator and access to family support services as supplementary. When describing the 
group sessions, staff highlighted appealing aspects for couples, such as the skills couples would learn during group or the other couples they would meet.

The recruitment messages in Healthy Families sites often focused on the importance of learning parenting skills, child development and the benefits of home visiting, with the marriage and relationship skills as an equal or secondary emphasis. Staff at these sites tended to begin their description of services by discussing home visits and the personalized attention of the home visitor, the traditional focus of the Healthy Families program into which BSF was integrated. Staff varied in the degree to which they mentioned BSF services; some provided a detailed description of all available services and others gave less attention to the couple-focused services. In some cases, but not all, staff referred to BSF as an "add-on" to Healthy Families.

In a few cases, staff did not emphasize the couples groups because of concern that couples who entered the BSF study might be assigned to the control group and not receive any services. Although all couples had to meet the BSF eligibility criteria to be part of the study, the Healthy Families sites had an additional eligibility criterion--the family had to be at risk for child abuse and neglect. Staff at some sites indicated that, at least with families whose particularly high risk level was a serious concern, they preferred to present the available options in a way that might encourage the parents to opt for the narrower services of Healthy Families rather than enrolling in the BSF study.

Staff in most sites expressed enthusiasm for BSF during outreach, and some learned to tailor the message to couples' specific interests. The way that outreach and intake staff communicated to couples, since it was their first exposure to BSF, was critical in building interest and excitement for BSF. Some used humor; others engaged the couple in conversation about the common frustrations of getting along together; some highlighted the opportunity to meet other couples like themselves and have a weekly "night out." Instead of describing the program as requiring six months of weekly sessions, staff in the Atlanta site sometimes told couples there are "21 things you need to learn to keep your relationship solid"-which are revealed in the 21 weekly sessions and included topics like compromise and problem solving. Some sites also indicated that an effective strategy was to inform couples that there are limited slots available for the study. At a couple of locations, some outreach workers were less enthusiastic or communicative about the program--they usually knew little about the program and how it might help couples.

\section{Sites Created Procedures to Detect and Address Domestic Violence at Intake and Afterwards}

Identifying couples experiencing domestic violence was a major concern for BSF sites, at intake and later as couples participated in the program. The BSF sites recognized the possibility that in some cases, if a couple was experiencing domestic violence, participating in group-based marriage and relationship skills education could aggravate the situation and increase risk. The sites were committed to excluding such couples from BSF and connecting them with alternative services to ensure safety. Ideally, these couples would be identified at intake and excluded from the study and the program before going through random 
assignment. Sites developed screening procedures for use in intake, and procedures for ongoing screening for couples participating in the program. The sites consulted with local and in some cases state-level domestic violence coalitions on how to conduct screening.

BSF sites were divided on whether to use highly structured screening tools or more informal conversational assessment. Four sites used a formal screening tool, and the others included domestic violence screening in an in-depth, informally structured assessment. To encourage honesty and full disclosure without fear of repercussions, both approaches were used with only the mother, because she was viewed as the more likely victim of violence. Although both men and women can be abusive, men are on average more likely to be perpetrators of severe violence, so only women are screened in order to avoid putting them at more risk.

Formal screening at intake involved administering a structured sequence of 22 questions to the mother. The screening occurred after intake workers separated the couple so each member could go through the baseline data collection protocol in private. The domestic violence screening was thus incorporated into the intake procedure with the mother, but not the father. Three sites used a screening instrument (Gottman, Stith, Babcock, and McCollum 2004) that incorporated the Conflict Tactics Scale (Straus 2004) as well as additional items to identify men's controlling behavior and assess the woman's fear of her partner. The instrument was designed to distinguish between symmetrical or situational violence arising out of conflict escalation and "characterological" violence involving a clear perpetrator and victim and controlling behavior. The fourth site developed its own structured tool in collaboration with other domestic violence experts. In all cases, these structured tools included explicit decision rules that specified the responses that should result in screening of couples out of the BSF study at intake (or out of the group sessions if violence was detected later).

The remaining three BSF sites conducted domestic violence screening as part of an informal conversational assessment at intake. Sites typically completed this with only the mother, though fathers were included in the discussion if they were present. The assessment covered many topics with the mother, including her available emotional support and knowledge of child development. During the conversation, staff asked the mother to describe an argument with her partner, and used the response to explore how the couple addressed conflict and whether the couple had experienced violence. If the father was present, the staff observed the mother's non-verbal cues during the discussion and if necessary would try to follow up with the mother later when the father was not present. Over time, one of these sites became dissatisfied with this screening procedure and shifted to a more formal process involving a structured screener.

Where BSF was integrated into an existing program, sites had to reconcile domestic violence screening goals for BSF with screening designed for different purposes. In Florida, Indiana, and Texas, domestic violence assessment was already part of the Healthy Families services provided prior to BSF. The idea of screening to identify and exclude couples who might be endangered by participation in BSF was a departure from the goal of screening for the Healthy Families program. Domestic violence was viewed in 
Healthy Families programs as a factor that would support admission to, rather than exclusion from the intervention. A mother experiencing domestic violence would be invited into Healthy Families because the program might help her seek safety and shelter. In reviewing and revising existing policies with couples in mind, these programs were challenged to define a strategy that would still serve the original purpose of uncovering domestic violence but also address the BSF screening goals.

As a result, one site-Florida-found it necessary to revise its protocol, mostly to reconcile these goals. The original screening protocol there called for an in-depth, informally structured conversational assessment with the mother, and the father if he was present. During the private session with the mother to obtain consent, the mother was usually asked further questions guided by a short screener developed by the site. As time went on, however, staff found signs of violence among several couples who had been enrolled in and were participating in BSF. Program leaders became concerned that their initial screening at intake, designed for identifying a risk factor that would support a family's eligibility for Healthy Families, was not structured tightly enough to detect domestic violence warranting exclusion from BSF. This led to consultation meetings between state and local program staff, and representatives of local domestic violence organizations to define a new screening procedure and protocol. The new protocol was designed to detect domestic violence and to distinguish whether its specific manifestations warranted excluding the family from a couples' intervention.

BSF sites trained their staff to detect domestic violence and developed partnerships with local domestic violence organizations. BSF sites prepared their staff to use the screening tools they had adopted, and to address domestic violence when it was uncovered. Sites offered training, led by their own staff and often domestic violence coalition representatives, at the beginning of BSF implementation and later to deal with staff turnover and the need for refresher training. Staff received information on detecting domestic violence, including common patterns observed in victims and perpetrators, how to respond when domestic violence is identified, how to discuss it with the victim, where to refer victims for targeted services and shelter, and how to develop a safety plan. In sites that had chosen the Loving Couples, Loving Children curriculum, information on detecting nonverbal and other signs of domestic violence was part of the week-long training for group facilitators.

To help ensure the safety of individuals identified as victims of domestic violence, sites developed partnerships with local domestic violence organizations and shelters. These relationships also ensured that staff had knowledge of available community resources and knew how to access them, if needed. For example, the Baltimore program has a close partnership with the House of Ruth, a local shelter and advocacy organization, while Baton Rouge works with the Capitol Area Family Violence Intervention Center.

\section{Enrollment Progress to Date}

Large sample sizes are required for a reliable test of BSF's impact on parents and their children. Even in the absence of such a test, voluntary marriage education programs such as 
those supported by the Healthy Marriage Initiative are unlikely to achieve their goals unless couples sign up in substantial numbers. Little is known about whether such programs can attract low-income, culturally diverse couples, or about what strategies promote enrollment success. This section documents the extent of BSF sites' success in achieving enrollment targets for the evaluation, how enrollment varies across sites, whether sites improve their enrollment rates as they gain experience, and what factors are likely responsible for the variation across sites in enrollment.

Any examination of BSF enrollment levels must take into account the staggered schedule on which BSF sites began recruiting for the evaluation. The earliest sites, Florida and Texas, began enrolling evaluation sample in June 2005. Baton Rouge, Atlanta, Baltimore and Indiana began five to seven months later, and Oklahoma began in June 2006.

\section{BSF Had Enrolled Over 2,600 Couples at the End of March 2007}

As of March 31, 2007, BSF sites had enrolled 2,684 couples, randomly assigned to the intervention or control group (Table III.4). The pace of enrollment varied across sites, but in most cases met or exceeded the targets set for each site based on their experience in a pilot phase of implementation preceding the start of evaluation sample enrollment (Dion et al. 2006). Data from the most recent six months of enrollment during which all sites were operational and had gained some experience indicate that the seven BSF sites together were enrolling an average of about 210 couples per month (Table III.5).

Because the dates for starting enrollment of the evaluation sample differed across sites, we defined four cohorts based on when couples enrolled in the BSF sample (Table III.4). These four cohorts are a useful way to understand both enrollment patterns, including change over time, and ultimately participation rates (discussed in Chapter VI). Cohort 1 includes all couples enrolled in the eight months from June 1, 2005 to January 31, 2006, almost exclusively covering the early enrollment in Florida and Texas, since other sites had either not begun or had just begun enrollment by the end of this period. Cohort 2 includes couples enrolled in the four months from February 1, 2006, to May 31, 2006, a period during which all sites except Oklahoma were operational. Cohort 3 consists of couples enrolled from June 1, 2006, to September 30, 2006, and includes all sites. Cohort 4 is couples who entered the study in the six-month span from October 1, 2006, to March 31, 2007, a period during which all sites were operating; by the start of this period, all sites had had at least four months of experience with enrollment.

\section{Enrollment Success Is the Product of Complex Factors Related to Recruitment Practices, Site Context, and Management Control}

There is no simple explanation of the factors that affect success in recruitment. Recruiting practices undoubtedly play a role, as described earlier in this chapter, but they very likely interact with other key factors such as size of the community in which recruitment occurs, length of the site's experience, organizational capacity and staffing changes, and continued access to a steady source of potentially eligible couples. 
Table III.4. Number of Couples Enrolled by BSF Site and Cohort, Through March 2007

\begin{tabular}{|c|c|c|c|c|c|c|}
\hline & $\begin{array}{c}\text { Date } \\
\text { Evaluation } \\
\text { Enrollment } \\
\text { Began }\end{array}$ & Cohort 1 & Cohort 2 & Cohort 3 & Cohort 4 & $\begin{array}{c}\text { Total } \\
\text { Enrolled }\end{array}$ \\
\hline \multicolumn{7}{|l|}{ Atlanta } \\
\hline GSU & 12/12/05 & 3 & 64 & 116 & 205 & 388 \\
\hline LAA & $12 / 12 / 05$ & 0 & 19 & 37 & 17 & 73 \\
\hline Baltimore & 12/13/05 & 21 & 103 & 113 & 147 & 384 \\
\hline Baton Rouge & 11/30/05 & 7 & 79 & 87 & 135 & 308 \\
\hline \multicolumn{7}{|l|}{ Florida } \\
\hline Broward County & 12/1/05 & 20 & 40 & 45 & 130 & 235 \\
\hline Orange County & 6/30/05 & 64 & 69 & 61 & 126 & 319 \\
\hline \multicolumn{7}{|l|}{ Indiana } \\
\hline Allen County & $1 / 6 / 06$ & 4 & 14 & 17 & 24 & 59 \\
\hline Lake County & $1 / 6 / 06$ & 1 & 8 & 14 & 22 & 45 \\
\hline Marion County & $1 / 6 / 06$ & 2 & 37 & 28 & 72 & 139 \\
\hline Oklahoma & 6/8/06 & $\mathrm{N} / \mathrm{A}$ & N/A & 86 & 208 & 294 \\
\hline \multicolumn{7}{|l|}{ Texas } \\
\hline Houston & 7/15/05 & 60 & 49 & 29 & 82 & 220 \\
\hline San Angelo & 7/15/05 & 50 & 42 & 52 & 75 & 219 \\
\hline All Sites & --- & 232 & 525 & 685 & 1,242 & 2,684 \\
\hline
\end{tabular}

Notes: Sample includes all couples randomly assigned to either the program or control group. Sample was divided into cohorts to examine enrollment over time, and for later analyses, to permit an equal chance for participation over a specified observation period.

Cohort 1: June 1, 2005 to January 31, 2006 (8 months of enrollment)

Cohort 2: February 1, 2006 to May 31, 2006 (4 months of enrollment)

Cohort 3: June 1, 2006 to September 30, 2006 (4 months of enrollment)

Cohort 4: October 1, 2006 to March 31, 2007 (6 months of enrollment)

Although simply accumulating experience might contribute to enrollment success, close attention to recruitment methods is clearly important. It would be reasonable to expect that enrollment would increase as sites gain experience. This did occur to some extent in some sites (Table III.5). However, long experience did not necessarily lead to pre-eminence in recruitment; sites that started earliest have been outstripped by later start-up sites like Atlanta GSU. Breakthroughs in recruitment method seem more instrumental in achieving high enrollment than simply the accumulation of experience. Atlanta's large increase in enrollment may be due to the site's shift from relying on referrals from neighborhood health clinics to its more recent practice of stationing BSF staff at a major hospital's prenatal clinic. Improvements in Oklahoma's multiple recruitment methods may likewise be behind its substantial increase from Cohort 3 to Cohort 4 . In both cases, attention to analyzing 
recruitment success and challenges, and making substantial changes in recruitment strategy, have likely played a key role in expanding enrollment.

Table III.5. Average Monthly Enrollment at BSF Sites, by Cohort

\begin{tabular}{|c|c|c|c|c|c|}
\hline & $\begin{array}{c}\text { Date } \\
\text { Evaluation } \\
\text { Enrollment } \\
\text { Began }\end{array}$ & Cohort 1 & Cohort 2 & Cohort 3 & Cohort 4 \\
\hline \multicolumn{6}{|l|}{ Atlanta } \\
\hline GSU & $12 / 12 / 05$ & --- & 21 & 38 & 34 \\
\hline LAA & $12 / 12 / 05$ & --- & 5 & 9 & 3 \\
\hline Baltimore & $12 / 13 / 05$ & --- & 26 & 28 & 25 \\
\hline Baton Rouge & $11 / 30 / 05$ & --- & 20 & 22 & 23 \\
\hline \multicolumn{6}{|l|}{ Florida } \\
\hline Broward County & 12/1/05 & --- & 10 & 11 & 22 \\
\hline Orange County & $6 / 30 / 05$ & 8 & 17 & 15 & 21 \\
\hline \multicolumn{6}{|l|}{ Indiana } \\
\hline Allen County & $1 / 6 / 06$ & --- & 4 & 4 & 4 \\
\hline Lake County & $1 / 6 / 06$ & --- & 2 & 4 & 4 \\
\hline Marion County & $1 / 6 / 06$ & --- & 9 & 7 & 12 \\
\hline Oklahoma & $6 / 8 / 06$ & --- & --- & 22 & 35 \\
\hline \multicolumn{6}{|l|}{ Texas } \\
\hline Houston & 7/15/05 & 8 & 12 & 7 & 14 \\
\hline San Angelo & $7 / 15 / 05$ & 6 & 11 & 13 & 13 \\
\hline All Sites & --- & 22 & 137 & 180 & 210 \\
\hline
\end{tabular}

Notes: Sample includes all couples randomly assigned to either the program or control group. Sample was divided into cohorts to examine enrollment over time, and for later analyses, to permit an equal chance for participation over a specified observation period.

Cohort 1: June 1, 2005 to January 31, 2006 (8 months of enrollment)

Cohort 2: February 1, 2006 to May 31, 2006 (4 months of enrollment)

Cohort 3: June 1, 2006 to September 30, 2006 (4 months of enrollment)

Cohort 4: October 1, 2006 to March 31, 2007 (6 months of enrollment)

\section{CharaCteristics OF ENROlleES}

Since BSF was a new kind of program, little was known about the couples it would attract. Although couples must meet eligibility criteria relating to their marital and relationship status and age of their child, it was unclear beyond that who would be interested in the program. Would BSF appeal to a racially and ethnically diverse population? How economically advantaged or disadvantaged would these couples be? What would the quality of their couple relationships be and how would they view marriage? What kinds of personal challenges and resources would BSF couples enter the study with? 
These questions can be addressed with data from the Baseline Information Form (BIF) completed at intake by both mothers and fathers separately after consenting to be in the BSF study. This baseline information, collected prior to any exposure to the program, covers demographic characteristics, economic well-being, personal attitudes, and each partner's description of their relationship for the 2,684 couples (5,368 individual parents) enrolled from the start of the evaluation through March 31, 2007. In the data presented below, the sample is first divided by gender, highlighting similarities and differences between men and women, averaged across all BSF sites. Averages, of course, often obscure interesting variations, so we next focus on how the sample differs across sites. Finally, we examine characteristics at the couple, rather than individual level, since couples are the focus of the study.

\section{Characteristics of Enrolled Individuals}

BSF has attracted a culturally diverse group of mostly young, low-income couples (Table III.6). Although many have multiple children by the same or a former partner, the BSF focal child is their first for about half of the sample. Generally, these are not "new" couples. Most have known their BSF partner for some time and live together. Although most couples are economically disadvantaged, many work and have a high school education and social support. The majority hope to marry, and view marriage as better for children, but also see single parenthood as a viable alternative.

Individuals who enroll in BSF represent the diverse populations served by the site organizations, are young, and often have children from prior relationships. BSF was intended to attract unmarried couples over 18 and to include the diverse populations served by the sponsoring organizations and recruitment sources. The overall evaluation sample reflects this intent.

1. The majority of BSF couples are African American. Reflecting the communities served by BSF sites, approximately 57 percent of women, and 60 percent of men were African American, roughly a quarter were Hispanic, and 13 to 16 percent were non-Hispanic white.

2. Participants are typically in their mid-twenties. More than two-thirds of women enrolled were between the ages of 20 and 29. However, an additional one-quarter of women were between 18-20 years old. Women were generally younger than men, on average, by about three years.

3. The individuals enrolled in BSF have an average of two children. One of these children was the child with whom the couple was entering BSF; the other was either another child they had in common, or a child from a previous relationship.

4. Multiple partner fertility is common. Nearly a third of mothers reported having one or more children from prior relationships; 29 percent of fathers reported one or more children by other partners. 
Table III.6. Baseline Characteristics of BSF Evaluation Sample, by Gender

\begin{tabular}{|c|c|c|c|}
\hline & Mothers & Fathers & Overall \\
\hline \multicolumn{4}{|l|}{ Demographics } \\
\hline $\begin{array}{l}\text { Age (Percentage) } \\
\text { Younger than } 20 \\
20-24 \\
25-29 \\
30-34 \\
35-39 \\
40 \text { and older }\end{array}$ & $\begin{array}{r}25 \\
47 \\
18 \\
7 \\
2 \\
1\end{array}$ & $\begin{array}{r}12 \\
42 \\
27 \\
10 \\
5 \\
3\end{array}$ & $\begin{array}{r}19 \\
45 \\
22 \\
9 \\
4 \\
2\end{array}$ \\
\hline $\begin{array}{l}\text { Race and Ethnicity (percentage) } \\
\text { African American } \\
\text { Hispanic } \\
\text { White } \\
\text { Other }\end{array}$ & $\begin{array}{r}57 \\
23 \\
16 \\
4\end{array}$ & $\begin{array}{r}60 \\
23 \\
13 \\
4\end{array}$ & $\begin{array}{r}58 \\
23 \\
14 \\
4\end{array}$ \\
\hline $\begin{array}{l}\text { Primary Language (percentage) } \\
\text { English } \\
\text { Spanish } \\
\text { Other }\end{array}$ & $\begin{array}{r}87 \\
12 \\
1\end{array}$ & $\begin{array}{r}86 \\
13 \\
1\end{array}$ & $\begin{array}{r}87 \\
12 \\
1\end{array}$ \\
\hline $\begin{array}{l}\text { Socioeconomic Status (percentage) } \\
\text { High school diploma or GED } \\
\text { Currently employed } \\
\text { Earnings past } 12 \text { months } \\
\text { No earnings } \\
\$ 1-\$ 15,000 \\
\$ 15,000-\$ 24,999 \\
\$ 25,000-\$ 34,999 \\
\$ 35,000 \text { or more }\end{array}$ & $\begin{array}{r}67 \\
29 \\
23 \\
62 \\
11 \\
2 \\
1\end{array}$ & $\begin{array}{r}7 \\
53 \\
26 \\
9 \\
5\end{array}$ & $\begin{array}{r}15 \\
58 \\
18 \\
6 \\
3\end{array}$ \\
\hline $\begin{array}{l}\text { Receives Any Public Assistance (percentage) } \\
\text { Cash welfare/TANF } \\
\text { Food stamps } \\
\text { Medicaid/SCHIP } \\
\text { SSI or SSDI } \\
\text { WIC } \\
\text { Unemployment compensation }\end{array}$ & $\begin{array}{r}81 \\
10 \\
40 \\
69 \\
6 \\
65 \\
4\end{array}$ & $\begin{array}{r}44 \\
3 \\
17 \\
31 \\
3 \\
33 \\
3\end{array}$ & $\begin{array}{r}62 \\
6 \\
28 \\
50 \\
5 \\
49 \\
3\end{array}$ \\
\hline \multicolumn{4}{|l|}{ Family Structure } \\
\hline $\begin{array}{l}\text { Marriage and cohabitation (percentage) } \\
\text { Married to current partner } \\
\text { Unmarried, cohabiting all or most of the time } \\
\text { Unmarried, cohabiting some of the time } \\
\text { Unmarried, not cohabiting }\end{array}$ & $\begin{array}{r}6 \\
72 \\
11 \\
11\end{array}$ & $\begin{array}{r}6 \\
73 \\
11 \\
10\end{array}$ & $\begin{array}{r}6 \\
72 \\
11 \\
10\end{array}$ \\
\hline Multiple Partner Fertility (percentage) & 31 & 29 & 30 \\
\hline
\end{tabular}


Table III.6 (continued)

\begin{tabular}{|c|c|c|c|}
\hline & Mothers & Fathers & Overall \\
\hline Number of Children (Total) ${ }^{a}$ & 1.9 & 1.9 & 1.9 \\
\hline Number of children in common & 1.4 & 1.4 & 1.4 \\
\hline Number of children with other partners & 0.5 & 0.6 & 0.5 \\
\hline \multicolumn{4}{|l|}{ Pregnancy and Birth } \\
\hline Mother Is Pregnant (percentage) & 55 & 55 & 55 \\
\hline Focal Child's Age, Months (If Born) & 1.1 & 1.1 & 1.1 \\
\hline Birth Intended (percentage) & 31 & 42 & 36 \\
\hline \multicolumn{4}{|l|}{ Couple Relationship } \\
\hline Time Known One Another (years) & 3.4 & 3.4 & 3.4 \\
\hline Relationship Quality (scale score) ${ }^{b}$ & 25.2 & 25.9 & 25.6 \\
\hline High Chance of Marriage (percentage) & 65 & 70 & 67 \\
\hline \multicolumn{4}{|l|}{$\begin{array}{l}\text { Attitudes about Marriage and Children (scale } \\
\text { score) }\end{array}$} \\
\hline $\begin{array}{l}\text { Believes a Single Parent Can Bring Up a Child } \\
\text { as Well as a Married Couple } \\
\text { Believes it is Better For Children if Their Parents }\end{array}$ & 2.0 & 2.3 & 2.1 \\
\hline Are Married & 1.9 & 1.8 & 1.9 \\
\hline \multicolumn{4}{|l|}{$\begin{array}{l}\text { Mental Health, Social Support, and Religious } \\
\text { Attendance }\end{array}$} \\
\hline $\begin{array}{l}\text { Level of Mental Distress (scale score) } \\
\text { Hiah risk of serious mental illness }\end{array}$ & 6.1 & 5.4 & 5.8 \\
\hline (percentage) & 8 & 6 & 7 \\
\hline \multicolumn{4}{|l|}{ Social Support (percentage) } \\
\hline Emergency child care available & 94 & 94 & 94 \\
\hline Could borrow $\$ 100$ from someone & 89 & 90 & 89 \\
\hline $\begin{array}{l}\text { Frequency of Religious Attendance (scale } \\
\text { score) }\end{array}$ & 2.4 & 2.2 & 2.3 \\
\hline Number of Observations & 2,684 & 2,684 & 5,368 \\
\hline
\end{tabular}

Source: $\quad$ BSF Baseline Information Form, couples randomly assigned by March 31, 2007.

ancludes unborn children.

${ }^{\mathrm{b}}$ Ranges from 8 to 32, with higher numbers indicating better reported relationship quality.

${ }^{c} 1$ = strongly agree, 2 = agree, 3 = disagree, 4 = strongly disagree.

${ }^{d}$ Measured by a standardized scale developed by Kessler et al. 2003, who indicate the optimal cut-point for detecting serious mental illness is a score of 13 or higher.

$\mathrm{e}_{1}=$ never, 2 = few times a year, 3 = few times a month, $4=$ once a week or more. 
Most enrollees have a high school education, but individual earnings are often low. Although income was not an eligibility criterion for BSF, programs were selected for the evaluation in part because they were capable of reaching low-income couples. The BIF data indicates this strategy was effective in reaching the intended groups.

1. Most men and women have at least a high school degree. Slightly more than 66 percent of both men and women had a high school diploma or GED. This suggests that the recruited couples thus far are not the most disadvantaged in terms of education.

2. More than three-quarters of women and 93 percent of men report some earnings in the year prior to enrollment-but earnings are low for most. Over half of men and nearly two-thirds of women reported earning less than $\$ 15,000$.

3. At enrollment, more than three-quarters of men are working, but only 29 percent of women are employed. The low rate of women's employment at enrollment is probably due in large part to the eligibility requirement that women be pregnant or within three months of having delivered a child.

4. More than 80 percent of women in the sample receive some sort of public assistance for themselves or their children, but few are receiving TANF benefits. Most of the women in the sample received Medicaid or participated in SCHIP and/or WIC, a food and nutrition service for low income families. Many participated in the Food Stamp Program. Averaged across sites, only 6 percent of mothers and fathers reported receiving TANF, ranging from a high of 17 percent in Baltimore to one percent in Houston. Public assistance was common among men (44 percent), who were most likely to report receiving Medicaid/SCHIP or WIC. However, it is likely that at least some fathers were reporting the same public assistance as the mothers because the question was about receipt of assistance "for themselves or on behalf of their children."

Most couples are cohabiting at intake and have high hopes for marrying their partner. To be eligible for BSF, both parents had to independently indicate that they were romantically involved "on a steady basis" or in an "on again, off again" relationship-but expecting to still be together in a year. There were no eligibility requirements in terms of cohabitation status or marriage expectations. Nonetheless, the data indicate the couples had some history together and were likely to be cohabiting and expecting to marry.

1. Most of the couples are unmarried cohabiters. More than 70 percent of men and women reported living with their partner all or most of the time, and another 11 percent reported cohabiting some of the time. Approximately 6 
percent had married their partner after conceiving their child, but before being enrolled in the BSF sample. ${ }^{17}$

2. The average couple has known each other for several years and believes their chances of marriage are high. Both men and women reported they had known each other for approximately 3.5 years. Sixty-five percent of women and 70 percent of men reported that there was a pretty good or almost certain chance they would marry their BSF partner.

3. The quality of couple relationships appears to be fairly good. On an 8item scale of relationship quality, with a highest possible score of 32 , mothers scored an average of 25 and fathers 26 . The measure asked parents their level of agreement with statements such as "your partner shows love and affection toward you," "your partner will not cheat on you," and "you are satisfied with the way you and your partner handle problems and disagreements."

4. Men were more likely than women to report the birth of their child was intended. Only a minority of individuals indicated that conception of the child who made them eligible for BSF was intended. Men (42 percent) were more likely than women (31 percent) to say the conception was intentional. Onequarter of parents reported having another biological child with their BSF partner.

5. Respondents believe marriage is ideal for children, but see single parenthood as adequate. Most men and women agreed that it is better for children if their parents are married. However, they were also likely to think that a single parent can bring up a child as well as a married couple. Parents may be indicating a preference for raising children in a married family, but still view single parenthood as acceptable for children. Thus they may view marriage as the ideal, but other family arrangements as adequate for children.

Social support is high, attendance at religious services modest, and the prevalence of serious mental illness low. To provide information on other aspects of the respondents' lives, the BIF also collected information on attitudes, mental health measures, social support, and religious attendance.

1. The vast majority of respondents indicate social support is available to them. More than 90 percent of men and women indicated that they could find someone to provide emergency child care or borrow $\$ 100$.

${ }^{17}$ Eligibility criteria specified that couples could be married if they had married after conception of the BSF child. 
2. The average BSF parent attends religious services a few times a year. The average frequency of attendance at religious services during the prior 12 months was reported to be a few times among both men and women.

3. The prevalence of serious mental illness is fairly low. Fewer than nine percent of women and seven percent of men scored above the clinical cutoff on a measure of distress indicating the likelihood of serious mental illness.

\section{Individual-Level Baseline Characteristics Within and Across Sites}

The 12 BSF locations are diverse in their program practices and context, but also in the populations they serve, despite some striking similarities. In all locations, most couples report similar relationship quality and beliefs about marriage and parenting, but racial/ethnic composition, expectations for marriage, rates of post-conception marriage, and religiosity show interesting variation (Table III.7).

Many locations serve primarily couples of a single race or ethnicity. In 6 of the 12 locations, at least three-quarters of BSF participants were of a single race or ethnicity. More than 90 percent of BSF participants in the Atlanta GSU and Baltimore locations, and over three-quarters in Baton Rouge, for example, were African American. In contrast, more than 90 percent of participants in Atlanta LAA and Houston, and 73 percent in San Angelo were Hispanic. Other sites were more evenly split, but tended to serve no more than two racial or ethnic groups. The sites with the highest proportions of white couples were Oklahoma and Indiana.

Although all sites serve a disadvantaged population, there is some variation in level of disadvantage. In terms of indicators of socioeconomic status, such as education, employment, and earnings, some sites tend to have participants with lower levels of disadvantage, although the pattern is not always consistent across indicators. Houston and Atlanta LAA have the lowest rates of high school graduation or GED attainment. These locations, along with San Angelo, also have the largest percentage of enrollees with no earnings in the year prior to enrollment, relative to other sites. Nevertheless, the percentages currently employed in these locations are comparable to that of other sites.

Receipt of public assistance varies across sites overall and by type of assistance. Receipt of public assistance of all types ranged from 86 percent in San Angelo, Texas, to 35 percent in Allen County, Indiana. Medicaid/SCHIP receipt was also highest in San Angelo and low in some Indiana locations and Houston. Although the receipt of TANF averaged across all sites was only 6 percent, it varied from a high of 17 percent in Baltimore and 12 percent in some Indiana locations to a low of just 1 percent in Houston and 3 percent in Atlanta LAA, Baton Rouge, and Orange County, Florida. 
Table III.7. Individual-Level Baseline Characteristics of Mothers and Fathers, by Site

\begin{tabular}{|c|c|c|c|c|c|c|c|c|c|c|c|c|}
\hline & \multicolumn{2}{|c|}{ Atlanta } & \multirow[b]{2}{*}{ Baltimore } & \multirow[b]{2}{*}{$\begin{array}{l}\text { Baton } \\
\text { Rouge }\end{array}$} & \multicolumn{2}{|c|}{ Florida } & \multicolumn{3}{|c|}{ Indiana } & \multirow[b]{2}{*}{ Oklahoma } & \multicolumn{2}{|c|}{ Texas } \\
\hline & GSU & LAA & & & $\begin{array}{l}\text { Broward } \\
\text { County }\end{array}$ & $\begin{array}{l}\text { Orange } \\
\text { County }\end{array}$ & $\begin{array}{l}\text { Allen } \\
\text { County }\end{array}$ & $\begin{array}{l}\text { Lake } \\
\text { County }\end{array}$ & $\begin{array}{l}\text { Marion } \\
\text { County }\end{array}$ & & Houston & $\begin{array}{c}\text { San } \\
\text { Angelo }\end{array}$ \\
\hline \multicolumn{13}{|l|}{ Demographics } \\
\hline Age & 25 & 27 & 25 & 24 & 24 & 24 & 24 & 25 & 25 & 25 & 27 & 24 \\
\hline \multicolumn{13}{|l|}{ Race and Ethnicity (Percentage) } \\
\hline African American & 93 & 2 & 95 & 76 & 72 & 60 & 29 & 56 & 61 & 31 & 8 & 4 \\
\hline Hispanic & 4 & 97 & 2 & 3 & 18 & 24 & 7 & 11 & 4 & 10 & 90 & 73 \\
\hline White & 1 & 1 & 2 & 17 & 9 & 13 & 53 & 35 & 28 & 41 & 1 & 21 \\
\hline Other & 1 & 1 & 1 & 4 & 1 & 4 & 11 & 0 & 7 & 18 & 2 & 1 \\
\hline \multicolumn{13}{|l|}{ Primary Language (Percentage) } \\
\hline English & 98 & 4 & 100 & 99 & 90 & 92 & 100 & 100 & 98 & 88 & 19 & 94 \\
\hline Spanish & 1 & 95 & 0 & 1 & 5 & 5 & 0 & 0 & 1 & 12 & 80 & 6 \\
\hline Other & 0 & 1 & 0 & 0 & 5 & 3 & 0 & 0 & 0 & 0 & 1 & 1 \\
\hline \multicolumn{13}{|l|}{ Socioeconomic Status } \\
\hline $\begin{array}{l}\text { High School Diploma or GED } \\
\text { (Percentage) }\end{array}$ & 68 & 48 & 60 & 67 & 69 & 71 & 83 & 75 & 70 & 70 & 58 & 64 \\
\hline Currently Employed (Percentage) & 52 & 53 & 47 & 59 & 50 & 51 & 53 & 42 & 56 & 54 & 51 & 53 \\
\hline \multicolumn{13}{|l|}{ Earnings Past 12 Months (Percentage) } \\
\hline No earnings & 15 & 25 & 17 & 7 & 9 & 11 & 7 & 14 & 11 & 13 & 25 & 35 \\
\hline$\$ 1$ to $\$ 15,000$ & 62 & 54 & 55 & 70 & 55 & 59 & 70 & 66 & 54 & 59 & 45 & 47 \\
\hline$\$ 15,000$ to $\$ 24,999$ & 15 & 16 & 16 & 14 & 29 & 20 & 17 & 12 & 20 & 18 & 27 & 13 \\
\hline$\$ 25,000$ to $\$ 34,999$ & 5 & 2 & 7 & 5 & 5 & 8 & 4 & 6 & 10 & 8 & 3 & 2 \\
\hline$\$ 35,000$ or more & 4 & 3 & 5 & 5 & 2 & 3 & 3 & 2 & 5 & 2 & 1 & 3 \\
\hline Receive Public Assistance (Percentage) & 73 & 72 & 61 & 59 & 63 & 68 & 35 & 39 & 40 & 51 & 60 & 86 \\
\hline Cash welfare/TANF & 4 & 3 & 17 & 3 & 5 & 3 & 8 & 12 & 12 & 6 & 1 & 3 \\
\hline Food stamps & 34 & 13 & 32 & 27 & 23 & 22 & 19 & 22 & 23 & 31 & 14 & 52 \\
\hline Medicaid/SCHIP & 61 & 43 & 44 & 50 & 55 & 54 & 33 & 29 & 34 & 41 & 32 & 80 \\
\hline SSI or SSDI & 4 & 1 & 5 & 6 & 4 & 5 & 9 & 8 & 9 & 5 & 2 & 3 \\
\hline WIC & 59 & 65 & 48 & 29 & 49 & 54 & 31 & 34 & 36 & 42 & $5 \overline{1}$ & 77 \\
\hline Unemployment Compensation & 4 & 1 & 3 & 4 & 2 & 2 & 11 & 11 & 11 & 3 & 2 & 2 \\
\hline
\end{tabular}




\begin{tabular}{|c|c|c|c|c|c|c|c|c|c|c|c|c|}
\hline & \multicolumn{2}{|c|}{ Atlanta } & \multirow[b]{2}{*}{ Baltimore } & \multirow[b]{2}{*}{$\begin{array}{l}\text { Baton } \\
\text { Rouge }\end{array}$} & \multicolumn{2}{|c|}{ Florida } & \multicolumn{3}{|c|}{ Indiana } & \multirow[b]{2}{*}{ Oklahoma } & \multicolumn{2}{|c|}{ Texas } \\
\hline & GSU & LAA & & & $\begin{array}{l}\text { Broward } \\
\text { County }\end{array}$ & $\begin{array}{l}\text { Orange } \\
\text { County }\end{array}$ & $\begin{array}{l}\text { Allen } \\
\text { County }\end{array}$ & $\begin{array}{l}\text { Lake } \\
\text { County }\end{array}$ & $\begin{array}{l}\text { Marion } \\
\text { County }\end{array}$ & & Houston & $\begin{array}{l}\text { San } \\
\text { Angelo }\end{array}$ \\
\hline \multicolumn{13}{|l|}{ Family Structure } \\
\hline Marriage and Cohabitation (Percentage) & & & & & & & & & & & & \\
\hline $\begin{array}{l}\text { Married to current partner }{ }^{\mathrm{a}} \\
\text { Unmarried, cohabiting all or most of }\end{array}$ & 5 & 13 & 3 & 6 & 5 & 5 & 12 & 9 & 8 & 7 & 11 & 8 \\
\hline $\begin{array}{l}\text { the time } \\
\text { Unmarried, cohabiting some of the }\end{array}$ & 67 & 84 & 67 & 65 & 66 & 75 & 76 & 72 & 75 & 79 & 83 & 81 \\
\hline time & 14 & 1 & 13 & 15 & 21 & 9 & 10 & 10 & 7 & 8 & 4 & 7 \\
\hline Unmarried, not cohabiting & 14 & 2 & 18 & 14 & 9 & 12 & 3 & 9 & 10 & 6 & 2 & 4 \\
\hline Multiple Partner Fertility (Percentage) & 36 & 27 & 40 & 29 & 27 & 22 & 28 & 30 & 31 & 27 & 26 & 32 \\
\hline Number of Children (Total) & 2.0 & 2.3 & 2.1 & 1.7 & 1.9 & 1.8 & 1.7 & 1.8 & 1.8 & 1.8 & 2.0 & 2.0 \\
\hline Number of children in common & 1.3 & 1.8 & 1.3 & 1.2 & 1.4 & 1.4 & 1.3 & 1.3 & 1.3 & 1.3 & 1.6 & 1.4 \\
\hline Number of children with other partners & 0.7 & 0.5 & 0.7 & 0.5 & 0.5 & 0.4 & 0.5 & 0.5 & 0.6 & 0.5 & 0.4 & 0.5 \\
\hline \multicolumn{13}{|l|}{ Pregnancy and Birth } \\
\hline Mother Is Pregnant (Percentage) & 86 & 73 & 72 & 91 & 2 & 0 & 22 & 64 & 35 & 86 & 64 & 17 \\
\hline Focal Child's Age, Months (if Born) & 1.6 & 1.1 & 2.2 & 2.1 & $0 . \overline{6}$ & 0.5 & 1.0 & 1.5 & 2.0 & 1.9 & 1.7 & 0.8 \\
\hline Birth Intended (Percentage) & 30 & 59 & 42 & 33 & 38 & 37 & 23 & 32 & 29 & 31 & 54 & 33 \\
\hline \multicolumn{13}{|l|}{ Couple Relationship } \\
\hline Time Known One Another (Years) & 3.3 & 4.3 & 3.7 & 3.3 & 3.6 & 3.4 & 1.8 & 2.0 & 2.6 & 3.2 & 3.7 & 3.5 \\
\hline Relationship Quality $^{\mathrm{b}}$ & 24.7 & 25.7 & 24.5 & 25.6 & 24.7 & 26.5 & 27.2 & 25.3 & 25.3 & 26.0 & 26.2 & 26.8 \\
\hline High Chance of Marriage ${ }^{c}$ (Percentage) & 63 & 65 & 53 & 82 & 49 & 62 & 79 & 73 & 79 & 73 & 69 & 80 \\
\hline \multicolumn{13}{|l|}{ Attitudes about Marriage and Children ${ }^{d}$} \\
\hline Believes a Single Parent Can Bring Up & & & & & & & & & & & & \\
\hline $\begin{array}{l}\text { a Child as Well as a Married Couple } \\
\text { Believes it is Better For Children if Their }\end{array}$ & 2.1 & 2.6 & 2.0 & 2.1 & 2.0 & 2.0 & 2.1 & 2.1 & 2.1 & 2.2 & 2.6 & 2.1 \\
\hline Parents Are Married & 1.8 & 1.6 & 1.9 & 1.7 & 2.0 & 2.0 & 2.0 & 2.0 & 2.0 & 1.8 & 1.5 & 1.9 \\
\hline
\end{tabular}




\begin{tabular}{|c|c|c|c|c|c|c|c|c|c|c|c|c|}
\hline & \multicolumn{2}{|c|}{ Atlanta } & \multirow[b]{2}{*}{ Baltimore } & \multirow[b]{2}{*}{$\begin{array}{l}\text { Baton } \\
\text { Rouge }\end{array}$} & \multicolumn{2}{|c|}{ Florida } & \multicolumn{3}{|c|}{ Indiana } & \multirow[b]{2}{*}{ Oklahoma } & \multicolumn{2}{|c|}{ Texas } \\
\hline & GSU & LAA & & & $\begin{array}{l}\text { Broward } \\
\text { County }\end{array}$ & $\begin{array}{l}\text { Orange } \\
\text { County }\end{array}$ & $\begin{array}{l}\text { Allen } \\
\text { County }\end{array}$ & $\begin{array}{l}\text { Lake } \\
\text { County }\end{array}$ & $\begin{array}{l}\text { Marion } \\
\text { County }\end{array}$ & & Houston & $\begin{array}{l}\text { San } \\
\text { Angelo }\end{array}$ \\
\hline \multicolumn{13}{|l|}{$\begin{array}{l}\text { Mental Health, Social Support, and } \\
\text { Religious Attendance }\end{array}$} \\
\hline $\begin{array}{l}\text { Level of Mental Distress } \\
\text { High risk of serious mental illness }\end{array}$ & 7 & 4 & 5 & 6 & 5 & 6 & 7 & 6 & 7 & 6 & 5 & 7 \\
\hline (percentage) & 10 & 7 & 5 & 7 & 4 & 7 & 12 & 13 & 9 & 8 & 5 & 9 \\
\hline Social Support (Percentage) & & & & & & & & & & & & \\
\hline Emergency child care available & 92 & 80 & 94 & 97 & 99 & 98 & 98 & 99 & 94 & 95 & 87 & 94 \\
\hline Could borrow $\$ 100$ from someone & 88 & 75 & 88 & 91 & 96 & 95 & 92 & 89 & 89 & 88 & 87 & 89 \\
\hline Frequency of Religious Attendance ${ }^{f}$ & 2.3 & 2.5 & 2.0 & 2.6 & 2.2 & 2.2 & 2.1 & 2.3 & 2.2 & 2.4 & 2.4 & 2.3 \\
\hline Number of Observations & 776 & 146 & 768 & 616 & 470 & 638 & 120 & 90 & 278 & 588 & 440 & 438 \\
\hline
\end{tabular}

Source: BSF Baseline Information Form, couples randomly assigned by March 31, 2007.

${ }^{a}$ In addition to unmarried couples, those who married post-conception were also eligible for BSF.

${ }^{\mathrm{b}}$ Ranges from 8 to 32 , with higher numbers indicating better reported relationship quality.

${ }^{c}$ Asked only of currently unmarried respondents.

$\mathrm{d}_{1}=$ strongly agree, 2 = agree, 3 = disagree, 4 = strongly disagree.

${ }^{\mathrm{e}}$ Kessler et al. 2003 indicate that the optimal cut-point for detecting serious mental illness is a score of 13 or higher.

$\mathrm{f}_{1}=$ never, 2 = few times a year, 3 = few times a month, 4 = once a week or more. 
There are substantial variations across sites in the family structure of their BSF samples. Across all sites, the majority of couples report being unmarried and living together all or most of the time. This ranges, however, from 65 percent in Baton Rouge to 83 percent in Houston. The number of unmarried couples who are not cohabiting is generally much smaller, but also varies, from only 2 percent in Houston and Atlanta LAA to 14 percent in Baton Rouge. The two sites with high proportions of first-generation Hispanic families-Houston and Atlanta LAA - have the highest proportions of couples who are either unmarried cohabitors or married after conception. Few couples in these sites (only 2 percent) were unmarried but not living together, compared to nearly 18 percent in Baltimore. Across the sample, a substantial proportion of respondents report multiple partner fertility, but this varies from a high of almost 40 percent in Baltimore to 22 percent in Orange County, Florida.

Respondents vary across sites in their reported likelihood of marriage, but this is not necessarily linked to relationship quality. In all sites, the majority of unmarried respondents report a high chance of marriage, ranging from nearly 50 percent in Broward County, Florida, to 82 percent in Baton Rouge. There is less cross-site difference in reported relationship quality, a measure that was asked of all respondents, married and unmarried.

Of all BSF participants, first generation Hispanic immigrants may be most likely to report the birth was intended. In only two locations, Atlanta LAA and Houston, do the majority of respondents report the birth was intended. These sites are also at least 90 percent Hispanic, the highest percentage of all locations, and the majority report Spanish as their primary language. In contrast, the couples served in San Angelo are more than 73 percent Hispanic, but only a third of respondents report the birth was intended. The vast majority of San Angelo enrollees report English as their primary language, and are thus less likely to be first generation immigrants.

\section{Couple-Level Characteristics}

When individuals come together as a couple, they each bring to the union resources and disadvantages - social, emotional, educational, and financial. For example, a partner may bring resources, such as education, but also challenges, such as children from other relationships. The net effect of these factors may determine whether individuals see themselves better off as a couple or as individuals. In accordance with the focus of BSF, we explore couple-level characteristics, particularly with regard to socioeconomic factors. Given the diversity of the BSF sample, we also explore whether couple-level characteristics differ by race and ethnicity. (Table III.8).

Eighty-three percent of couples have at least one partner with a high school education. At the individual level, approximately 66 percent have at least a high school education, and thus coupling increases the proportion who can consider education a resource. In only half of couples, however, do both partners have a high school degree. 
60

Almost half of BSF couples have experienced multiple partner fertility. Earlier analyses (Table III.6) showed that roughly a third of men and women report having children from previous relationships. In 46 percent of couples either the mother, father, or both have children from prior relationships.

Combining earnings in the year prior to enrollment would yield 61 percent with joint earnings of less than $\$ \mathbf{2 5 , 0 0 0}$. These combined earnings are near the federal poverty level for a family of four.

Hispanics tended to be most economically disadvantaged. Hispanic couples, for instance, are about half as likely as other couples to have both partners employed, and are less likely than others to be earning more than $\$ 25,000$ per year. In Hispanic couples, it is less likely that both partners have a high school degree-37 percent, compared to 51 to 56 percent in other sample groups. 
Table III.8. Couple-Level Characteristics, by Race/Ethnicity

\begin{tabular}{|c|c|c|c|c|c|}
\hline & Overall & $\begin{array}{l}\text { African } \\
\text { American }\end{array}$ & Hispanic & White & Other \\
\hline \multicolumn{6}{|l|}{ Demographics } \\
\hline $\begin{array}{l}\text { More Than } 10-Y e a r \text { Age Difference } \\
\text { (percentage) }\end{array}$ & 7 & 7 & 5 & 9 & 9 \\
\hline $\begin{array}{l}\text { Race and Ethnicity (percentage) } \\
\text { Both African American } \\
\text { Both Hispanic (any race) } \\
\text { Both white } \\
\text { Both other } \\
\text { Partners of different races/ethnicities }\end{array}$ & $\begin{array}{r}54 \\
19 \\
11 \\
2 \\
15\end{array}$ & $\begin{array}{r}100 \\
0 \\
0 \\
0 \\
0\end{array}$ & $\begin{array}{r}0 \\
100 \\
0 \\
0 \\
0\end{array}$ & $\begin{array}{r}0 \\
0 \\
100 \\
0 \\
0\end{array}$ & $\begin{array}{r}0 \\
0 \\
0 \\
10 \\
92\end{array}$ \\
\hline $\begin{array}{l}\text { Primary Language (percentage) } \\
\text { Both speak English } \\
\text { Only mother speaks English } \\
\text { Only father speaks English } \\
\text { Neither speak English }\end{array}$ & $\begin{array}{r}84 \\
3 \\
2 \\
11\end{array}$ & $\begin{array}{r}98 \\
1 \\
1 \\
0\end{array}$ & $\begin{array}{r}35 \\
7 \\
5 \\
52\end{array}$ & $\begin{array}{r}100 \\
0 \\
0 \\
0\end{array}$ & $\begin{array}{r}88 \\
5 \\
3 \\
5\end{array}$ \\
\hline \multicolumn{6}{|l|}{ Socioeconomic Status } \\
\hline $\begin{array}{l}\text { High School Diploma or GED (percentage) } \\
\text { Both completed } \\
\text { Only mother completed } \\
\text { Only father completed } \\
\text { Neither completed }\end{array}$ & $\begin{array}{l}50 \\
17 \\
16 \\
17\end{array}$ & $\begin{array}{l}51 \\
17 \\
16 \\
17\end{array}$ & $\begin{array}{l}37 \\
20 \\
18 \\
26\end{array}$ & $\begin{array}{l}56 \\
16 \\
16 \\
13\end{array}$ & $\begin{array}{l}54 \\
17 \\
16 \\
13\end{array}$ \\
\hline $\begin{array}{l}\text { Currently Employed (percentage) } \\
\text { Both employed } \\
\text { Only mother employed } \\
\text { Only father employed } \\
\text { Neither employed }\end{array}$ & $\begin{array}{r}22 \\
7 \\
53 \\
18\end{array}$ & $\begin{array}{l}24 \\
10 \\
44 \\
22\end{array}$ & $\begin{array}{r}13 \\
3 \\
76 \\
8\end{array}$ & $\begin{array}{r}26 \\
5 \\
53 \\
16\end{array}$ & $\begin{array}{r}25 \\
5 \\
53 \\
17\end{array}$ \\
\hline $\begin{array}{l}\text { Earnings (percentage) } \\
\quad \text { No earnings } \\
\quad \$ 1-\$ 15,000 \\
\$ 15,000-\$ 24,999 \\
\$ 25,000-\$ 34,999 \\
\$ 35,000-\text { more }\end{array}$ & $\begin{array}{r}3 \\
34 \\
27 \\
19 \\
17\end{array}$ & $\begin{array}{r}3 \\
36 \\
23 \\
19 \\
19\end{array}$ & $\begin{array}{r}3 \\
33 \\
37 \\
17 \\
10\end{array}$ & $\begin{array}{r}2 \\
28 \\
25 \\
24 \\
22\end{array}$ & $\begin{array}{r}1 \\
33 \\
31 \\
19 \\
17\end{array}$ \\
\hline \multicolumn{6}{|l|}{ Family Structure } \\
\hline $\begin{array}{l}\text { Multiple Partner Fertility (percentage) } \\
\text { Both partners have children from other } \\
\text { relationships } \\
\text { Only mother has child(ren) from other } \\
\text { relationships } \\
\text { Only father has child(ren) from other } \\
\text { relationships } \\
\text { Neither have children from other } \\
\text { relationships }\end{array}$ & $\begin{array}{l}15 \\
54 \\
\end{array}$ & $\begin{array}{r}16 \\
48 \\
\end{array}$ & 11 & 15 & 14 \\
\hline Number of Couples & 2,684 & 1,433 & 509 & 282 & 426 \\
\hline
\end{tabular}

Source: $\quad$ BSF Baseline Information Form, couples randomly assigned by March 31, 2007.

Notes: $\quad$ There are 21 couples who cannot be classified by race/ethnicity.

${ }^{a}$ The response options for earnings were in categories (e.g., none, $\$ 1-\$ 4,999 ; \quad \$ 5,000-\$ 9,999$; $\$ 10,000-\$ 14,999 ; \$ 15,000-\$ 19,999 ; \$ 20,000-\$ 24,999 ; \$ 25,000-\$ 34,999, \quad \$ 35,000$ or above). To obtain an estimate of joint per-couple earnings, the midpoint of the reported category for mothers and fathers was combined. This is not necessarily a measure of household income since not all couples live together, but represents a rough estimate of both parents' income that may be available to the family. 



\title{
C H A P T E R I V
}

\section{M P L E M E N T A T I O N OF THE B S F MARRIAGE AND RELATIONSHIP SKILLS PROGRAM C OMPONENT}

\begin{abstract}
he BSF program offers interested couples a package of services to support and strengthen their relationship. It consists of intensive, group-based marriage and relationship skills education, individual support by program staff, and linkage to family support services outside the BSF program. Although sites were expected to follow the conceptual model described in the BSF guidelines (discussed in Chapter I), they had considerable discretion to decide on operational details. This chapter focuses on how sites chose to implement the marriage and relationship skills component of BSF.
\end{abstract}

According to the BSF model, group sessions on marriage and relationship skills were to be the centerpiece of the intervention-the core element that sets it apart from most social services for low-income families. Couples-rather than individual parents-would attend group sessions together, and sites were encouraged to use research-based curricula that were intensive and sustained enough to help couples internalize key skills. The expectation was that by learning and practicing skills together, couples could apply the skills in their relationship, strengthen it, and be prepared to enter and sustain a healthy marriage, if they chose to marry.

Offering these group sessions was a new challenge for all sites, and it required a major service development and implementation effort. They had to identify and train qualified group facilitators, plan the overall format and time for sessions, coordinate logistics such as meeting space, and plan the steps they would take to facilitate attendance. Once groups began, sites found that they needed to actively encourage couples to participate in scheduled sessions. They employed a range of strategies to get couples started in a group and promote sustained involvement. This chapter focuses on how sites delivered group sessions, the obstacles they encountered and how they addressed them, and their approaches for accommodating couples' schedules and promoting attendance.

\section{A. Preparation for Group Sessions}

Substantial preparation was required before group sessions could begin. Some of this preparation occurred as sites began their pilot operations, but expansion to the scale required for the evaluation meant that they had to revisit issues and confront new ones. Across these 
two stages of implementation, sites had to build a team capable of operating multiple concurrent groups, ensure adequate supports, and determine what formats and schedules would be workable for couples and staff.

\section{KEy Findings on DELIVERING MARRIAGE AND RELATIONSHIP SKILLS}

- Sites hired new staff as group facilitators, aiming for male-female cofacilitator teams. Lead facilitators were usually required to have some combination of college and experience. Co-facilitators were often people from the community to whom couples could easily relate.

- Sites had to be flexible in assigning couples to groups in light of their limited and often changing availability. All sites offered group sessions during evenings, and many offered weekend sessions.

- Sites anticipated barriers to attendance, which they addressed through support services, including child care, transportation, and meals.

- To encourage initial group participation and avoid loss of interest, sites tried to engage couples in some form of BSF activity even before they started attending group sessions.

- To promote ongoing group participation, programs maintained frequent contact, offered ways to make up missed sessions, fostered social interactions with other couples, offered incentives, and held celebrations for graduates.

- Providing make-up sessions presented challenges for most sites. The frequency, regularity, and approach to make-ups varied across and within sites.

- Nearly all programs used incentives to encourage initial and ongoing group participation, but the purpose, value, and level of emphasis placed on them varied across sites.

\section{Building a Strong Team of Group Facilitators Required Considerable Effort}

BSF sites, first in starting their pilot and then for the evaluation, developed and refined their approach to staffing the group facilitator and co-facilitator positions. They identified a set of qualifications and likely candidates, hired and trained staff, and developed a system of supervision.

Sites recruited outside their organizations to hire group facilitators, and aimed to create male-female co-facilitator teams. Most sites hired new staff for the group facilitator position, often consciously seeking out male and female candidates so that co- 
facilitator teams of mixed gender could be created. Depending on their program's organizational structure, sites hired full-time or part-time staff or used contract staff (or some combination of these) to fill facilitator positions. Some sites designated a lead facilitator position, an individual with some combination of college education and past experience. The co-facilitator was often someone from the community, a family coordinator, or other individual with perhaps less education and experience but who had the ability to relate well to the couples being served. Once hired, all lead and co-facilitators participated in intensive curriculum training before starting to lead group sessions.

Qualified facilitators typically had at least a bachelor's degree and relevant previous experience. Sites defined facilitator qualifications in terms of a combination of education and previous professional and personal experience. Sites described themselves as highly selective in hiring, but the types of candidates sought and the emphasis placed on specific characteristics varied by site.

To fill lead facilitator positions, almost all sites sought individuals with at least a bachelor's degree in a clinical or related field, such as psychology, social work, counseling, or marriage and family therapy. A few sites, however, indicated that they did not view group facilitation as requiring such specialized training. One site had no specific educational requirement, instead emphasizing past experience in counseling or mentoring couples. Two sites preferred a degree in public health or education. At least six of the 12 locations specified that they preferred that group facilitators have a master's degree. Since lead facilitators were the BSF staff most likely to address highly sensitive issues with couples, they were often the most credentialed staff.

Most sites had specific preferences with regard to candidates' prior professional or personal experience, which often depended on the site's general philosophy or approach. Sites frequently expected group facilitators to have worked with low-income children and families or to have facilitated groups, though not necessarily with couples or with a focus on relationships. Some sites looked for personal experience with marriage or parenting. Several preferred to hire individuals who were married so that they could draw on their own experiences during group facilitation. One site preferred to hire group facilitator couples who were married to each other, so that during co-facilitation they could also function as role models. Another site preferred group facilitators with personal experience in parenting children.

Sites used multiple staffing arrangements to ensure coverage of the group curriculum component. In deciding what combination of full-time, part-time and contract staff to use, sites took into account the overall staff hours required, the relative costs of staff in different statuses, and the nonstandard work hours often required of facilitators (groups often met evenings or weekends). Sites also factored in the cost of employing highly trained individuals on a full-time basis, which was one reason some sites used part-time or contract staff.

Nevertheless, the most common arrangement was to employ full-time staff as facilitators, but to give them other responsibilities to make efficient use of their time. Most of the six locations (in Florida and Indiana) that used full-time staff gave them additional 
responsibilities, such as supervising home visitors working with BSF couples, assisting in recruitment of fathers or providing father-focused case management, or planning for new groups and monitoring ongoing attendance.

BSF locations in Baton Rouge, Baltimore, and Oklahoma tended to use part-time contract staff as group facilitators. This arrangement allowed programs to hire individuals with the preferred background, while controlling costs and ensuring that all groups were covered. Contract staff were generally expected only to facilitate groups, and were backed up by a full-time BSF staff member who provided logistical support. Often, these contracted group facilitators had full-time positions outside of BSF and led one or two groups at a time. Facilitators only committed to their current groups and, as those were completed, waited for an additional group to start at a time that they could fit in their schedule. Most sites employing contract facilitators developed procedures to ensure that facilitators and other BSF staff, such as family coordinators, communicated on a regular basis about concerns arising during group sessions. For example, facilitators at some sites entered information about specific couples in the "case notes" section of the site's MIS. Others communicated directly with their supervisors about the progress of couples in their groups.

The two Texas locations and Atlanta GSU used a combination of full- and part-time or contract staff for group facilitators. In Texas, this arrangement allowed the site to capitalize on qualified full-time individuals already on staff but to round out the necessary roster of facilitators with part-timers. Atlanta GSU employed both full-time and part-time facilitators. These staff, especially the full-time ones, also performed family coordinator functions, working with couples in their groups.

Sites generally did not experience great difficulty hiring facilitators with the desired qualifications. Although a few sites experienced some initial difficulties, all were able to identify and recruit facilitators with the desired qualifications. Sites found potential facilitators through formal postings and informal methods such as word of mouth or personal referrals. In general, sites relied on formal postings when hiring for full-time positions. Sites using part-time or contract staff more frequently used informal channels for identifying potential facilitators. For example, one site had previously offered a co-parenting group. The male-female facilitator team for that program became BSF group facilitators and provided recommendations for additional facilitators.

Group facilitators received intensive training and technical assistance from curriculum developers. Group facilitators, co-facilitators, and in some sites "coaches" were required to participate in formal training in the selected marriage and relationship skills curriculum before leading group sessions. (In two locations, sites included "coaches" in certain group sessions to provide assistance as individual couples practiced communication skills) This training was usually conducted by the curriculum developer, or an individual certified by the developer to teach the curriculum. Training was intensive, lasting 3-6 days, covered the substantive topics in the curriculum, provided instruction in methods for facilitating groups, and often included role-playing. 
Following initial training, each curriculum developer offered subsequent technical assistance or supervision, though the format, purpose, and intensity varied. The developers of Loving Couples, Loving Children offered the most intensive supervision. Facilitators were required to videotape the group sessions they led, which were then reviewed by the curriculum developer's staff. Facilitators were sent detailed written feedback on their videotaped sessions to help them refine their techniques. They also participated in regular conference calls over an extended period with the curriculum developer to discuss situations arising in group and how to handle them. Facilitators received feedback and assistance in this way until the curriculum developer determined they were proficient-a process that could last several months or more.

The Becoming Parents Program offered supervision through conference calls and occasional site visits. The purpose of this supervision was to exchange feedback on potential revisions to the curriculum and to ensure that the presented material and mode of delivery were appropriate for the low-income couples served in BSF. The facilitators shared their first-hand knowledge of the couples' needs with the developer, whose expertise lay more in addressing the needs of expecting and new parents than working specifically with lowincome unmarried couples. These communications led to a refinement of the curriculum as the program continued.

Supervision of the delivery of Love's Cradle sessions focused on certifying one "master facilitator" at each of the two BSF locations where it was used, who could later train other facilitators hired due to expansion or turnover. This meant that periodic conference calls to discuss facilitation were held with only the individual training to become a "master facilitator" rather than with all group facilitators at the site. During calls, the facilitator and developer discussed how the curriculum was working during group and successes and challenges experienced during facilitation. To attain proficiency, master facilitators had to demonstrate their proficiency in teaching the curriculum to other new facilitators, a process that could take six months or more. Given the fact that BSF administration of Love's Cradle was the first time it was ever used, the "master facilitators" also provided feedback to the curriculum developer on recommended revisions.

\section{Anticipating Barriers to Participation, Most Sites Worked Hard to Arrange Transportation, Child Care, and Meals}

In preparing to offer group sessions, BSF sites anticipated that couples would face barriers to ongoing participation and planned to address issues related to transportation and child care. Since group sessions often occurred in the evening, sites also realized that providing refreshments would be an important element. Although some sites encountered challenges in assisting couples with child care or transportation, most ultimately succeeded in finding satisfactory solutions.

Child care issues were important because participating couples were already new parents or might have a newborn while participating in the program. Moreover, some couples had older children who needed care while the parents attended group sessions. Most sites made arrangements for on-site child care by licensed providers. To make parents more 
comfortable, sites often gave couples the option of keeping very young infants with them during group sessions. However, older infants and children proved to be distracting, so sites set up child care arrangements in separate but adjacent spaces. Three locations could not offer on-site child care for logistical or cost reasons, but these sites reimbursed couples for child care they paid for themselves. Oklahoma's office space at first did not lend itself to a separate child care area; but after long negotiation the site acquired and outfitted additional space and hired an outside child care provider. Allen and Lake counties in Indiana found that on-site care was prohibitively expensive due to licensing and insurance/liability requirements.

Reliable transportation to group sessions was an issue for some BSF couples. The simplest solution was to provide transit tokens, but this was only feasible in communities with public transit systems that came near the group location on a convenient schedule. For couples who owned cars, sites often provided gas cards to offset costs. To help couples without cars, sites tried several strategies. A few sites had a van they could use to transport multiple couples simultaneously. The van rides offered an opportunity for social interaction among couples and picking couples up at home increased the chances they would attend. Sites without vans asked family coordinators to transport couples, which had the benefit of providing direct contact with the couple, although this was a time-consuming strategy if many couples required transportation. A third strategy was to use taxis. Some sites negotiated arrangements with companies to ensure that the company would bill the BSF site for the cost of the ride. These arrangements sometimes took a good deal of time to establish, and taxi service was sometimes unreliable, which made it difficult to begin and end sessions on time. Sites often found that addressing the transportation issue with a group of couples required using several of the strategies discussed above.

Meals associated with group sessions were essential for three reasons. First, they addressed a potential barrier to attendance at both evening and weekend groups. Couples scheduled for an early evening session often had no chance to eat dinner between work and group; the result might be that they would not attend, or came but had difficulty focusing on the session. Weekend sessions tended to be longer, so a meal during a break could help couples sustain their attention and interest. Second, having a meal together was also seen by site staff as a way to facilitate social cohesion, support, and friendship within the group. Couples often conversed with one another and shared stories and experiences during this time. Third, program staff indicate that they often used this time to make individual connections with the couples, assess where they are, and use this information to make the session specifically relevant. To provide meals, sites typically ordered food from nearby restaurants or brought prepared food from local grocery stores.

\section{The Need to Hold Group Sessions During Non-Standard Hours Sometimes Raised Staffing and Space Issues}

From the beginning, BSF sites planned to offer group sessions outside of standard business hours to accommodate couples' schedules. This meant that sites had to ensure that facilitators and space were available evenings and weekends. Multiple staffing arrangements helped make this possible. However, a few sites faced constraints as they tried to plan off- 
hours groups at their BSF office location. Houston and Broward County in Florida had to hold group sessions outside of their program office, due to lack of space on-site. It proved challenging for both sites to acquire suitable space at convenient locations and reasonable cost, with the desired level of privacy, comfort, kitchen facilities for meals, and space for child care. Baton Rouge experienced some space constraints at their host organization, and had to coordinate with the hosts of other activities occurring at the Family Road center in the evenings to work out mutually acceptable schedules.

\section{B. ENCOURAgING INITIAL ATTENDANCE AT Group SESSIONS}

Sites learned early that not all couples who enrolled and were assigned to the intervention group would attend group sessions. They also noticed, however, that couples who come at least once to a group session tend to participate multiple times, so actively encouraging couples to initiate attendance became an important priority. This section describes strategies BSF sites used to promote initial participation and sites' perceptions of their effectiveness.

\section{Encouraging Participation Began with Group Session Schedules}

Couples assigned to a group that meets at a time that is inconvenient for them are unlikely to attend. Thus, flexibility in scheduling was important.

Sites explored couples' availability before assigning them to groups. As they planned new group sessions, many sites solicited the availability and preferences of newly enrolled BSF couples before setting schedules for upcoming groups. Most sites informally gathered this information in conversations with the couple at enrollment. Some sites used a more formal questionnaire to identify not only preferred times, but also child care and transportation needs. Site that recruited large numbers of couples on steady basis were able to arrange a pre-set standing schedule.

Most couples preferred weekday evening or weekend sessions. Ultimately, sites decided to offer group sessions weekday evenings, weekend days, and sometimes weekday mid-days. The most common meeting time was weekday evenings. Two-thirds of the locations also offered weekend group sessions, since some couples were available at no other time. While attempted, weekday mid-day group sessions were infrequently used, and only Baltimore has succeeded in sustaining such a group, typically on Fridays. At the request of the couples, San Angelo also attempted to schedule weekday mid-day group sessions, but couples did not consistently attend.

Allowing transfers between groups added flexibility in scheduling but could be disruptive to group cohesion. Allowing couples to transfer between groups helped sites respond flexibly to couples' changing schedule constraints. Two of the three curriculum developers emphasized the importance of group stability and cohesion and cautioned that using this strategy could disrupt group cohesiveness. Although four sites indicated that they transferred couples occasionally, they recognized the potential for disruption and thus made 
decisions on a case-by-case basis depending on the couple's circumstances and the number of meetings already held of the group to which they might transfer.

Some sites offered couples a choice in the length and number of sessions. The curriculum adopted by each BSF site except one consists of 21 modules that take about two hours each to complete. Most of these sites offered the curriculum in two-hour segments during a weekday or weekend, for 21 weeks. Although this format worked well for most sites, a few locations began to offer other formats out of concern that the overall time required to complete the curriculum was contributing to low completion rates. The Florida locations began to offer the single-module, two-hour format during the week and a doublemodule, four-hour format on Saturdays, which allowed the curriculum to be completed in less elapsed time. Houston offered multiple formats to meet couples' needs, and in particular to help reduce the number of times couples had to undertake the long commute that many faced to attend a session. In addition to single-module, two-hour groups during the week, Houston offered double-module, biweekly, four-hour groups on the weekend, and three-module, six-hour groups on the weekend that met only monthly. It is unclear how successful these alternative formats have been in improving rates of completion, but the use of multiple formats does provide couples with greater choice and flexibility.

The curriculum used in Oklahoma was shorter, requiring 30 hours to complete. The curriculum includes more modules, but of shorter duration (20-45 minutes) than the curricula used in the other sites. Oklahoma combines the modules in different ways to offer two formats: a three-hour session that meets weekly for ten weeks; and a five-hour format provided during weekends for six consecutive weeks.

Scheduling groups at times convenient to all couples was not always possible because of constraints on sites and couples. Sites were constrained in the number of scheduling choices they could offer couples as a result of the pace at which new groups could be formed. Sites needed to identify enough couples available at the same time in order to create a group of a minimum acceptable size. ${ }^{18}$ This meant that when the enrollment pace was slow, the ability to start new groups was limited-reducing couples' schedule options. The ability to start new groups also depended on the availability of space and facilitators. Running multiple group sessions on the same night was not an option if a site had only one room available. As the curriculum took up to six months to complete, the ability of each facilitator to start new groups was also constrained.

Couples were also constrained. Many low-income parents worked at jobs with unpredictable schedules, often involving shift work, such as fast-food servers or seasonal construction. In addition, circumstances or interest could change between enrollment and the couple's first scheduled group session. Family members could become ill, parents could separate, or mothers could decide to go back to work after recovering from childbirth.

${ }^{18}$ In sites using Loving Couples, Loving Children and Love's Cradle, the minimum number of couples to start a group was generally about 5 to 8. In Oklahoma, groups were larger, with a minimum of about 12 couples. 
Changes in a mother or father's availability could interfere with attendance at the outset of the group, and later as well.

\section{Quick Engagement in BSF Program Activities and Early Interactions with Staff Encouraged Initial Group Attendance}

BSF programs encouraged attendance at the initial group session from their first interaction with couples until they attended a session. Sites employed specific practices leading up to and during the first group session to encourage attendance. Before the first session, sites tried to engage couples in other BSF activities to build interest in and commitment to BSF. As shown in Table IV.1, while the manner that sites engaged couples varied, all sites used at least one, if not several, strategies to get people started in BSF activities. These early activities were probably helpful, as couples often had to wait at least a few weeks for their group to start. To encourage attendance at group, sites invited couples to social activities or meetings with their family coordinator or group facilitator, initiated parenting-focused home visits, or scheduled group orientation sessions.

Table IV.1. Practices to Encourage Initial Group Attendance

\begin{tabular}{|c|c|c|c|c|c|}
\hline & $\begin{array}{c}\text { Social } \\
\text { Activities } \\
\text { with Other } \\
\text { BSF Couples }\end{array}$ & $\begin{array}{l}\text { Meetings } \\
\text { with BSF } \\
\text { Family } \\
\text { Coordinators }\end{array}$ & $\begin{array}{l}\text { Meetings } \\
\text { with Group } \\
\text { Facilitator }\end{array}$ & $\begin{array}{l}\text { Parenting- } \\
\text { Focused } \\
\text { Home Visits }\end{array}$ & $\begin{array}{l}\text { Group } \\
\text { Orientation } \\
\text { Session }\end{array}$ \\
\hline $\begin{array}{c}\text { Atlanta } \\
\text { GSU } \\
\text { LAA }\end{array}$ & $\checkmark$ & $\checkmark$ & $\begin{array}{l}\checkmark \\
\checkmark \\
\end{array}$ & & $\checkmark$ \\
\hline Baltimore & $\checkmark$ & $\checkmark$ & & & \\
\hline Baton Rouge & & $\checkmark$ & & & $\checkmark$ \\
\hline $\begin{array}{l}\text { Florida } \\
\text { Broward County } \\
\text { Orange County }\end{array}$ & & $\begin{array}{l}\checkmark \\
\checkmark \\
\end{array}$ & & $\begin{array}{l}\checkmark \\
\checkmark \\
\end{array}$ & \\
\hline $\begin{array}{l}\text { Indiana } \\
\text { Allen County } \\
\text { Lake County } \\
\text { Marion County } \\
\end{array}$ & $\begin{array}{l}\checkmark \\
\checkmark \\
\end{array}$ & & $\begin{array}{l}\checkmark \\
\checkmark\end{array}$ & $\begin{array}{l}\checkmark \\
\checkmark \\
\checkmark \\
\end{array}$ & \\
\hline Oklahoma & & $\checkmark$ & & & \\
\hline $\begin{array}{l}\text { Texas } \\
\text { Houston } \\
\text { San Angelo }\end{array}$ & & $\begin{array}{l}\checkmark \\
\checkmark\end{array}$ & & $\begin{array}{l}\checkmark \\
\checkmark\end{array}$ & $\checkmark$ \\
\hline
\end{tabular}

Social activities got couples acquainted with other current and past participants. A few BSF locations hosted social activities to which they invited all enrolled couples. Sites described these activities as a way for couples to meet other couples and hear first-hand about their program experiences. Sites planned activities that would be appealing to pregnant couples and new parents, such as education-focused activities on post-partum depression or activity-focused events like bowling or a movie. However, the frequency of 
such activities varied from monthly to several times a year, depending on the location, which meant that not all newly enrolled couples could participate as they waited to begin group sessions.

Family coordinators encouraged group attendance by meeting couples prior to the first session. The BSF program model includes family coordinator staff who meet with couples one-on-one to offer ongoing support and encouragement. Three-quarters of the BSF locations initiated these meetings soon after couples enrolled. A key function fulfilled by the family coordinator was to encourage the couple to attend group. By beginning to meet with couples quickly, family coordinators were positioned to build a supportive relationship with the couple and foster excitement about the group sessions. During early meetings, family coordinators answered questions about group, described what couples could expect and incentives they could receive by attending, and discussed potential barriers to participation and how the couple and BSF staff could address them. Some sites used these early meetings between the family coordinator and couple to conduct needs assessments and begin linking the couple to outside family support services.

In some sites, group facilitators met with couples before the first group session. A few sites arranged for group facilitators to meet individually with couples in their group. Often the facilitators at these sites played multiple BSF roles, which involved not only group facilitation but also providing couples with individual support in the role of family coordinator. These meetings occurred in the couple's home and gave the facilitator a chance to stimulate the couple's enthusiasm for starting group, discuss the curriculum and answer questions, and explain applicable incentives.

Staff at parenting-focused home visits sometimes encouraged couples to attend initial group sessions. Three sites offered the Healthy Families home-visiting program prior to implementing BSF, and two of these three sites fully incorporated BSF into the parenting-focused home visits. The visits began soon after program enrollment, which was usually before the couple began attending group sessions. In these sites, home visitors typically spent a few minutes discussing the group sessions and encouraging the couple to attend. In the third site, BSF and the parent-focused home visits were not as aligned, and direct encouragement to attend group may not have been provided. Nevertheless, the initial home visits served as a way to engage the couple in some services.

A few sites held group orientations. A few locations scheduled orientation sessions for couples before they started their group, to introduce them to the format without the formality of an actual session. Group facilitators led the orientation, but often other BSF program staff were in attendance. During this session facilitators led icebreakers and games to help couples get to know one another, and illustrated the format of a session, sometimes by conducting an abbreviated session. While sites commonly used such orientation sessions, they did not describe them as critical to encouraging initial group attendance. Many of the activities of orientation sessions were incorporated into initial group sessions at sites that did not schedule a separate orientation. The key distinguishing feature between a formal orientation session and the start of group was whether a full curriculum module was provided during the initial session. Instead of formal orientation sessions, some sites offered 
a module focused on one of the less weighty curriculum topics as a way to introduce couples to the group sessions without focusing immediately on sensitive topics.

\section{Promoting Ongoing Group AtTendance And Completion}

As more fully discussed in later chapters of this report, both initial and ongoing group attendance was a challenge for BSF sites. Although BSF attendance rates may be similar to those in other voluntary social services, ensuring that the program group receives a reasonable dosage of the intervention is particularly important in an evaluation intended to determine the intervention's effects. For this reason, BSF programs actively encourage ongoing attendance at group sessions. The sites use a variety of practices to sustain couples' involvement in group sessions. This section describes the practices sites use to promote sustained involvement with group sessions. It concludes with a detailed description of the ways sites provide incentives to couples to encourage both initial and ongoing attendance.

\section{Reminders, Follow-Up, and Encouragement of Group Cohesion Promoted Ongoing Attendance}

BSF sites promoted ongoing group attendance throughout the curriculum cycle. Participation patterns suggest that once engaged in group, couples are likely to continue attending. To encourage ongoing attendance, sites continued using a variety of strategies (Table IV.2). Many of these strategies, such as reminders about upcoming group sessions, follow-up on absences, and providing missed material, occurred outside of the group session with the intention of maintaining contact with couples and stressing the importance of attending.

\footnotetext{
All sites reminded couples to attend ongoing sessions, though frequency of reminders was sometimes tailored to a couple's attendance pattern. Site staff reminded couples about the time and location of their next meeting, and in these contacts inquired if the couple was planning to attend and any barriers that may prevent them from coming. The Atlanta, Baltimore, Baton Rouge, Indiana, and Oklahoma staff relied mostly on telephone reminders. Sites that regularly conducted home visits reminded the couple about upcoming group sessions during these visits. Sites were cautious about excessive reminders, and some therefore tailored the frequency of reminders based on a couple's attendance pattern. If a couple consistently attended group sessions, the site might not contact the couple with a reminder every week, instead focusing on reminders to couples who attended inconsistently.
} 
Table IV.2. Practices to Encourage Ongoing Group Attendance

\begin{tabular}{|c|c|c|c|c|c|c|c|}
\hline & $\begin{array}{c}\text { Staff } \\
\text { Reminders }\end{array}$ & $\begin{array}{l}\text { Ongoing } \\
\text { Social } \\
\text { Activities }\end{array}$ & $\begin{array}{l}\text { Meet with } \\
\text { Current/Past } \\
\text { Participants }\end{array}$ & $\begin{array}{l}\text { Telephone } \\
\text { Contact } \\
\text { After Group } \\
\text { Absence }\end{array}$ & $\begin{array}{c}\text { Home } \\
\text { Visit After } \\
\text { Group } \\
\text { Absence }\end{array}$ & $\begin{array}{l}\text { Couples } \\
\text { Get } \\
\text { Missed } \\
\text { Curriculum } \\
\text { Material }\end{array}$ & $\begin{array}{l}\text { Make-Up } \\
\text { Sessions }\end{array}$ \\
\hline \multicolumn{8}{|l|}{ Atlanta } \\
\hline GSU & $\checkmark$ & $\checkmark$ & $\checkmark$ & & $\checkmark$ & & $\checkmark$ \\
\hline LAA & $\checkmark$ & $\checkmark$ & & & $\checkmark$ & & $\checkmark$ \\
\hline Baltimore & $\checkmark$ & $\checkmark$ & & $\checkmark$ & $\checkmark$ & & \\
\hline Baton Rouge & $\checkmark$ & $\checkmark$ & & $\checkmark$ & & & $\checkmark$ \\
\hline \multicolumn{8}{|l|}{ Florida } \\
\hline Broward County & $\checkmark$ & $\checkmark$ & & $\checkmark$ & & & \\
\hline Orange County & $\checkmark$ & $\checkmark$ & & $\checkmark$ & & & $\checkmark$ \\
\hline \multicolumn{8}{|l|}{ Indiana } \\
\hline Allen County & $\checkmark$ & $\checkmark$ & & $\checkmark$ & & & $\checkmark$ \\
\hline Lake County & $\checkmark$ & & & & & & \\
\hline Marion County & $\checkmark$ & $\checkmark$ & & $\checkmark$ & & & $\checkmark$ \\
\hline Oklahoma & $\checkmark$ & $\checkmark$ & & $\checkmark$ & & & \\
\hline \multicolumn{8}{|l|}{ Texas } \\
\hline Houston & $\checkmark$ & $\checkmark$ & & $\checkmark$ & $\checkmark$ & $\checkmark$ & $\checkmark$ \\
\hline San Angelo & $\checkmark$ & $\checkmark$ & $\checkmark$ & $\checkmark$ & $\checkmark$ & $\checkmark$ & $\checkmark$ \\
\hline
\end{tabular}

Ongoing social activities were intended to promote social cohesion. Fostering a sense of involvement in BSF extended beyond promoting group attendance. All sites offered social activities to promote bonding and provide a social outlet. Some sites organized activities for all enrolled couples, or for couples in a particular group, and some did both. All sites scheduled activities at least a few times a year and some sites had monthly activities. Often events were planned around holidays, such as Valentine's Day or a holiday party in December, and social activities were sometimes held in celebration of weddings and births. Several sites planned graduation events to recognize couples who had achieved specific attendance milestones or who completed the curriculum.

One location tried to encourage participation by asking past BSF participants to attend an initial group session. One location, San Angelo, invited couples already participating in BSF to the initial session of another group to discuss their experienceswhat they enjoyed about group, what they learned, and how participating benefited their relationship. Having couples familiar with the group process also served as an icebreaker for new couples, who could observe the behaviors and actions of the more experienced participants. By making the first group session comfortable and enjoyable for couples, San Angelo hoped to encourage couples to attend ongoing group sessions.

Contact after an absence conveyed the message that the couple was missed. Sites often used absence from group as an opportunity to check in with the couple and let them know that they were missed during the session. During these contacts, site staff inquired about any barriers that may limit the couple's ability to attend group and discussed 
strategies for working around them. Most sites relied on telephone contact with couples following a group absence, though three BSF locations conducted home visits at least some of the time. On some occasions staff made such visits even without a confirmed appointment, in the hope of reconnecting with a couple who had not been participating or had been difficult to reach.

Providing couples with material missed during absences from group keeps them up-to-date. The BSF locations in Texas provided couples with material such as handouts and worksheets from group sessions they missed. The site staff thought that such materials conveyed the message that their absence was noted and the information covered in the session was important. Typically, the family coordinator brought this material to the home visit following a missed session and often spent time reviewing the material with the couple to keep them updated.

Make-up sessions were deemed important by site staff, but were often challenging to coordinate. About half of the BSF locations arranged make-up sessions, at least occasionally. For efficiency, make-up sessions often involved couples from more than one group. Facilitators ran the make-up session as if it were a regular session by covering all module components, though the session sometimes took less time if there were only a few couples in attendance. The logistics of make-up sessions were difficult, so use of make-ups was more limited than some sites first intended. Convening a make-up session entailed coordinating the facilitator's schedule with, ideally, the schedules of several couples. Facilitators had to fit make-up sessions in with their other responsibilities and couples' availability was often limited due to work and family commitments. To address some of these concerns, Baton Rouge often conducted make-up sessions on weekends, when they did not offer regularly scheduled groups. Florida attempted to conduct one-on-one make-up sessions in a couple's home, but found these to be too time-consuming for the facilitator.

Offering group sessions in a comfortable setting encouraged ongoing attendance, especially for pregnant women. Providing a warm and comfortable atmosphere for group sessions likely contributed to ongoing attendance. Offering group in a space that provided comfort to women in the late stages of pregnancy was emphasized by several sites. A comfortable setting may also encourage couples to communicate more openly in group sessions. To promote comfort, San Angelo and Oklahoma obtained comfortable furniture, such as recliners or couches. Other sites purposely arranged furniture to encourage group dialogue, for example, by arranging chairs in a circle. In Baltimore, one pair of facilitators "set the scene" for group sessions by lighting candles and playing soft background music. When sites arranged for space in locations outside of their program office, they were often limited in the extent to which they could alter the setting. Sometimes this led to a less than ideal physical setting for sessions.

\section{Sites Offered Incentives to Encourage Attendance, in Varying Degrees}

Incentives were used at almost all BSF sites. Whether gift certificates, cash, or baby items, many sites regularly distributed incentives to couples to recognize initial and ongoing attendance (Table IV.3). The purpose and level of emphasis placed on the incentives varied 
dramatically across sites. Some sites viewed incentives as a primary tool for encouraging attendance and actively promoted them, while other sites were more cautious about using incentives or "talking them up" to promote attendance.

For the most part, sites used incentives to encourage initial or ongoing attendance or to recognize group completion. To encourage couples to "try out" the group sessions by coming at least once, most sites offered couples some type of incentive. Thereafter, incentives rewarded group attendance and promoted continued participation and completion. Sites distributed incentives at various times throughout the curriculum sequence. Some used these incentives to encourage attendance at the first quarter or first half of sessions, while other sites provided incentives throughout the entire sequence.

Half of the BSF locations recognized long-term attendance and group completion by providing incentives in recognition of high attendance. They informed couples of the incentives during the curriculum sequence as a strategy to sustain long-term involvement in the group. For example, Baltimore distributed gift cards to couples at their graduation ceremonies. The value of the gift card corresponded to the couple's level of attendance. Couples who attended all curriculum sessions received an overnight stay at a local hotel (funded by local donors) in addition to the gift card.

Oklahoma placed the greatest emphasis on incentives to encourage attendance. The site believed it was important to recognize the time couples spent during group. Oklahoma provided cash incentives after a couple completed six, fifteen, and thirty hours of the curriculum. Additionally, couples accumulated "crib cash" for attending each group session and some family coordinator meetings, which could be redeemed for new baby items. A gift drawing also occurred during most group sessions. Couples learned about the incentives during the recruitment process and facilitators described the structure in detail during the initial group session.

It is difficult to conclude with great confidence how instrumental incentives are in promoting attendance. Many factors affect participation, and not all sites were consistent in their use of incentives over the course of operations. Some sites continue to revise their approaches to see whether different incentive combinations or approaches may promote better attendance. 
Table IV.3. BSF Sites' Approaches to Participation Incentives

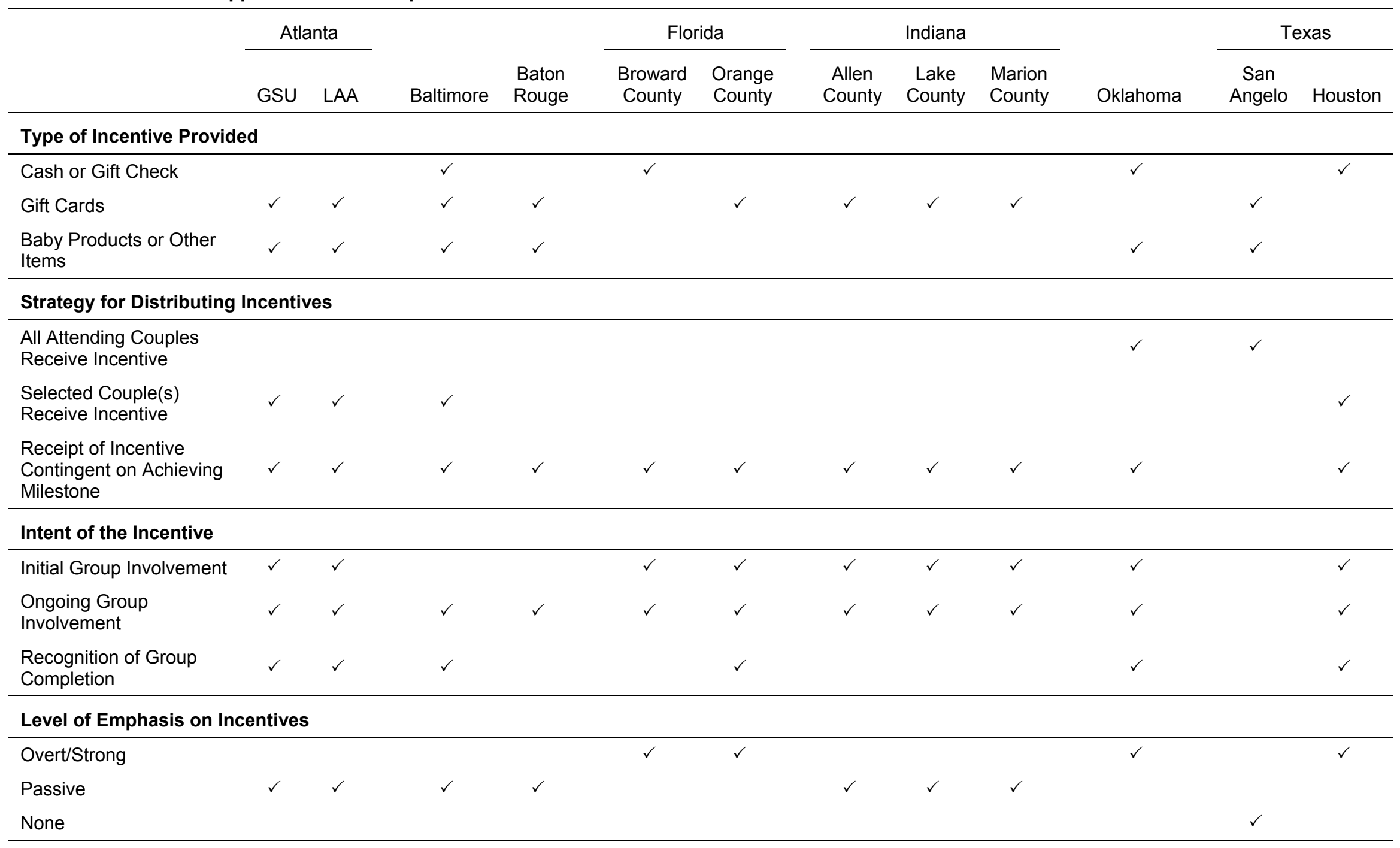





\section{H A P T E R V}

\section{M P L E M E N T A T I O N O F THE B S F F A M ILY COORDINATOR COMPONENT A N D LIN KA G E S T O FAM I L Y S U P O R T SERVICES}

$\mathrm{I}$ $\mathrm{n}$ the BSF model, couples would not only attend group sessions on marriage and relationship skills, but also receive individualized services from staff known as Family Coordinators. These staff would encourage couples to attend group sessions, identify issues the couples were facing that might affect their wellbeing and their relationship, and make referrals to additional services, as needed. The combination of the group sessions, the attention of the family coordinator (FC), and the availability of additional family support services was to provide a comprehensive intervention to support the couple's relationship.

Although the model guidelines specified functions of FCs, sites had wide latitude in developing and implementing this component. For instance, sites could decide in what manner and how frequently the FCs would provide support, and they could set the qualifications FC staff must have. The result was that sites took different approaches to FC staffing, and did not always assign responsibility for the defined FC activities to a single position. For example, some sites divided FC functions across group facilitators and outreach workers. Therefore, rather than focus solely on staff with the title of FC (or its equivalent), this chapter discusses how sites fulfilled the FC functions. First we describe the standards sites set for carrying out the FC functions, and then discuss how they were performed and by whom. We also discuss how the FCs assessed and linked couples to family support services.

\section{A. Delivery of the Family Coordinator Component}

According to the BSF model guidelines, each couple would be assigned a program staff member whose role was to maintain individual contact and, at a minimum, perform the following functions:

- Encourage both members of the couple to attend group sessions.

- Reinforce the relationship skills being taught in the group sessions and provide emotional support 
- Assess the couple individually for various basic needs, and link them to appropriate family support services.

\section{KEY FINDINGS ON THE FAMILY COORDINATOR COMPONENT}

- Sites varied considerably in designating staff to fulfill FC functions, and in their standards for frequency and mode of contact with couples. Staff often tailored the frequency of contact to meet the individual needs of couples.

- Site differences in design of the FC component meant variation in the emphasis placed on each function and expectations for intensity of the FC component.

- Program staff - whether group facilitators, home visitors, or intake staffwere more likely to reinforce marriage and relationship skills when they had received specific training and tools from the curriculum developer.

- Encouraging group attendance and providing ongoing emotional support were FC activities that required less professional expertise and sites found easier to implement.

Sites made different decisions on how to carry out these three functions, and the result was variation in the focus and intensity of the FC component. Variation arose from decisions on how sites would organize staff for FC functions, and how the staff would address each of the functions.

\section{Design and Implementation of the FC Component Varied Greatly Across Sites}

BSF sites each took their own approach to designating FC staff and defining the purpose, frequency, mode, and focus of their contact with couples. Sites were guided by their own interpretation of how FC support should be provided, and influenced by issues related to management and existing program infrastructure.

Staffing arrangements had implications for sites' capacity to focus on the family coordinator component. Sites were creative in how they designated staff to fulfill the FC functions (Table V.1). Some sites felt that the three FC functions required staff with different types of background and experience. Sites where BSF was implemented in the context of an existing program infrastructure made staffing decisions designed to make efficient use of existing staff. A few sites sought efficiencies by combining the FC role with other BSF roles. The result was more staff capacity for FC functions in some sites than in others. 
Table V.1. Staffing the BSF Family Coordinator Component

\begin{tabular}{|c|c|c|c|c|}
\hline Site & $\begin{array}{c}\text { Group } \\
\text { Facilitators }\end{array}$ & $\begin{array}{l}\text { Dedicated } \\
\text { Family } \\
\text { Coordinators or } \\
\text { HF Home } \\
\text { Visitors }\end{array}$ & Intake Staff & $\begin{array}{l}\text { FC Staff Also } \\
\text { Serving Non- } \\
\text { BSF Families }\end{array}$ \\
\hline $\begin{array}{c}\text { Atlanta } \\
\text { GSU } \\
\text { LAA }\end{array}$ & $\begin{array}{l}\checkmark \\
\checkmark\end{array}$ & $\checkmark$ & $\checkmark$ & \\
\hline Baltimore & & & $\checkmark$ & \\
\hline Baton Rouge & & $\checkmark$ & & \\
\hline $\begin{array}{l}\text { Florida } \\
\text { Broward County } \\
\text { Orange County }\end{array}$ & & $\begin{array}{l}\checkmark \\
\checkmark\end{array}$ & $\begin{array}{l}\checkmark \\
\checkmark\end{array}$ & \\
\hline $\begin{array}{l}\text { Indiana } \\
\text { Allen County } \\
\text { Lake County } \\
\text { Marion County }\end{array}$ & $\begin{array}{l}\checkmark \\
\checkmark \\
\checkmark\end{array}$ & $\begin{array}{l}\checkmark \\
\checkmark \\
\checkmark\end{array}$ & $\begin{array}{l}\checkmark \\
\checkmark \\
\checkmark\end{array}$ & $\begin{array}{l}\checkmark \\
\checkmark \\
\checkmark\end{array}$ \\
\hline Oklahoma & & $\checkmark$ & & $\checkmark$ \\
\hline $\begin{array}{l}\text { Texas } \\
\text { Houston } \\
\text { San Angelo }\end{array}$ & & $\begin{array}{l}\checkmark \\
\checkmark\end{array}$ & & \\
\hline
\end{tabular}

Four sites concentrated FC functions in a single staff position, although in some cases these were not the only roles the staff played. Baton Rouge and Oklahoma created new positions to fulfill the FC functions, and only those functions. Baltimore assigned all FC functions to what they called their intake/outreach workers, but as the title suggests they also had responsibilities related to recruitment and enrollment. The Texas locations used home visitors to carry out all FC activities, but they also continued their pre-BSF roles in teaching parenting and child development skills.

Several sites divided FC functions across multiple positions. Atlanta used intake staff to provide initial emotional support to couples and group facilitators to fulfill the remaining functions; Atlanta LAA gave primary responsibility for addressing the FC functions to a dedicated position and back-up responsibility to the group facilitators. In Florida, intake workers conducted an initial assessment of family needs, and Healthy Families home visitors completed the other FC responsibilities.

The family coordinator role in Indiana was diluted in several ways for much of the implementation period covered in this report by staffing arrangements. For more than a year, group facilitators reinforced relationship skills, encouraged attendance, and provided emotional support to BSF couples through contacts outside the group sessions. Assigning a large share of the FC functions to group facilitators kept much of the FC role out of the hands of the home visitor staff who were nevertheless nominally designated to serve FC 
functions. In addition, home visitors worked not only with BSF couples but with non-BSF Healthy Families caseloads, providing instruction in parenting and child development as they did before BSF was implemented. BSF cases were spread across many home visitors, so home visitor staff typically had at most one or two BSF families in their caseloads. This may have had the unintended effect of reducing the emphasis these home visitors placed on carrying out FC functions. This site eventually decided to concentrate its BSF cases in the caseloads of a more limited number of home visiting staff.

Many sites planned for FCs to respond to couples on an "as-needed" basis, with expectations about the intensity of contact left undefined. Many sites saw contact between FCs and couples as best determined by each couple's level of need-rather than uniformly applied. A few, however, felt that it was important to ensure individual contact on a regular schedule and to focus on pre-identified content. Although all sites tried to engage both partners in FC interactions, the extent to which sites emphasized this also varied. Table V.2 depicts the variation in planned intensity across sites, as classified by their general approach to meeting with couples.

Table V.2. Site Plans for Primary Mode, Frequency, and Average Length of FC Contacts

\begin{tabular}{|c|c|c|c|c|c|c|c|}
\hline \multirow[b]{2}{*}{ Site } & \multicolumn{3}{|c|}{ Primary Mode or Location } & \multicolumn{4}{|c|}{$\begin{array}{c}\text { Frequency and Average Length in } \\
\text { Minutes }\end{array}$} \\
\hline & $\begin{array}{l}\text { Telephone } \\
\text { Call }\end{array}$ & $\begin{array}{l}\text { Home } \\
\text { Visit }\end{array}$ & $\begin{array}{l}\text { Office } \\
\text { Visit }\end{array}$ & Weekly & $\begin{array}{l}\text { Semi- } \\
\text { Monthly }\end{array}$ & Monthly & $\begin{array}{c}\text { As } \\
\text { Needed }\end{array}$ \\
\hline \multicolumn{8}{|l|}{ Atlanta } \\
\hline GSU & $\checkmark$ & & & & & & 20 \\
\hline LAA & & $\checkmark$ & & 15 & & & \\
\hline Baltimore & & $\checkmark$ & & & & 30 & \\
\hline Baton Rouge & $\checkmark$ & & & & 30 & & \\
\hline \multicolumn{8}{|l|}{ Florida } \\
\hline Broward County & & $\checkmark$ & & 60 & & & \\
\hline Orange County & & $\checkmark$ & & 60 & & & \\
\hline \multicolumn{8}{|l|}{ Indiana } \\
\hline Allen County & & $\checkmark$ & & 60 & & & \\
\hline Lake County & & $\checkmark$ & & 60 & & & \\
\hline Marion County & & $\checkmark$ & & 60 & & & \\
\hline Oklahoma & & & $\checkmark$ & & 30 & & \\
\hline \multicolumn{8}{|l|}{ Texas } \\
\hline Houston & & $\checkmark$ & & 60 & & & \\
\hline San Angelo & & $\checkmark$ & & 60 & & & \\
\hline
\end{tabular}

Note: $\quad$ Primary mode or location for ongoing communication describes the site's main approach for meeting with couples on an on-going basis. Most, if not all, sites use multiple strategies for connecting with couples. 
At least one site "triaged" couples by classifying them according to level of risk and planning more structured and intense contact with higher risk couples. Baton Rouge identified higher and lower risk couples based on their physical and mental health status, relationship strength, and likelihood of group participation. FCs were expected to meet with high risk couples weekly and with lower risk couples semi-monthly.

Two sites, Atlanta and Baltimore, felt it was important to be responsive to couples' needs, but not to burden couples for whom intensive individual services seemed unnecessary. In these sites, FC services may be at an intense level for some couples, but less so for other couples. Except for an initial home visit, family coordinators of both Atlanta GSU and LAA met with couples as needs arose. Baltimore combined as-needed and structured approaches, responding to participants' expressed needs, but also scheduling regular monthly contacts.

Healthy Families sites continued their previous practice of regular scheduled home visits, following a "leveling" system that gradually lowered visit frequency over time. In most cases, home visits were conducted weekly for a family's first six to nine months. Over time, the frequency of home visitation in the Florida, Indiana, and Texas sites gradually decreases to twice monthly and then to monthly.

Oklahoma also decided to set the frequency of FC contact based on the couple's time in the program, although not for the purpose of conforming to any pre-existing practice. Oklahoma expected couples to come for one office visit with their FC every other week. After three months, couples would switch to a schedule of monthly meetings, and after another three months to a schedule of one office visit and one telephone call every quarter.

The content and duration of meetings with FC staff were defined loosely in most sites, but stated precisely where Healthy Families specifications were being applied. Sites set general expectations for amount of time to be spent in contacts between FCs and couples, and some sites defined the content to be covered. Healthy Families sites schedule one-hour home visits, until babies are 18 months to 3 years old, depending on the site, though at decreasing frequency. The major focus of these weekly meetings was not BSF; the visits primarily covered the Healthy Families parenting skills and child development curriculum. Nevertheless, sites expected that at least a portion of each home visit would touch upon FC activities. The expectation for the attendance of both parents at home visits varied considerably from site to site. In some cases, conflicts between the FC's schedule and the work schedule of fathers meant that visits were often held with mothers only.

With one exception, other BSF sites allowed FC staff to define meeting content based on the couple's immediate concerns. FC meetings in Oklahoma were to follow a structured format and agenda, lasting about 30 minutes, scheduled so that both parents attended together, over a period lasting until their baby was a year old. Other sites had few structured plans. Baltimore arranged for FC meetings to last about 30 minutes and occur with both parents until six months after group completion. Other than updating a "Family Strengthening Plan" which involved a set of goals established by the couple and the FC in early visits, FC staff had flexibility to identify appropriate content for each meeting. Like Baltimore, Baton Rouge intended for meetings to occur with both partners to update a goal 
plan, primarily while the couple actively attended group, but with some follow-up after group completion. Atlanta allowed couples to set the pace of FC meetings, by responding on an as-needed basis. Depending on each couples' specific needs, group facilitators or family coordinators connected with couples, primarily through telephone contact, throughout the six-month curriculum period.

\section{Most FCs Concentrated on Encouraging Group Attendance, but Only Some Reinforced Relationship Skills}

Despite variation across sites in the emphasis placed on some FC functions, most sites developed systems for encouraging attendance at group sessions and providing emotional support to couples. However, where FC staff were not also serving as group facilitators, sites found it more difficult to have FC staff work on reinforcing the skills being developed in the group sessions. FC staff did better at reinforcing skills after tools were created to help them with this task, so they weren't left applying the curriculum on their own.

All sites encouraged group attendance, typically through telephone contact and regular home visits. All sites encouraged BSF staff to support attendance at initial and ongoing group sessions and to follow-up with couples who missed a group session. Sites contacted couples through telephone calls and home visits to encourage attendance and may have involved multiple staff in the process (Table V.3). Some sites tailored the frequency of reminders to couples' attendance patterns.

Most sites that made home visits used them as occasions to encourage attendance at groups. Home visitors in Healthy Families sites typically began encouraging group attendance at the initial visit and continued during subsequent contacts. In Florida, staff gathered information from couples on availability and group scheduling preferences during the initial home visit. These staff later informed the couple of their start date for group and provided encouragement to attend. In San Angelo's home visits to couples before they started attending group sessions, staff showed them a scrapbook that the program compiled to illustrate the group environment, and provided a flyer that answered "frequently asked questions" about group sessions. In several sites staff dropped by couples' homes to encourage ongoing attendance, especially when couples' attendance was spotty.

Staff in Atlanta, Baltimore, Baton Rouge, Indiana, and Oklahoma contacted couples primarily by telephone to encourage attendance, striking a balance between regular reminders and attention geared to each couple's apparent need for them. Some couples benefited from weekly reminders, whereas other couples who were already regular attendees may have found weekly reminders to be annoying or intrusive. In Baltimore, staff found a way to make reminder calls less obvious: an outreach worker called all couples each week about transportation to group, and the timing of the call allowed it to serve as a reminder about the meeting group the following day. 
Table V.3. Reinforcing Marriage and Relationship Skills

\begin{tabular}{|c|c|c|c|c|c|c|c|c|}
\hline \multirow[b]{2}{*}{ Site } & \multicolumn{3}{|c|}{ Staff } & \multicolumn{3}{|c|}{ Mode or Location } & \multicolumn{2}{|c|}{ Frequency } \\
\hline & $\begin{array}{c}\text { Group } \\
\text { Facilitators }\end{array}$ & $\begin{array}{c}\text { Family } \\
\text { Coordinator/HF } \\
\text { Home Visitor }\end{array}$ & Intake Staff & $\begin{array}{c}\text { Telephone } \\
\text { Call }\end{array}$ & Home Visit & $\begin{array}{l}\text { Office } \\
\text { Visit }\end{array}$ & Regular Basis & As Needed \\
\hline \multicolumn{9}{|l|}{ Atlanta } \\
\hline GSU & $\checkmark$ & & & $\checkmark$ & & & & $\checkmark$ \\
\hline LAA & & $\checkmark$ & & $\checkmark$ & & & $\checkmark$ & \\
\hline Baltimore & & & $\checkmark$ & & $\checkmark$ & & & $\checkmark$ \\
\hline Baton Rouge & & $\checkmark$ & & $\checkmark$ & & & & $\checkmark$ \\
\hline \multicolumn{9}{|l|}{ Florida } \\
\hline Broward County & & $\checkmark$ & & & $\checkmark$ & & $\checkmark$ & \\
\hline Orange County & & $\checkmark$ & & & $\checkmark$ & & $\checkmark$ & \\
\hline \multicolumn{9}{|l|}{ Indiana } \\
\hline Allen County & & $\checkmark$ & & & $\checkmark$ & & $\checkmark$ & \\
\hline Lake County & & $\checkmark$ & & & $\checkmark$ & & $\checkmark$ & \\
\hline Marion County & $\checkmark$ & & & $\checkmark$ & & & & $\checkmark$ \\
\hline Oklahoma & & $\checkmark$ & & & & $\checkmark$ & $\checkmark$ & \\
\hline \multicolumn{9}{|l|}{ Texas } \\
\hline Houston & & $\checkmark$ & & & $\checkmark$ & & & $\checkmark$ \\
\hline San Angelo & & $\checkmark$ & & & $\checkmark$ & & $\checkmark$ & \\
\hline
\end{tabular}


Sites found that specialized training was needed for family coordinators to reinforce relationship skills outside group sessions. Seven of the 12 BSF locations had structured plans to regularly reinforce marriage and relationship skills, though some were implemented only after their program had been underway for some time. Through modeling and/or coaching, sites expected staff to work with couples to revisit the skills they were learning as they went through the sequence of group sessions and after completing them. To make this reinforcement possible, sites found it necessary to train FC staff in the group curriculum, at least in abbreviated form. While sites varied in the frequency of skills reinforcement, most eventually adopted a formalized strategy for reinforcement (Table V.4).

Participation in curriculum training did not ensure that FCs would be equipped to reinforce relationship skills in their contacts with couples in a systematic way. Some sites went as far as including FCs in the full training given to group facilitators on their chosen curriculum. However, this training was not focused on how to reinforce skills with individual couples outside of group. Even in these sites (Atlanta GSU, Baltimore, Baton Rouge, and Houston), FCs tended to provide reinforcement in relationship skills on an asneeded basis, and often only through telephone contact.

Table V.4. Encouraging Group Attendance

\begin{tabular}{|c|c|c|c|c|c|c|c|}
\hline \multirow[b]{2}{*}{ Site } & \multicolumn{3}{|c|}{ Staff } & \multicolumn{2}{|c|}{ Mode } & \multicolumn{2}{|c|}{ Frequency } \\
\hline & $\begin{array}{c}\text { Group } \\
\text { Facilitators }\end{array}$ & $\begin{array}{c}\text { Family } \\
\text { Coordinator/HF } \\
\text { Home Visitor }\end{array}$ & $\begin{array}{l}\text { Intake } \\
\text { Staff }\end{array}$ & $\begin{array}{c}\text { Telephone } \\
\text { Call }\end{array}$ & $\begin{array}{l}\text { Home } \\
\text { Visit }\end{array}$ & $\begin{array}{c}\text { Regular } \\
\text { Basis }\end{array}$ & $\begin{array}{c}\text { As } \\
\text { Needed }\end{array}$ \\
\hline \multicolumn{8}{|l|}{ Atlanta } \\
\hline GSU & $\checkmark$ & & & $\checkmark$ & & & $\checkmark$ \\
\hline LAA & $\checkmark$ & & & $\checkmark$ & & & $\checkmark$ \\
\hline Baltimore & & & $\checkmark$ & $\checkmark$ & & $\checkmark$ & \\
\hline Baton Rouge & & $\checkmark$ & & $\checkmark$ & & & $\checkmark$ \\
\hline \multicolumn{8}{|l|}{ Florida } \\
\hline Broward County & & $\checkmark$ & & & $\checkmark$ & $\checkmark$ & \\
\hline Orange County & & $\checkmark$ & & & $\checkmark$ & $\checkmark$ & \\
\hline \multicolumn{8}{|l|}{ Indiana } \\
\hline Allen County & $\checkmark$ & $\checkmark$ & & & $\checkmark$ & $\checkmark$ & \\
\hline Lake County & $\checkmark$ & & & $\checkmark$ & & $\checkmark$ & \\
\hline Marion County & $\checkmark$ & & & $\checkmark$ & & $\checkmark$ & \\
\hline Oklahoma & & $\checkmark$ & & $\checkmark$ & & & $\checkmark$ \\
\hline \multicolumn{8}{|l|}{ Texas } \\
\hline Houston & & $\checkmark$ & & & $\checkmark$ & $\checkmark$ & \\
\hline San Angelo & & $\checkmark$ & & & $\checkmark$ & $\checkmark$ & \\
\hline
\end{tabular}


KEY FINDINGS ON FAMILY SUPPORT SERVICES

- Around the time of enrollment, all BSF sites assessed mothers and about half assessed fathers. Three-quarters of the sites did follow-up assessments with mothers and less than half of the sites conducted additional assessments with fathers.

- Most sites asked couples to identify their needs and goals as part of the assessment process. Some sites used a structured tool to guide assessments.

- All BSF sites used an informal referral process to connect couples to family support services. The extent of follow-up provided by BSF staff varied by site and by a couple's circumstances.

- All BSF sites identified and referred to existing community resources. Two sites connected couples to existing on-site services, which included fatherhood, employment, and other family-focused services.

Perhaps because staff in Florida and Indiana had contact with staff through regular home visits, the two states pushed for more specialized training and resources to help FC staff reinforce skills outside of the group setting. Although it seemed efficient to use Healthy Families home visitors for FC functions as part of regular home visits, home visitors had difficulty reinforcing relationship skills because they had little exposure to the group curriculum component. After the home visitors got special training on reinforcing skills outside the group setting, they felt more equipped for that part of their job.

The division of FC tasks across several staff positions in Indiana made it particularly difficult for home visitor staff to reinforce relationship skills. Assignment of responsibility for FC functions to group facilitators meant a kind of bifurcation of BSF and Healthy Families, with facilitators invested in providing and supporting BSF, and home visitors more focused on Healthy Families services. To make the program more cohesive, Indiana also provided its home visitors with special training led by the curriculum developer and specific tools they can use to reinforce skills in the home setting. FC staff in Florida and Indiana received this special training and resources near the end of 2006, and could then begin to take a more systematic and formal approach to skill reinforcement.

\section{B. Linking Couples to FAmily Support SERvices}

The third component of the BSF model is the links the program provides to family support services to help couples address barriers that could affect their relationship. Programs were encouraged to think broadly about the types of services that may benefit couples, utilize existing on-site resources, and develop linkages to community resources. It was expected that services might include infant care and parenting education, employment and education services, physical or mental health care, substance abuse, housing, or domestic 
violence programs. BSF programs were not expected to provide these services but to link or refer couples to existing services in the community. Family coordinators would assess couples' needs and connect them to appropriate services, and sites had flexibility in establishing standards for assessment and making referrals. This section discusses sites' assessment approaches, how sites completed assessments, the process for making referrals, and the types of services available in site communities.

\section{Assessments Varied in Setting, Timing, Frequency, and Method}

Family coordinators conducted most assessments, although in some cases group facilitators or intake staff were also involved (Table V.5). In several sites, assessment occurred in stages, with responsibility handed off from one staff member to another. For example, in Florida the intake worker completed an initial assessment with the mother as part of recruitment. A home visitor, who fulfilled many of the FC functions, completed all subsequent assessments. Home visitors were usually well aware of couples' needs as revealed in the intake assessment because of internal staff communication procedures.

Table V.5. Staff and Location for Conducting Assessments

\begin{tabular}{|c|c|c|c|c|c|c|}
\hline \multirow[b]{2}{*}{ Site } & \multicolumn{3}{|c|}{ Staff } & \multicolumn{3}{|c|}{ Location } \\
\hline & $\begin{array}{l}\text { Group } \\
\text { Facilitators }\end{array}$ & $\begin{array}{c}\text { Family } \\
\text { Coordinator/HF } \\
\text { Home Visitor }\end{array}$ & $\begin{array}{l}\text { Intake } \\
\text { Staff }\end{array}$ & $\begin{array}{l}\text { Home } \\
\text { Visit }\end{array}$ & $\begin{array}{l}\text { Office } \\
\text { Visit }\end{array}$ & Hospital \\
\hline \multicolumn{7}{|l|}{ Atlanta } \\
\hline GSU & $\checkmark$ & & & $\checkmark$ & & \\
\hline LAA & & $\checkmark$ & & $\checkmark$ & & \\
\hline Baltimore & & & $\checkmark$ & $\checkmark$ & & \\
\hline Baton Rouge & & $\checkmark$ & & $\checkmark$ & & \\
\hline \multicolumn{7}{|l|}{ Florida } \\
\hline Broward County & & $\checkmark$ & $\checkmark$ & $\checkmark$ & & $\checkmark$ \\
\hline Orange County & & $\checkmark$ & $\checkmark$ & $\checkmark$ & & $\checkmark$ \\
\hline \multicolumn{7}{|l|}{ Indiana } \\
\hline Allen County & & $\checkmark$ & $\checkmark$ & $\checkmark$ & & $\checkmark$ \\
\hline Lake County & & & $\checkmark$ & & & $\checkmark$ \\
\hline Marion County & & $\checkmark$ & $\checkmark$ & $\checkmark$ & & \\
\hline Oklahoma & & $\checkmark$ & & & $\checkmark$ & \\
\hline \multicolumn{7}{|l|}{ Texas } \\
\hline Houston & & $\checkmark$ & $\checkmark$ & $\checkmark$ & & $\checkmark$ \\
\hline San Angelo & & $\checkmark$ & & $\checkmark$ & & \\
\hline
\end{tabular}


Planned Location of Assessments. Assessments most often occurred during home visits with the couple, but several sites assessed couples' needs in office visits or in hospitals around the time of the child's birth. Ten BSF locations conducted assessments in the home, but four of these also conducted assessments in other locations. Oklahoma did not routinely conduct home visits, so assessments were done in the program office.

When Parents Were Assessed. BSF sites conducted assessments during intake before couples were enrolled in the evaluation, soon after enrollment, or while they participated in BSF (Table V.6). All sites completed an initial needs assessment during intake or shortly after program enrollment. Seven BSF locations conducted these initial assessments shortly after program enrollment (which avoided conducting full assessments on couples who would then be assigned to the evaluation control group). Six of these seven locations planned for comparable attention to assessing mothers and fathers, either joint assessment or individual assessments.

Whom to Assess, and How Often. Many BSF sites did ongoing assessment. Some sites defined intervals for reevaluating couples' needs. At these sites, FCs were to help couples set goals based on their initial assessment and then reevaluate them at set intervals of one to six months. Other sites tended to rely on informal assessments in the course of conversations between the family coordinator and the couple. In these cases, the frequency of ongoing assessment was not specified in advance. Initially, the sites that assessed both mothers and fathers continued to do so at later points whenever possible. However, sites that focused mostly on assessing the mother's needs tended to emphasize ongoing assessment only with mothers. Fathers could be included in an assessment, but only if they attended meetings arranged with the FC and mother.

How Assessments Were To Be Conducted. BSF sites assessed couples for a wide range of needs using formal, structured tools or informal means. Baton Rouge, Baltimore, and Oklahoma used a structured outline that guided staff to ask questions such as "are you currently enrolled in school?" or "are you currently employed?" "how well does this salary cover your financial needs?" and "list any difficulties you may have finding/keeping work". 19 They also gathered information on housing, transportation, nutrition, budgeting and finances, parenting knowledge, infant health and safety, physical or mental health, employment and education, legal or criminal history, available social support, and the couple's relationship. San Angelo and Atlanta GSU and LAA took a more informal, less structured conversational approach. The informal approach was intended to explore similar potential issues as the more formal tools. Several sites screened mothers for post-partum depression, often using the Edinburgh Depression Scale, a widely used and easily administered screening tool.

Sites that built on a Healthy Families program used the Kempe Assessment, or an adapted version of it, during the initial encounter with a mother. The Kempe is an in-depth but informally structured procedure for guiding a conversation, which focuses on assessing

\footnotetext{
${ }^{19}$ Sample questions are from an assessment form used by the Baton Rouge site.
} 
parent-child interactions and the child's risk of experiencing abuse. The assessment gathers information on risk factors such as education, income, marital status, housing, social support, dysfunction in family of origin, parenting skills and awareness of discipline options, past abusive relationships, health behaviors during pregnancy, and presence of other children with special needs. Assessment results determine whether the mother is eligible to receive Healthy Families services based on the risk of child abuse. The BSF programs in Florida and Indiana incorporated this assessment into their recruitment process, using the information it generated to provide answers to the BSF eligibility questions - and to provide the basis for later referrals to other needed services.

\section{At Some Sites, Assessment Helped Identify Goals and Guide Referrals}

On the basis of initial assessments, sites often worked with couples to develop a plan that reflected their priorities, needs, and short- and long-term goals. The needs assessment and resulting plan guided staff in providing referrals for services. Sites typically referred to these documents as Family Support Plans or Family Strengthening Plans. Ideally, both members of the couple contributed to the development of a single plan that captured joint needs and goals. Staff asked couples to identify their personal goals for the next three or six months, and ways to achieve them. For example, Baltimore used a plan that included sections on group workshop attendance, employment and education, family support services, child care, and parenting. Baton Rouge's plan asked couples to identify goals for employment, parenting, education/career, and their relationship as a couple.

Referrals were typically informal. Program staff suggested resources the couple might find useful, based on the needs assessment and identified goals. Often, program staff provided contact information for a service organization, including a specific contact person. Staff exercised some discretion in deciding how much assistance to give couples in contacting the service provider.

Several sites adopted overarching philosophies that guided their interactions with couples. Family Expectations in Oklahoma adopted an "opening doors" approach to linking couples to services. This meant that BSF staff would provide information to couples with the name, telephone number, and location for an agency, but staff would not escort a couple to the agency, as they felt it was up to the couple to "walk through" the door. As an organization, the Center for Fathers, Families, and Workforce Development (CFWD) in Baltimore followed an "empower, not enable" philosophy. BSF staff were careful not to encourage couples to rely heavily on program staff to deal with emergencies. However, staff were available to support and guide couples, as they worked to empower themselves, which sometimes entailed providing informal referrals or calling an agency on behalf of a couple to expedite services.

\section{Sites Identified Community Resources, and a Few Offered Existing On-Site Services}

Most BSF sites used available community resources to address couples' needs. Several sites already had relationships with service providers and built on these connections to link couples to services. BSF staff who had been at the site agency for some time already knew

\section{$V:$ BSF Family Coordinators and Links to Family Support Services}


how to navigate external systems to ensure that couples had access to services. The institutional knowledge of lead staff at these sites helped them bring newly hired staff up to speed quickly. Sites that did not have this knowledge base developed it quickly during the design, pilot, and early implementation phases for BSF, because they found it essential in working with couples.

Two BSF sites, Baltimore and Baton Rouge, provided some family support services onsite. In both sites, BSF was offered by multi-service agencies that provided a variety of services before BSF. Family Road in Baton Rouge serves as a one-stop organization for new parents offering a wide range of services such as parenting classes, mental health counseling, prenatal programs, GED attainment, Healthy Start, WIC, and Medicaid. Staff referred BSF couples to these services as needed. CFWD in Baltimore specialized in employment services prior to operating BSF and staff referred BSF couples on an as-needed basis. For example, couples with employment needs could be referred to STRIVE, an intensive job readiness program offered by CFWD. At both sites, however, the on-site services could not address every need a couple might have, so even these sites needed to have knowledge of and relationships with community service providers to ensure that couples could be linked to the wide range of services.

Several BSF sites offered on-site services specifically for fathers. The BSF programs in Baltimore, Baton Rouge, Oklahoma, and San Angelo offered father-focused groups and individual case management to assist BSF fathers and engage them in services. BSF programs in Orange and Broward counties in Florida and in Houston primarily offered individual case management to fathers that focused on BSF engagement. To facilitate this work, the Florida sites, Houston, Oklahoma, and San Angelo employed staff dedicated to working with fathers.

The extent to which services were available in communities affected the BSF sites' ability to identify and develop relationships with community resources. Some BSF locations, such as Atlanta, benefited from an abundance of available organizations that provide services to low-income families. Other BSF sites were creative in identifying accessible family support services, sometimes by finding ways to offer the service (at least on a limited basis) themselves. For example, accessible transportation was a concern in many areas, especially when the community lacked a public transit system. To address the concern, BSF programs offered couples taxi service or personally transported couples to other service providers, such as a doctor's appointment, on occasion. However, staff noted that they needed to exercise some restraint in offering this service so couples did not become overly dependent. 



\section{H A P T E R V I}

\section{PAR T I C I P A T I O N I N B S F}

$\mathrm{P}$ articipation is a central outcome of program implementation. Unless couples assigned to the experimental group participate in BSF, the program is unlikely to have any impact on them or their children. Although the "dosage" of program activity needed to achieve positive impacts is unknown, at least some exposure to the program is likely to be necessary. This chapter focuses on participation in the three main services offered by the BSF program in the evaluation sites: group sessions on marriage and relationship skills, individual meetings with family coordinators, and assessment and referral to family support services. We use data from the programs' management information systems to examine how many experimental group members participate in BSF program activities and how much they participate.

\section{A. Attendance at Marriage and Relationship Skills Group Sessions}

A basic measure of participation in BSF is the percentage of the experimental group that attended one or more sessions of the core marriage and relationship skills groups. We call these couples who attended a session at least once "initiators." We also examine how quickly after their enrollment couples attend their first session - a factor that may affect their eventual extent of participation. For example, sites that have difficulty getting couples engaged in program activities soon after enrollment may have lower rates of participation overall. To explore the extent of program "dosage," we compute the total number of hours couples participate in group sessions, as well as the percentage of the curriculum they completed.

To examine group attendance, we must limit our data to couples whose attendance can be measured over an extended period after their enrollment. For most sites, we have limited the analysis reported here to couples who have been in the sample a minimum of eight months. This period of observation was chosen because constraints related to couples' availability and sites' capacity often delayed couples' assignment to a group for a month or two, and in all sites except Oklahoma the curriculum took about six months to complete. The observational period for Oklahoma can be briefer because its curriculum length is shorter than at other sites (six to ten weeks). Because of this shorter curriculum format and 
because Oklahoma began sample enrollment later than most sites (thus limiting the amount of data available for the current analysis), we examine group attendance for Oklahoma over four months following each couple's random assignment.

These restrictions mean that we can, at this time, report on participation only among earlier cohorts of enrolled couples. The analysis sample includes couples enrolled through September 2006 for Oklahoma, and through May 2006 for all other sites. The sample in each site is divided into several cohorts, and for some analyses we take advantage of the extended enrollment period to include participation results over a longer period for the earliest cohorts. ${ }^{20}$

\section{Among Early Cohorts, 61 Percent of the Intervention Group Initiated Attendance at BSF Group Sessions}

Across all sites, 61 percent of the early program sample attended BSF group sessions one or more times (Table VI.1). Rates of initial attendance varied widely across program sites, from 40 to 80 percent. Houston and the three Indiana locations had the lowest rates of initial attendance, from 40 to 50 percent. Both Atlanta locations and Oklahoma had the highest rates, from 70 to 80 percent. The remaining sites-Baltimore, Baton Rouge, San Angelo, and both Florida locations-had initiation rates near the all-site average, ranging from 57 to 64 percent. Despite the voluntary consent of both parents to participate in the study, a sizable proportion of all program group couples (39 percent on average) did not attend any group sessions during the period studied.

\section{KEY FINDINGS ON PROGRAM PARTICIPATION}

- Of the couples assigned to the program group, 61 percent initiated attendance at group sessions. This measure of attendance varied widely across sites, from 40 to 80 percent.

- Among those who initiated group attendance, couples participated in about 21 total hours, on average.

- Most couples were contacted by program staff (such as family coordinators) outside group, but the average number of such contacts ranged from 1 to 8 contacts per month.

- The percentage of program group couples who received a referral to family support services was higher where contacts were made in person.

${ }^{20} \mathrm{It}$ is possible that group attendance rates may differ in later cohorts. A later analysis will examine and present participation data among couples enrolled after the current sample cutoff dates. 
Table VI.1. Percentage of BSF Program Couples Initiating Group Attendance Through January 31, 2007

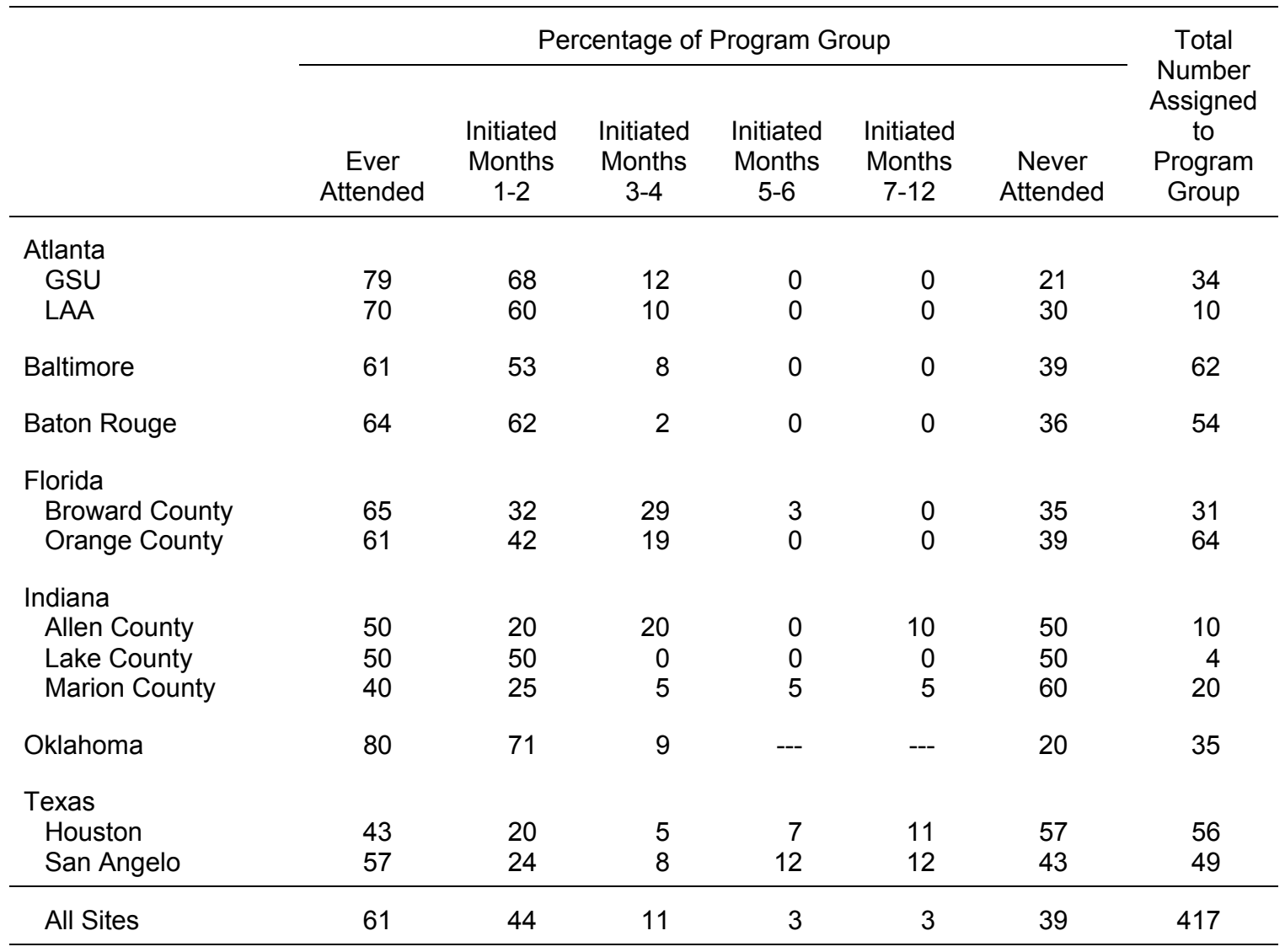

Source: MIS data collected by sites.

Notes: Denominator for all percentages is total number of couples randomly assigned to the program group. Initiated attendance is defined as either member of couple attending one or more group sessions during the observation period.

For all sites except Oklahoma, attendance is examined for couples randomly assigned to the program group June 1, 2005 to May 31, 2006, n = 382 (Cohorts 1 and 2). Each couple's attendance was examined for 8-12 months following their random assignment date. Due to its later enrollment start date, Oklahoma's sample is composed of couples randomly assigned to the program group from June 1, 2006 to September 30, 2006 (Cohort 3), and observed for four months.

Although lower than hoped, the rate at which couples ever attend BSF group sessions is similar to that reported by evaluators of standard marriage education interventions with middle-class couples. For instance, a report on the experimental evaluation of the Prevention and Relationship Enhancement Program (PREP) indicated that 50 percent of the couples who were assigned to receive the intervention did not participate at all (Markman et al. 1993), compared to 39 percent in BSF. Other researchers have anecdotally reported similar rates of no-shows. 
Most couples who began attending group sessions did so within the first four months following enrollment. Although many couples began attending group sessions within the first two months of enrollment (44 percent of enrollees, on average), a substantial proportion started during their third and fourth months after enrollment (11 percent). Even 5 to 12 months after random assignment, there was some further attendance initiation (6 percent). The couples starting group sessions very late after enrollment appear primarily in the Texas and Indiana locations.

Discussions with the Texas and Indiana sites suggest that during the earlier evaluation period, staff engaged participants in home visits for an extended period before scheduling them for and inviting them to a BSF group session. The sites assumed that this approach would result in greater group participation in later months, once staff had established a trusting relationship with the parents. This strategy may instead have inadvertently caused some couples to lose interest. These sites later implemented changes to ensure that couples are more promptly assigned to a curriculum group; future data should indicate whether this was an effective move.

BSF was successful in attracting the participation of couples rather than individual parents. Rates of group attendance were similar whether attendance was counted when only one partner attended, or only if both partners attended-indicating that most attendance involved couples together rather than individuals alone. For instance, 58 percent (compared to 61 percent) of the program group initiated attendance when only participation by couples was counted. This pattern was seen in nearly every site. This is a striking result, given that prior to BSF so little information was known about how to engage the participation of low-income unmarried couples. An earlier study of a similar program for unmarried couples had much higher rates of parents attending as individuals, but had placed less emphasis on couples' participation. ${ }^{21}$

\section{Among Initiators, Couples Averaged About 21 Hours of Group Sessions-Less Than Planned, but More Than Most Standard Marriage Education Programs}

The curricula used by BSF sites offer about 42 hours' worth of material, except for Oklahoma, which offers 30 hours. For most sites, the average couple that attended groups ended up receiving about half the total number of hours they were offered (Table VI.2). There is no basis for judging at this point whether that dosage is sufficient to achieve impacts on couples and children, but the average of 21 hours received by BSF participants exceeds the dosage maximum in other marriage education programs, including those that have demonstrated positive impacts on couple relationships and marriage. For example, PREP requires about 8 to 12 hours of instruction (Markman et al. 1993); Relationship Enhancement is typically provided over 8 to 14 hours (Guerney 1977); and the Couples

${ }^{21}$ The evaluation of Family Connections, a pilot program for low-income, unwed expectant parents and unmarried parents with a child under three years of age, indicated that only 31 percent of participation was attendance of couples together, and 69 percent was of individuals without their partners. (Adler-Baeder et al. 2004). 
Communication program takes about 8 hours to complete (Miller et al. 1976). Of course, the average BSF dosage of 21 hours was only received by those couples who initiated attendance, so the average dosage across the impact analysis sample as a whole is lower.

Table VI.2. Average Number of Hours Attended Group Sessions, Among Initiators

\begin{tabular}{|c|c|c|c|c|c|c|c|c|}
\hline & $\begin{array}{c}\text { Months } \\
1-2\end{array}$ & $\begin{array}{c}\text { Months } \\
3-4\end{array}$ & $\begin{array}{c}\text { Months } \\
5-6\end{array}$ & $\begin{array}{c}\text { Months } \\
7-8\end{array}$ & $\begin{array}{c}\text { Months } \\
9-10\end{array}$ & $\begin{array}{c}\text { Months } \\
11-12\end{array}$ & $\begin{array}{l}\text { Total } \\
\text { Hours }\end{array}$ & $\begin{array}{c}\text { Total N } \\
\text { (number } \\
\text { initiated } \\
\text { attendance) }\end{array}$ \\
\hline \multicolumn{9}{|l|}{ Atlanta } \\
\hline GSU & 5.6 & 7.3 & 7.2 & 1.5 & 0 & 0 & 21.6 & 53 \\
\hline LAA & 8.0 & 10.0 & 8.6 & 2.0 & 0 & 0 & 29.4 & 13 \\
\hline Baltimore & 6.2 & 5.1 & 3.8 & 1.2 & 1.3 & 1.6 & 19.1 & 64 \\
\hline Baton Rouge & 7.4 & 6.8 & 6.6 & 1.0 & 0 & 0 & 21.8 & 49 \\
\hline \multicolumn{9}{|l|}{ Florida } \\
\hline Broward County & 2.6 & 5.1 & 4.2 & 1.0 & 0 & 0 & 12.9 & 30 \\
\hline Orange County & 4.2 & 7.2 & 3.1 & 1.5 & 0 & 0 & 16.0 & 60 \\
\hline \multicolumn{9}{|l|}{ Indiana } \\
\hline Allen County & 2.5 & 6.5 & 7.2 & 9.6 & 0 & 0 & 25.8 & 8 \\
\hline Lake County & 6.9 & 7.1 & 5.0 & 0 & 0 & 0 & 19.0 & 7 \\
\hline Marion County & 5.1 & 9.6 & 8.3 & 5.3 & 0 & 0 & 28.2 & 14 \\
\hline Oklahoma & 15.6 & 8.7 & --- & -- & --- & --- & 24.3 & 28 \\
\hline \multicolumn{9}{|l|}{ Texas } \\
\hline Houston & 4.4 & 3.3 & 3.1 & 3.3 & 4.6 & 1.4 & 20.0 & 30 \\
\hline San Angelo & 3.4 & 7.1 & 6.4 & 3.5 & 3.2 & 1.6 & 25.1 & 46 \\
\hline All Sites & 5.8 & 6.6 & 5.1 & 2.1 & 1.7 & 0.8 & 20.7 & 402 \\
\hline
\end{tabular}

Source: MIS data collected by sites.

Notes: Hours were computed on the basis of attendance at scheduled sessions. Each attendance at a non-Oklahoma site is counted as two hours unless multiple modules were presented (one module is counted as two hours). Attendance at an Oklahoma 10-session group counted as three hours, and attendance at an Oklahoma six-session group counted as five hours. Make-up sessions conducted within a group session are included; make-ups provided to individual couples are not included (and are reflected in service contacts data). Table shows average hours for couples where one or both members of the couple attended at least once (initiators). Results were similar when counting attendances by both members of the couple (generally about an hour less on average).

Due to differences in the period available for observing attendance across cohorts, data from cohorts 1, 2, and 3 for all sites except Oklahoma were used to compute average hours for months one to four. Data from cohort 3 was used to compute average hours in the first four months for Oklahoma; no data are available thereafter for Oklahoma due to its late enrollment start date. For all other sites, data from cohorts 1 and 2 were used to compute averages for months 5-8, and data from cohort 1 was used to compute averages for months 9-12. 
The overall average of 21 total hours among initiators obscures substantial variation across sites, which ranged from 10 to 29 hours. The sites that had attendance below the all-site average of 21 hours included Houston, one Indiana location, and both the Florida locations. The highest total hours reported, on average, were at two of the Indiana locations and Atlanta LAA. Sites whose total average hours were around the all-site average included Baltimore, Baton Rouge, Atlanta GSU, San Angelo, and Oklahoma.

At most sites, the total average hours attended were fairly evenly distributed across the first six months of group sessions. On average, couples attended about six hours in the first two months, seven hours in the second two months, and five hours in the third two months (Table VI.2). Comparing sites reveals some variation in the distribution of hours over this period. As expected, the majority of time spent in group sessions in Oklahoma took place within the first two months, due to its format and overall shorter length.

About 16 percent of the full intervention group came close to or succeeded in completing the full curriculum, but completion rates varied dramatically-from 3 to 40 - percent across sites. The percentage of curriculum completed is computed based on the number of curriculum modules covered in sessions each couple attended, compared to the total number of modules in the site's curriculum (Table VI.3). The proportion of the experimental group that completed between 80 and 100 percent of the curriculum is highest in Oklahoma (40 percent), where couples can finish the curriculum in a relatively short time. It is the same in Atlanta LAA's, where the curriculum takes six months to complete, but for a very small sample. Baton Rouge and Atlanta GSU have the next highest rates of completion, at 30 and 23 percent, respectively.

Sites' group attendance rates generally declined over time, but not at a consistent rate. To learn whether group attendance declines over time, we organized group sessions (for all sites except Oklahoma) into four blocks of five sessions each. Counting attendance only when couples attend at least three out of five sessions in each block, we saw that the overall percentage attending regularly across sites generally declines from block to block. However, this is not the case in some sites such as Atlanta GSU, where attendance remains fairly constant across blocks, nor Baltimore, where attendance in the last block is less than half of the percentage attending in the first block, nor in Houston, where regular attendance falls precipitously after the first two session blocks. In some locations, like Orange County, attendance jumps in the second block and then declines dramatically in blocks three and four. Therefore, attrition patterns do not seem to be consistent across sites.

Most couples who attended group sessions were exposed to key curriculum content topics. To gain an understanding of the content that most attending couples received, we categorized each BSF curriculum by the major topic areas specified in the BSF model guidelines. Then we looked at the group attendance data to see how many couples got at least some exposure to each of the key content areas. 
Table VI.3. Percentage of Curriculum Received by Program Group

\begin{tabular}{|c|c|c|c|c|c|c|}
\hline & None & $\begin{array}{l}1 \% \text { to } \\
19.9 \%\end{array}$ & $\begin{array}{l}20 \% \text { to } \\
39.9 \%\end{array}$ & $\begin{array}{l}40 \% \text { to } \\
59.9 \%\end{array}$ & $\begin{array}{l}60 \% \text { to } \\
79.9 \%\end{array}$ & $\begin{array}{c}80 \% \text { to } \\
100 \%\end{array}$ \\
\hline \multicolumn{7}{|l|}{ Atlanta } \\
\hline GSU & 20 & 23 & 8 & 5 & 17 & 23 \\
\hline LAA & 30 & 10 & 0 & 0 & 20 & 40 \\
\hline Baltimore & 38 & 19 & 19 & 1 & 8 & 12 \\
\hline Baton Rouge & 35 & 21 & 7 & 4 & 0 & 30 \\
\hline \multicolumn{7}{|l|}{ Florida } \\
\hline Broward County & 35 & 29 & 16 & 12 & 3 & 3 \\
\hline Orange County & 39 & 25 & 12 & 9 & 6 & 7 \\
\hline \multicolumn{7}{|l|}{ Indiana } \\
\hline Allen County & 50 & 20 & 0 & 0 & 10 & 20 \\
\hline Lake County & 50 & 0 & 0 & 0 & 50 & 0 \\
\hline Marion County & 60 & 10 & 0 & 15 & 0 & 15 \\
\hline Oklahoma & 20 & 0 & 17 & 8 & 14 & 40 \\
\hline \multicolumn{7}{|l|}{ Texas } \\
\hline Houston & 57 & 10 & 16 & 7 & 5 & 3 \\
\hline San Angelo & 42 & 18 & 10 & 10 & 6 & 12 \\
\hline All Sites & 39 & 18 & 12 & 7 & 8 & 16 \\
\hline
\end{tabular}

Source: MIS data collected by sites.

Notes: Percentage of the curriculum is the total number of curriculum modules received by the program group, divided by the total modules in the curriculum. Usually one module topic was presented at each session, but sometimes extended sessions included multiple modules. To account for this, attendance data was matched with module topic data to capture instances where one meeting covers multiple topics. All non-Oklahoma sites have 21-topic modules in their curricula, and each module is usually equivalent to one session. Oklahoma has 34 topics; these were divided into its six- and 10-session groups. Attendance was counted when either member of the couple received the modules.

Percentages for all sites are based on cohorts 1 and 2, except Oklahoma which did not begin enrollment until cohort 3. All non-Oklahoma sites use a curriculum that lasts about six months. Cohorts 1 and 2 have observation periods of 12 and 8 months, respectively, allowing sufficient time for couples in these sites to complete the curriculum. Cohort 3 allows for four months of observation, allowing sufficient time for Oklahoma's curriculum which takes less than two months. 
The specific modules, and thus the content of material that couples were exposed to, was influenced by how often they attended, placement of the material in the sequence of modules, and how much emphasis each curriculum places on the topic-such as the number of sessions the curriculum offers in each area. We found that there are some differences by curriculum as shown in Figure VI.1. However, collapsing across curriculum types shows that three-quarters or more of attending couples received at least some instruction in the key areas of communication, conflict management, and affection/intimacy (Figure VI.2). A little more than half the couples received material on the topic of considering marriage, which was probably due to the late placement of this module in most curricula. ${ }^{22}$ The specific placement of topics in the curricula is probably the main reason couples were less likely to participate in sessions on post-partum depression and communicating about finances.

\section{Although Participants and Nonparticipants Are Similar on Most Baseline Characteristics, There Are a Few Significant Differences Between Groups}

Although most couples attend group sessions, a substantial number do not show up. Lack of participation is likely driven by multiple factors, some temporary, such as a change in shift at work, and others more persistent. To address whether participants and nonparticipants differ in their background characteristics, we analyzed information from the Baseline Information Form completed by all enrollees prior to any group participation (Tables VI.4, VI.5). In this analysis, participation is defined as both members of the couple having attended at least one session together, compared to those who did not attend any sessions as a couple.

Participants and nonparticipants are more similar than different. This analysis suggests that for most of the measured baseline characteristics at the individual- and couplelevel, such as race and ethnicity, earnings, and receipt of public assistance, participants and nonparticipants are similar. These results indicate there is not a clear "type" of person who does or does not attend BSF groups. BSF appears to be equally appealing to different racial and ethnic groups, and to families at varying levels of economic disadvantage. As suggested in the qualitative telephone interviews described above, most nonattendance may be driven by more ephemeral factors, such as illness or extra shifts at work, rather than substantial differences in many long-standing characteristics. Nevertheless, a few differences were found between participants and nonparticipants.

A handful of factors that suggest greater commitment and stability are associated with attendance. A few demographic factors, likelihood of marriage, and religious attendance are linked with ever attending a BSF group session.

${ }^{22}$ In the beginning of 2007, curriculum developers authorized adjustments to move the "considering marriage" module earlier in the curriculum sequence, but that change would not have affected most of the sample included in analyses reported here. 
Figure VI.1. Percentage of Couples Receiving Instruction in Topic Areas-By Curriculum

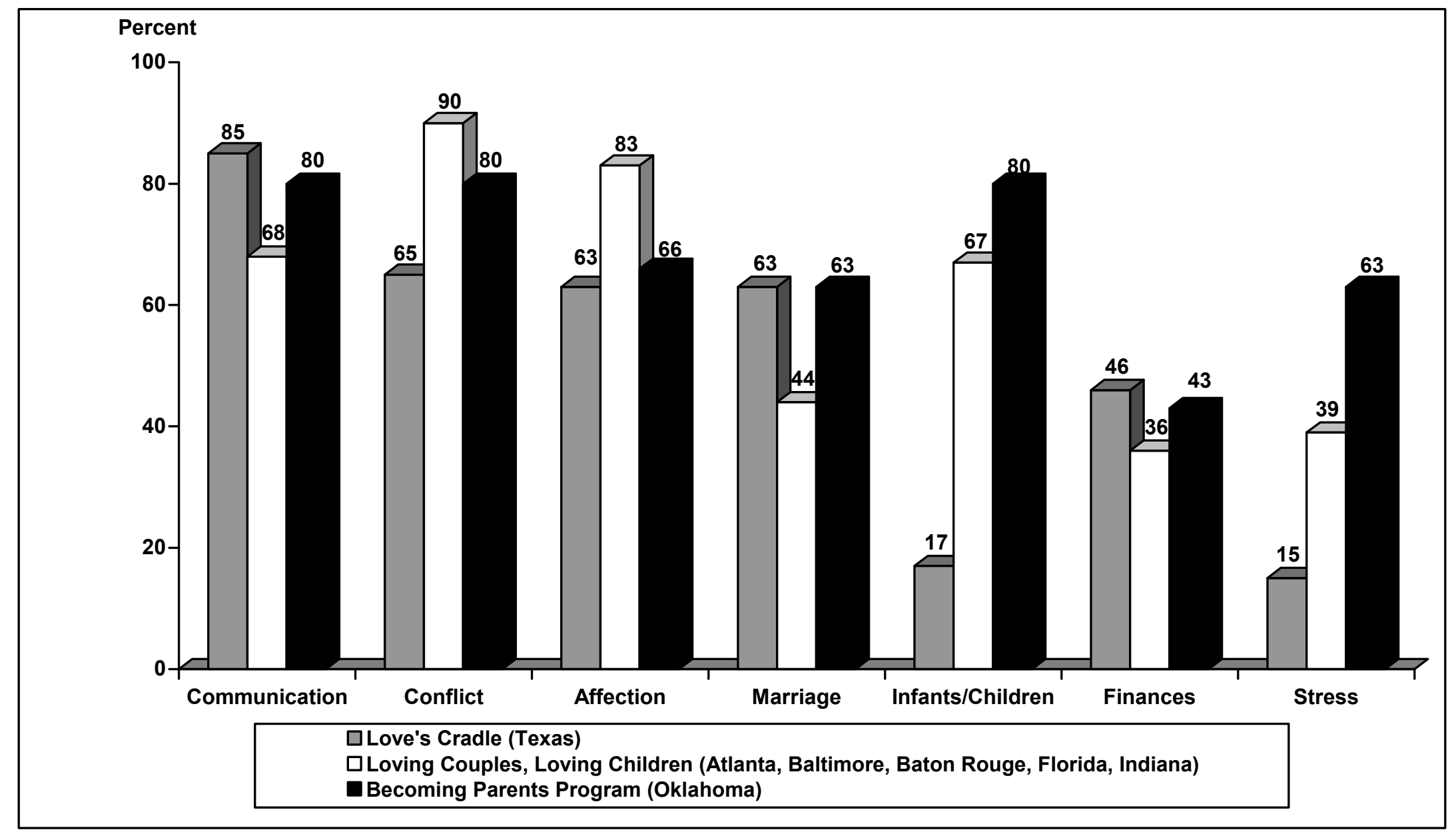

\section{Source: Program MIS data.}

Note: Denominator for all percentages is the number of couples in each site that attended at least one group session. The numerator is the number of couples who participated in at least one session within the topic area. 
Figure VI.2. Percentage of Couples Receiving Instruction in Curriculum Topic Areas-All Sites

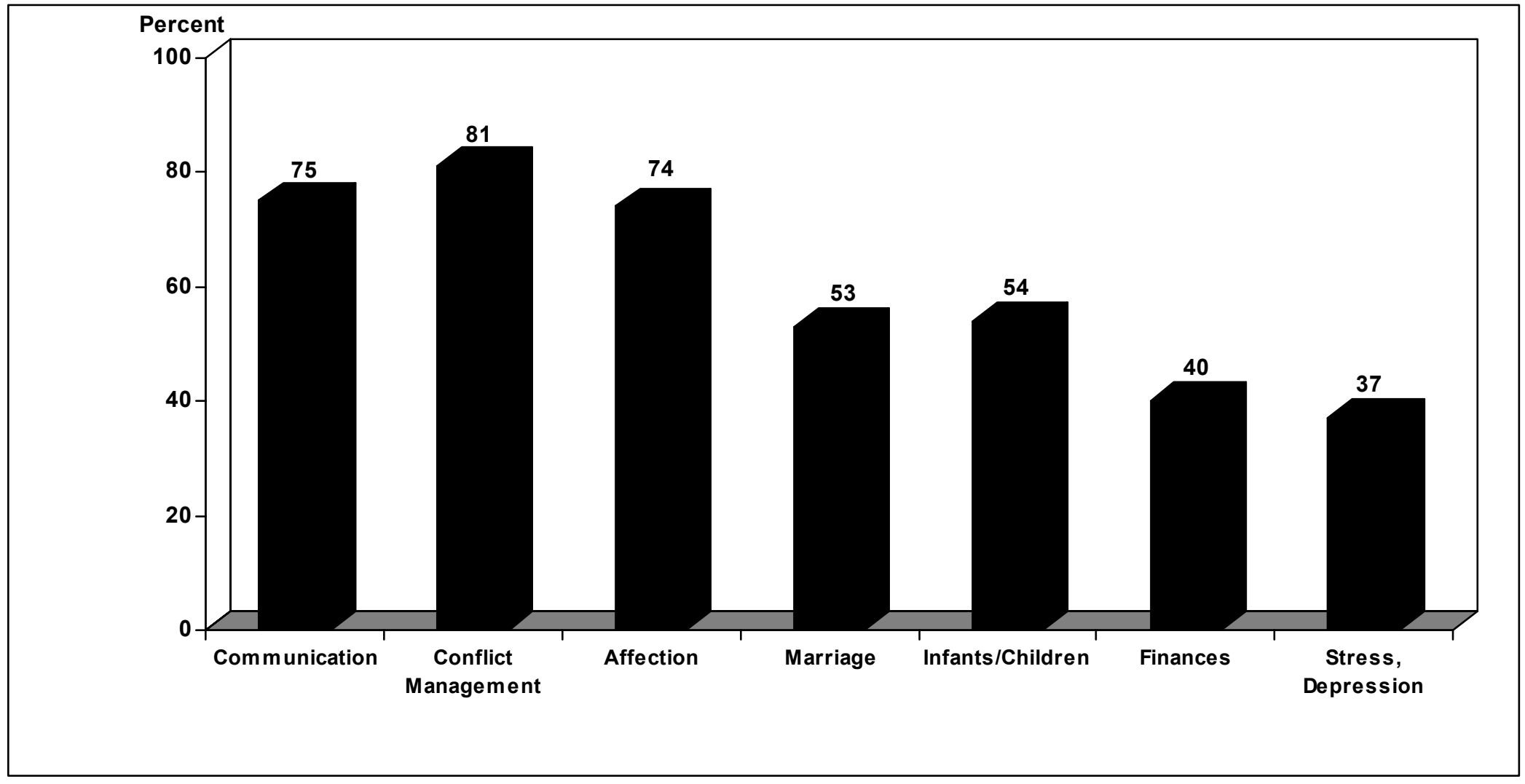

Source: Program MIS data.

Note: Denominator for all percentages is the number of couples in each site that attended at least one group session. The numerator is the number of couples who participated in at least one session within the topic area 
Table VI.4. Individual-Level Baseline Characteristics of BSF Treatment Group, by Attendance Status

\begin{tabular}{|c|c|c|c|}
\hline & $\begin{array}{l}\text { Attended at } \\
\text { Least One } \\
\text { Session } \\
\text { Together }\end{array}$ & $\begin{array}{l}\text { Did Not Attend } \\
\text { Any Sessions } \\
\text { Together }\end{array}$ & $\begin{array}{c}\text { Statistical } \\
\text { Significance }^{\mathfrak{f}}\end{array}$ \\
\hline \multicolumn{4}{|l|}{ Demographics } \\
\hline $\begin{array}{l}\text { Age (Percentage) } \\
\text { Less than } 20 \\
20 \text { to } 24 \\
25 \text { to } 29 \\
30 \text { to } 34 \\
35 \text { to } 39 \\
40 \text { and older }\end{array}$ & $\begin{array}{r}17 \\
46 \\
21 \\
9 \\
6 \\
2\end{array}$ & $\begin{array}{r}17 \\
48 \\
23 \\
7 \\
3 \\
3\end{array}$ & * \\
\hline $\begin{array}{l}\text { Race and Ethnicity (Percentage) } \\
\text { African American } \\
\text { Hispanic } \\
\text { White } \\
\text { Other }\end{array}$ & $\begin{array}{r}58 \\
27 \\
13 \\
2\end{array}$ & $\begin{array}{r}56 \\
28 \\
13 \\
3\end{array}$ & ns \\
\hline $\begin{array}{l}\text { Primary Language (Percentage) } \\
\text { English } \\
\text { Spanish } \\
\text { Other }\end{array}$ & $\begin{array}{l}87 \\
12 \\
0.9\end{array}$ & $\begin{array}{r}83 \\
15 \\
2\end{array}$ & * \\
\hline \multicolumn{4}{|l|}{ Socioeconomic Status } \\
\hline High School Diploma or GED (Percentage) & 71 & 64 & ** \\
\hline Currently Employed (Percentage) & 54 & 54 & ns \\
\hline $\begin{array}{l}\text { Earnings Past } 12 \text { Months } \\
\text { No earnings } \\
\$ 1 \text { to } 15,000 \\
\$ 15,000 \text { to } \$ 24,999 \\
\$ 25,000 \text { to } \$ 34,999 \\
\$ 35,000 \text { or more }\end{array}$ & $\begin{array}{r}15 \\
57 \\
19 \\
5 \\
4\end{array}$ & $\begin{array}{r}17 \\
55 \\
21 \\
5 \\
2\end{array}$ & ns \\
\hline $\begin{array}{l}\text { Receive Any Public Assistance (Percentage) } \\
\text { Cash welfare/TANF } \\
\text { Food stamps } \\
\text { Medicaid/SCHIP } \\
\text { SSI or SSDI } \\
\text { WIC } \\
\text { Unemployment compensation }\end{array}$ & $\begin{array}{r}60 \\
7 \\
26 \\
47 \\
5 \\
48 \\
3\end{array}$ & $\begin{array}{r}57 \\
7 \\
26 \\
46 \\
4 \\
47 \\
3\end{array}$ & ns \\
\hline \multicolumn{4}{|l|}{ Family Structure } \\
\hline $\begin{array}{l}\text { Marriage and Cohabitation (Percentage) } \\
\text { Married to current partner }{ }^{\mathrm{a}} \\
\text { Unmarried, cohabiting all or most of the time } \\
\text { Unmarried, cohabiting some of the time } \\
\text { Unmarried, not cohabiting }\end{array}$ & $\begin{array}{r}6 \\
73 \\
13 \\
8\end{array}$ & $\begin{array}{r}4 \\
74 \\
12 \\
10\end{array}$ & ns \\
\hline Multiple Partner Fertility (Percentage) & 31 & 30 & ns \\
\hline $\begin{array}{l}\text { Number of Children (Total) } \\
\text { Number of children in common } \\
\text { Number of children with other partners }\end{array}$ & $\begin{array}{l}1.9 \\
1.3 \\
0.5\end{array}$ & $\begin{array}{l}2.0 \\
1.4 \\
0.5\end{array}$ & ns \\
\hline
\end{tabular}




\begin{tabular}{|c|c|c|c|}
\hline & $\begin{array}{l}\text { Attended At } \\
\text { Least One } \\
\text { Session } \\
\text { Together }\end{array}$ & $\begin{array}{l}\text { Did Not Attend } \\
\text { Any Sessions } \\
\text { Together }\end{array}$ & $\begin{array}{c}\text { Statistical } \\
\text { Significance }^{f}\end{array}$ \\
\hline \multicolumn{4}{|l|}{ Pregnancy and Birth } \\
\hline $\begin{array}{l}\text { Mother Is Pregnant } \\
\text { Focal Child's Age, Months (if Born) } \\
\text { Birth Intended (Percentage) }\end{array}$ & $\begin{array}{r}55 \\
1.1 \\
37\end{array}$ & $\begin{array}{r}50 \\
1.1 \\
39\end{array}$ & $\begin{array}{l}\text { ns } \\
\text { ns } \\
\text { ns }\end{array}$ \\
\hline \multicolumn{4}{|l|}{ Couple Relationship } \\
\hline $\begin{array}{l}\text { Time Known One Another (Years) } \\
\text { Relationship Quality } \\
\text { High Chance of Marriage (Percentage) }\end{array}$ & $\begin{array}{r}3.3 \\
25.6 \\
72\end{array}$ & $\begin{array}{r}3.5 \\
25.3 \\
67\end{array}$ & $\begin{array}{l}\mathrm{ns} \\
\mathrm{ns} \\
*\end{array}$ \\
\hline \multicolumn{4}{|l|}{ Attitudes About Marriage and Parenting ${ }^{c}$} \\
\hline $\begin{array}{l}\text { Believes a Single Parent Can Bring Up a Child as Well as } \\
\text { a Married Couple } \\
\text { Believes it is Better for Children if Their Parents are } \\
\text { Married }\end{array}$ & 1.8 & 1.8 & ns \\
\hline \multicolumn{4}{|l|}{ Mental Health, Social Support, and Religion } \\
\hline $\begin{array}{l}\text { Distress Level } \\
\quad \text { High distress (Percentage) }\end{array}$ & $\begin{array}{r}5.8 \\
9\end{array}$ & $\begin{array}{r}5.5 \\
8\end{array}$ & ns \\
\hline $\begin{array}{l}\text { Social Support (Percentage) } \\
\text { Emergency child care available } \\
\text { Could borrow } \$ 100 \text { from someone }\end{array}$ & $\begin{array}{l}94 \\
87\end{array}$ & $\begin{array}{l}94 \\
90\end{array}$ & $\begin{array}{l}\mathrm{ns} \\
\mathrm{ns}\end{array}$ \\
\hline Frequency of Religious Attendance ${ }^{\mathrm{e}}$ & 2.3 & 2.2 & * \\
\hline Number of Observations & 772 & 674 & \\
\hline
\end{tabular}

Source: $\quad$ BSF Baseline Information Form, couples randomly assigned to the treatment group by September 30, 2006. To minimize any bias that might result from some couples having more opportunities to participate than others (depending on their enrollment date), we restrict the sample to couples who have had at least four months but no more than 12 months in which to begin attending groups. Most couples who attend any groups usually do so within the first four months.

${ }^{\mathrm{a}}$ In addition to unmarried couples, those who married post-conception were also eligible for BSF.

${ }^{b}$ Range from 8 to 32 , with higher numbers indicating better reported relationship quality.

${ }^{c}$ Attitudes measured on a scale where 1 = strongly agree, 2 = agree, $3=$ disagree, $4=$ strongly disagree.

${ }^{d}$ Kessler et al. (2003) indicate that the optimal cut-point for detecting serious mental illness is a score of 13 or higher.

${ }^{\mathrm{e}}$ Response options were: 1 = never, 2 = few times a year, 3 = few times a month, 4 = once a week or more.

${ }^{f}$ The statistical significance of age, race, primary language, earnings, and marriage/cohabitation status tested with chi-square tests.

All other significance level based on two-tailed t-tests.

${ }^{* *} p<0.01,{ }^{*} p<0.05$, ns $=$ not significant. 
Table VI.5. Couple-Level Baseline Characteristics of Treatment Group, by Attendance Status

\begin{tabular}{|c|c|c|c|}
\hline & $\begin{array}{l}\text { Attended At } \\
\text { Least One } \\
\text { Session } \\
\text { Together }\end{array}$ & $\begin{array}{l}\text { Did Not Attend } \\
\text { Any Sessions } \\
\text { Together }\end{array}$ & $\begin{array}{c}\text { Statistical } \\
\text { Significance }^{b}\end{array}$ \\
\hline \multicolumn{4}{|l|}{ Demographics } \\
\hline More than 10 Year Age Difference (Percentage) & 8 & 7 & ns \\
\hline $\begin{array}{l}\text { Race and Ethnicity (Percentage) } \\
\text { Both African American } \\
\text { Both Hispanic (any race) } \\
\text { Both white } \\
\text { Both other } \\
\text { Partners of different races/ethnicities }\end{array}$ & $\begin{array}{c}53 \\
21 \\
9 \\
8 \\
15\end{array}$ & $\begin{array}{c}53 \\
24 \\
10 \\
1 \\
12\end{array}$ & ns \\
\hline $\begin{array}{l}\text { Primary Language (Percentage) } \\
\text { Both speak English } \\
\text { Only mother speaks English } \\
\text { Only father speaks English } \\
\text { Neither speak English }\end{array}$ & $\begin{array}{c}85 \\
3 \\
2 \\
10\end{array}$ & $\begin{array}{c}80 \\
4 \\
1 \\
14\end{array}$ & ns \\
\hline \multicolumn{4}{|l|}{ Socioeconomic Status } \\
\hline $\begin{array}{l}\text { High School Diploma or GED (Percentage) } \\
\text { Both completed } \\
\text { Only mother completed } \\
\text { Only father completed } \\
\text { Neither completed }\end{array}$ & $\begin{array}{l}56 \\
16 \\
14 \\
14\end{array}$ & $\begin{array}{l}48 \\
16 \\
15 \\
21\end{array}$ & ns \\
\hline $\begin{array}{l}\text { Currently Employed (Percentage) } \\
\text { Both employed } \\
\text { Only mother employed } \\
\text { Only father employed } \\
\text { Neither employed }\end{array}$ & $\begin{array}{c}25 \\
4 \\
55 \\
16\end{array}$ & $\begin{array}{c}21 \\
8 \\
57 \\
14\end{array}$ & ns \\
\hline $\begin{array}{l}\text { Earnings (Percentage) } \\
\quad \text { No earnings } \\
\$ 1 \text { to } \$ 15,000 \\
\$ 15,000 \text { to } \$ 24,999 \\
\$ 25,000 \text { to } \$ 34,999 \\
\$ 35,000 \text { or more }\end{array}$ & $\begin{array}{l}3 \\
34 \\
28 \\
18 \\
17\end{array}$ & $\begin{array}{c}3 \\
33 \\
26 \\
21 \\
17\end{array}$ & ns \\
\hline \multicolumn{4}{|l|}{ Family Structure } \\
\hline $\begin{array}{l}\text { Multiple Partner Fertility } \\
\text { Both partners have children from other relationships } \\
\text { Only mother has child(ren) from other relationships } \\
\text { Only father has child(ren) from other relationships } \\
\text { Neither have children from other relationships }\end{array}$ & $\begin{array}{l}15 \\
18 \\
16 \\
52\end{array}$ & $\begin{array}{l}13 \\
18 \\
15 \\
53\end{array}$ & ns \\
\hline Number of Couples & 386 & 337 & \\
\hline
\end{tabular}

Source: BSF Baseline Information Form, couples randomly assigned to the program group by September 30, 2006.

${ }^{a}$ Earnings are calculated based on summing the midpoint of the reported category for mothers and fathers. This is not necessarily a measure of household income since not all couples live together, but represents an estimate of both parents' income that may be available to the focal child.

${ }^{b}$ With the exception of age difference, statistical significance is calculated with a chi-square test. The statistical significance of the age difference is based on a two-tailed t-test.

${ }^{* *} p<0.01,{ }^{*} p<0.05$, ns $=$ not significant. 
- Having a high school education, speaking English as a primary language, and age are related to attendance status. Age, speaking English as a primary language, and having at least a high school diploma are all associated with having attended at least one session. Although measures of current economic well-being are not associated with attendance, education appears to matter.

- Belief that marriage is likely is more strongly associated with attendance than other characteristics of the family or relationship. A priori, we might expect that couples in more committed or stable relationships would be more likely to attend BSF groups than others. For most measures of family structure and the couple relationship, however, those who attend and those who never attend are similar. There are no significant differences between the groups on cohabitation status, multiple partner fertility, time know one another or relationship quality. The one exception is the belief that the individual is likely to marry their BSF partner.

- Religious attendance may be a marker of beliefs and stability. Frequency of religious attendance is one of the few variables associated with participation status, though the difference between groups is small (2.3 versus 2.2 ; where $2=$ attend a few times a year and $3=$ attend a few times a month).

\section{B. INDIVIDUAL CONTACT WITH FAMILy COORDINATORS AND OTHER STAFF}

In addition to their attendance at the group sessions, couples were expected to have individual-level interactions with program staff over a sustained period. This program contact was usually with family coordinators, but could also be with facilitators outside group sessions, or with other staff fulfilling the family coordinator role. The contact with BSF staff was intended to encourage couples to attend the group sessions, reinforce the relationship skills being taught and provide emotional support, and assess and link family members to other support services.

Information about program contact with couples outside the group sessions was recorded by site staff in their case management information systems. Four sites (Atlanta, Baltimore, Baton Rouge, and Texas) used the web-based BSF Information System (BSFIS) developed by the evaluation team. Three sites (Florida, Indiana, and Oklahoma) each used their own preexisting systems. Differences among these four systems, as well as adherence to data entry conventions across BSFIS programs, narrowed the range of information that could be collected consistently across sites. Two questions can, however, be clearly addressed: How much contact did couples have with BSF staff outside their attendance at group sessions? To what extent did these contacts involve both partners? 


\section{A Very High Percentage of Couples Had Contact with Program Staff}

The rate at which site staff were in contact with couples outside groups was generally quite high (Table VI.6). In most sites, between 80 and 100 percent of couples enrolled through a particular cutoff date in spring 2007 had had at least one contact with program staff. $^{23}$

Program staff had varying objectives in contacting couples outside of group sessions. Contacts were recorded when a couple met face-to-face with program staff, but in some cases also when staff had a brief telephone conversation just to remind a couple to attend group. The percentage contacted thus reflects the level of staff involvement in both promoting participation and in substantive interaction with couples.

\section{The Average Frequency and Mode of Contact Partly Reflect the Ways in Which Sites Set Up the Family Coordinator Component}

The sites that built BSF onto the Healthy Families home visiting service-Florida, Indiana, and Texas-had the highest average number of monthly contacts. ${ }^{24}$ These contacts included home visits, which to a large extent focused on delivering the Healthy Families parenting and child development curriculum and may often have had only tangential connection to BSF activities or topics.

In most sites that did not plan to conduct home visits on a structured and regularly scheduled basis (Atlanta, Baltimore, Baton Rouge) average contact rates were considerably lower, but they reflect contact specifically related to BSF activities and goals. It is possible to maintain high levels of contact even without a weekly home visiting regimen. In Oklahoma, where family coordinators were expected to meet regularly with couples in the program office, couples had an average of 4 contacts per month with BSF staff, although it is unclear how often these contacts were with one or both members of the couple.

The mode of contact also reflects the sites' organization of their programs and their plans for implementing the family coordinator component. In Healthy Families sites, about one-third to one-half of program contacts were home visits. Home visiting was similarly frequent in Atlanta LAA. The remaining sites (Baltimore, Baton Rouge, and Atlanta GSU) relied most heavily on telephone contact, reflecting their decision to make most individual in-person contact on an as-needed basis. With its regular schedule for meeting with couples at the program office, Oklahoma had the highest rate of contacting couples in this way.

\footnotetext{
${ }^{23}$ See notes to Table VI.4 for a description of the dates of data extracts used in this analysis.

${ }^{24}$ Average monthly contacts were computed across all couples, whether or not they had ever attended a group session or had any contact with program staff outside groups.
} 
Table VI.6. Contacts with Program Staff Outside Group Sessions

\begin{tabular}{|c|c|c|c|c|c|c|c|c|c|c|c|c|}
\hline & \multicolumn{2}{|c|}{ Atlanta } & \multirow[b]{2}{*}{ Baltimore } & \multirow[b]{2}{*}{$\begin{array}{l}\text { Baton } \\
\text { Rouge }\end{array}$} & \multicolumn{2}{|c|}{ Florida } & \multicolumn{3}{|c|}{ Indiana } & \multirow[b]{2}{*}{ Oklahoma } & \multicolumn{2}{|c|}{ Texas } \\
\hline & GSU & LAA & & & $\begin{array}{c}\text { Broward } \\
\text { County }\end{array}$ & $\begin{array}{l}\text { Orange } \\
\text { County }\end{array}$ & $\begin{array}{l}\text { Allen } \\
\text { County }\end{array}$ & $\begin{array}{l}\text { Lake } \\
\text { County }\end{array}$ & $\begin{array}{l}\text { Marion } \\
\text { County }\end{array}$ & & Houston & $\begin{array}{l}\text { San } \\
\text { Angelo }\end{array}$ \\
\hline $\begin{array}{l}\text { Ever Contacted }^{a} \\
\text { (Percentage) }\end{array}$ & 82 & 96 & 100 & 98 & 84 & 91 & 100 & 91 & 100 & 100 & 100 & 100 \\
\hline $\begin{array}{l}\text { Average Number of } \\
\text { Monthly Contacts Per } \\
\text { Couple }^{\text {b }}\end{array}$ & 2.4 & 1.0 & 1.6 & 1.6 & 4.2 & 5.1 & 7.8 & 4.1 & 4.4 & 4.3 & 4.0 & 5.2 \\
\hline \multicolumn{13}{|l|}{$\begin{array}{l}\text { Average Number of } \\
\text { Monthly Contacts } \\
\text { with }^{c}\end{array}$} \\
\hline Both parents & 2.2 & 0.2 & 1.1 & 0.5 & 0.8 & 1.4 & 3.8 & 1.3 & 1.5 & $\mathrm{~N} / \mathrm{A}$ & 0.7 & 2.2 \\
\hline Mother only & 0.2 & 0.6 & 0.4 & 0.8 & 2.9 & 3.1 & 3.6 & 2.8 & 2.8 & $N / A$ & 3.2 & 2.4 \\
\hline Father only & 0.1 & 0.2 & 0.1 & 0.3 & 0.3 & 0.5 & 0.4 & --- & 0.1 & $N / A$ & 0.2 & 0.5 \\
\hline \multicolumn{13}{|l|}{$\begin{array}{l}\text { Percentage of } \\
\text { Contacts by }\end{array}$} \\
\hline Telephone & 84 & 57 & 61 & 62 & 41 & 33 & 34 & 48 & 44 & 71 & 43 & 29 \\
\hline Home visit & 3 & 40 & 17 & 7 & 48 & 44 & 39 & 42 & 44 & $N / A$ & 53 & 51 \\
\hline Program office visit & 0 & 1 & 11 & 16 & $N / A$ & N/A & N/A & N/A & N/A & 25 & 0 & 1 \\
\hline Social events & 1 & 0 & 3 & 1 & $N / A$ & $\mathrm{~N} / \mathrm{A}$ & $\mathrm{N} / \mathrm{A}$ & $\mathrm{N} / \mathrm{A}$ & $\mathrm{N} / \mathrm{A}$ & $\mathrm{N} / \mathrm{A}$ & 0 & 2 \\
\hline Other & 12 & 2 & 9 & 14 & 11 & 23 & 27 & 11 & 13 & 4 & 3 & 17 \\
\hline $\begin{array}{l}\text { Percentage of } \\
\text { Couples Receiving } \text { Referral }^{\mathrm{e}}\end{array}$ & 3 & 26 & 27 & 25 & 62 & 75 & 64 & 76 & 87 & 61 & 56 & 40 \\
\hline $\begin{array}{l}\text { Total Number of } \\
\text { Couples in Sample }\end{array}$ & 164 & 42 & 197 & 157 & 81 & 126 & 28 & 19 & 63 & 75 & 116 & 114 \\
\hline
\end{tabular}

Sources: MIS data collected by sites. Data include all couples randomly assigned to the program group from the beginning of each site's evaluation sample enrollment to the following dates: Atlanta, Baltimore, Baton Rouge, Texas: April 13, 2007; Florida: January 31, 2007; Indiana: March 9, 2007; and Oklahoma: January 12, 2007. Data include all contacts, for couples meeting the above requirements, through: Atlanta, Baltimore, Baton Rouge, Texas: June 13, 2007; Florida: March 31, 2007; Indiana: May 9, 2007; and Oklahoma: March 12, 2007. This two-month contact window allows sites time to establish contact with couples after random assignment.

Notes: In Indiana, couples could be contacted by BSF staff or by Healthy Families (HF) staff.

N/A = Data not available

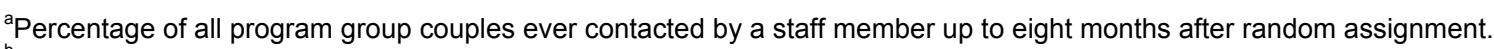

${ }^{6}$ Total number of contacts within eight months of random assignment, divided by the sum of the number of months each couple was in the sample, within the eight-month window.

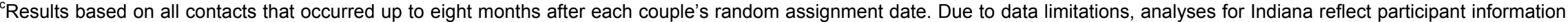
for home visits only. Percentages may not sum to 100 due to rounding.

'Percentage of all contacts within eight months of random assignment that were made using various modes. Percentages may not sum to 100 due to rounding. The definitions of 'Other' differs somewhat with each data set; it may include such activities as providing transportation for a referral, sending a letter, or social events that other data sets can capture in more specific categories.

e Multiple referrals may be provided during a single service contact. Results based on all contacts that occurred up to eight months after each couple's random assignment date. 


\section{In Most Sites, About One-Third to One-Half of All Contacts Were with Both Parents Together}

The BSF program was designed to focus its intervention and services on couples. The group sessions were intended to engage couples, not just individuals, and the objective was to use contacts outside of group sessions to encourage both partners and connect them both to support services they might need.

Sites varied in their frequency of overall contact with couples outside group sessions, so they also varied in how often they succeeded in engaging both partners together in contacts (Table VI.4). Sites did not all adhere to consistent practices for recording contacts; in some cases staff were scrupulous about recording every reminder telephone call that might have involved just one parent, while in other sites staff were more likely to record primarily "substantive" in-person or telephone conversations. Despite this "noise" in the data, some patterns are evident in the data. First, although Healthy Families sites conducted many of their contacts with only the mother, some of them still managed among the highest monthly numbers of contacts with both partners together. Many home-visit contacts in these sites, however, may end up being held with only the mother, particularly if visits must be conducted during normal work-day hours when an employed father cannot be present. Second, even in sites that were not focused on home visits, a substantial share of contacts end up being with one partner, usually the mother. It is important to remember, however, that many one-parent contacts may have been simple reminders to attend a group session.

\section{Assessment AND RefERrals to FAMILy Support SERVICES}

Linking couples to family services is the third component of the BSF model, to be carried out largely by family coordinators. Most communities have a variety of services available, often targeted at the populations served by BSF programs. However, BSF participants may not be aware of these services or may be hesitant or unable to access them. BSF programs are expected to assess couples for their needs and refer them to appropriate services. Staff, and FCs in particular, are expected to know what services are available to address employment and education needs, mental health or substance abuse, domestic violence, or problems with child care, transportation or housing. Some of these services may be available in-house at the BSF sponsor agencies, but more often they can be tapped only through contact with an outside service agency.

The extent to which sites made referrals can be gleaned from the information they recorded on contacts with couples, although variation in site coding practices makes this picture somewhat imprecise. Sometimes staff provided referrals or service information informally (for example, before or after group sessions), and staff may mention services or provide brochures or other information, but not consider this a referral. Unless they make a more formal written referral or possibly contact the agency or service in question, staff may not enter information about the referral into their MIS. For these reasons, the results on referrals may understate the frequency that couples are linked with services. 
The number of recorded referrals varied sharply, however, in ways that suggest how often contacts were made in person (Table VI.4). The Healthy Families sites in Florida, Indiana, and Texas clearly made substantial use of referrals, perhaps because their scheduled home visits gave frequent opportunities to uncover issues requiring attention. Although Oklahoma did not use home visiting, it regularly met with couples in the program office and achieved a high referral rate. Baton Rouge, Baltimore, and Atlanta LAA had lower rates of recorded referrals (around 25\% of couples), with Atlanta GSU having the lowest numbers of both in-person contact and recorded referrals. 


\section{H A P T E R V I I}

\section{OUPLES' EXPERIENCES AN D PERCEPTION O O THE BSF PROGRAM}

$\mathrm{M}$ uch of this report relies on data collected from or recorded by program staff, but some questions can only be answered by program participants. What did they think of the services they received? What were their expectations of the program? What kinds of skills did they learn? Do they think the program had any effect on their relationships? What did they value most and least about BSF? What motivated them to attend program activities, or if they did not attend, why not? These questions are important because the long-term success of the program is largely dependent on couples finding the groups helpful and appealing. The answers to these questions can provide insights into how low-income unmarried couples experience a service heretofore unavailable to this population. Do they feel that they are being told what to do with their lives? Or do they feel supported in their relationships, encouraged to work out their issues, and enter marriage when they are ready?

This chapter rounds out our information on how BSF sites implemented their programs by exploring how couples in the program group experienced the services. In interviews and focus groups with couples we asked about their expectations of BSF, reactions to the group sessions, reasons for attending or missing sessions, views of the assistance provided by family coordinators, and perceptions of the program's benefits. First we describe the experiences and perceptions of participating couples in the main component of the program - the marriage education groups. Next, we explore why some couples did not attend any group sessions, and why others started to attend but disengaged after attending no more than two sessions, to uncover the inducements and barriers to participation in BSF.

\section{A. Participants' Reactions to BSF Services}

To investigate the motivation of BSF couples and learn about their experiences, we conducted focus groups with participants - couples who had participated in at least three sessions of a group that had met five or more times. Participants who met this criterion were randomly selected from the program sample at each of the BSF sites and invited to a focus group in each of the seven sites, and in most cases, multiple locations within sites. 
Thirteen focus group discussions were held in all, with 145 participants. Each group had between 6 to 18 participants, in most cases couples with both members attending.

The focus group sample was similar to the overall sample of enrolled BSF couples in race/ethnicity, but somewhat more educated. Approximately 55 percent of the focus group sample was African American, 30 percent Hispanic, 10 percent White, and 6 percent of other race/ethnicities. About 76 percent of the focus group sample had at least a high school diploma compared to 66 percent of the evaluation sample, and approximately 64 percent of the focus group sample was working full- or part-time compared to 52 percent of the evaluation sample. Seventy-two percent of the focus group participants were between 21 and 30 years of age.

The couples who took part in the focus groups were on average in more settled relationships than was true of the overall sample at baseline. Focus group participants were, for example, more likely to be married by the time of the focus group ( 27 percent) than the BSF sample was at baseline (6 percent). A total of 94 percent of focus group participants were either cohabiting, married, or said they were "getting married soon." At baseline, 78 percent of couples described themselves as cohabiting (all or most of the time) or married.) Although some change may have occurred since baseline in these particular couples' relationships, we also know that not everyone who was randomly chosen for the focus groups actually participated, so these differences could simply be a result of self-selection.

KEY FINDINGS ON COUPLES’ EXPERIENCES AND PERCEPTIONS

- Prior to the start of BSF, many couples had difficulties with communication and managing conflict and anger, which often led to escalating arguments.

- Most couples had high hopes for the program, anticipating it would improve their relationship and parenting skills.

- Some couples were excited to start the program, while others were skeptical.

- Couples were enthusiastic about most aspects of the group sessions, particularly the facilitators and interacting with other couples.

- Most of the reasons for occasional absences from sessions were related to work or personal situations, such as illness in the family.

- Couples had few suggestions for improvements to the program, and the suggestions given reflected their positive experience, such as extending the length of the group sessions.

- Focus group participants perceived that BSF helped them improve their communication skills and ultimately, their relationships with their partners and their children. 


\section{Many Couples Had High Expectations of the Program, but Were Nervous Prior to Participating in Group Sessions}

The focus group participants were asked to think back to when they first enrolled in BSF but had not yet begun attending group sessions, and to describe their relationship and expectations, hopes, and concerns about the program.

In general, couples described their relationships prior to enrollment as burdened by problems with communication, trust, and managing conflict and anger. The most common problem was trouble with communication. They had difficulty understanding their partner's perspective, and conveying their own. Many also struggled with trusting their partner. These issues, combined with difficulty managing conflict and anger, sometimes led to explosive arguments. One man described punching walls, another leaving home for weeks at a time when he got angry.

After hearing about BSF, couples hoped that participating in the program would strengthen their relationship, improve communication, and bring them closer. One woman who had married post-conception explained, "I didn't get married to get divorced. I wanted as much help as possible." Another indicated that her relationship with her boyfriend was unstable, including a recent break up after becoming pregnant, and felt the program was her last chance at keeping her family together. In a different group, one couple said they wanted to learn how to get along with each other to avoid a separation. Another couple said they came to do exactly what the program name said-build a stronger family. Couples hoped that BSF would improve their relationships and help them learn how to keep going.

Although help for their relationships was most often the primary motivation for attending the program, the opportunity to receive assistance with other aspects of their lives, such as information about parenting or employment resources, also appealed to the participants. Many couples hoped to learn about child development and improve their parenting, particularly first-time parents. Other resources, such as employment assistance or help with housing, were also attractive. The participants that mentioned these resources were often at sites that had a history offering these services. In the Baltimore site, for instance, where the BSF sponsor had its roots in employment services, participants noted that the availability of these job resources were part of the program's appeal.

Despite their high expectations for the program, many described initial concerns and hesitation about participating. Some described feelings of nervousness or shyness, or seemed to lack confidence. The most common concern was a worry about sharing personal information with strangers. Participants recalled anxiety about airing their "dirty laundry," or "putting their business in the street," while others had worried that they would say the wrong thing or not fit in with the other couples. One person had been afraid the group would be "touchy-feely," another that the groups were for "crazy" people.

Some men, in particular, had concerns before they actually experienced the group sessions. Several said their partner "made" them attend despite their initial reluctance. Some feared it would turn out to be a "counseling" program. One man said "I thought they 
were going to judge us," and another said, "I thought they would want to know personal stuff."

Participants who expressed initial concerns about the groups-including menbecame more comfortable after experiencing a few sessions. Most said that after seeing what the group was like, they relaxed and were able to "let go" and fully participate in the sessions. Some credited the staff with creating a comfortable atmosphere and assuaging their fears. The men who had suggested their partners "made" them go, admitted they were glad they had attended the group sessions and began to look forward to them.

Focus group participants indicated that while intriguing, the idea of a program to support marriage and relationships was unfamiliar. Some initially thought the program might involve therapy or counseling, or feared that the programs would tell them how to run their lives. Once couples experienced the group sessions and found that they provide information and skills that can be applied as needed, they tended to relax and be able to participate.

\section{Participating Couples Found the Group Sessions Appealing and Typically Attended Whenever Possible}

To achieve sustained participation over the long term, participants need to find the groups appealing and feel comfortable with staff and other participants. To explore which program features they enjoyed or did not like, participants were asked for their perceptions of the various components of group sessions. For the most part, they were satisfied with numerous aspects of the groups, attended when possible, and had few suggestions for changes.

Couples cited the group discussions and hands-on exercises as the most helpful teaching methods in the group sessions. Not all BSF sites use a curriculum that relies heavily on discussion among the couples about various relationship issues, but where that was the case, the discussions were frequently cited as very helpful (of the three curricula, LCLC relies on group discussion the most). Couples appreciated the opportunity to vent about relationship challenges with an "expert" and others facing similar issues, and to hear how other couples have addressed them. The discussions normalized their experiences and often suggested the skills that would be taught in that session by the group facilitators. In several focus groups, couples mentioned the card decks used as part of specific exercises for illustrating concepts and strategies. These tools were used to help couples practice specific skills, or to provide a hands-on way for couples to work through specific problems. One couple described using a card deck during an argument, to help them remember the communication skills and keep the discussion calm.

Videos were seen as a useful tool for illustrating skills and concepts and focusing couples on specific relationship topics, although couples in about one-third of the focus groups thought they could be improved. Videos were used in each of the BSF curricula, though they differed in their purpose and construction. In one case, low-income couples were shown having a group discussion about various relationship issues. Many of 
the focus group participants who got this curriculum felt that these videos were the best part of the group sessions because they were easy to relate to, sparked discussion, and got the participants focused on specific topics. Some felt that they were good but went on too long and could become boring. (As a result of this feedback, the videos were shortened considerably to run no longer than 10 minutes.) Another curriculum used actors who looked like the target population but followed what appeared to be a guided script; focus group participants thought these videos were "corny" and artificial and saw them as the least helpful aspect of the program. The third curriculum used videos that had been developed for married middle-class couples, and participants were puzzled about why the videos focused on divorce and separation rather than marriage, and felt that they were "scripted and odd" because they never showed the couples' real frustrations. However, even participants who disliked the videos generally realized their use and accepted them as an important teaching tool, regardless of the curriculum or video type.

Couples were almost unanimously positive about the group facilitators. In general, participants thought the group facilitators were excellent. Facilitators were able to put lessons in their own words, and shared from their own experiences, making the sessions more realistic and they were better able to relate. Other couples commended the facilitators for being responsive and open to discussion, creating a safe and comfortable atmosphere, and making it easier to talk about personal issues. Facilitators showed genuine interest in the couples and often formed individual relationships with the participants. They sometimes maintained contact with couples after the group ended, which the couples enjoyed. As one participant said, "they do not abandon you after graduation." Out of all the focus groups, only one couple had a complaint about the facilitators, saying they were not open or familiar with the program. The facilitators the couple was referencing were new to the program; the couple's comment suggests that a certain level of skill, training, and experience is needed to successfully lead groups. Given the bulk of positive comments from the couples' perspectives, it appears that most facilitators were well-suited to lead groups.

Having other couples in the groups was an important part of the experience. Most participants greatly valued the opportunity to be with other couples in the group sessions. Sharing personal experiences normalized the problems many of the participants faced. Couples in several focus groups expressed relief at hearing other couples discuss their issues because it made some realize that everyone has problems and that they were not alone in having difficulties. One father stated: "By seeing others face the same problems, it made me feel like I wasn't crazy after all." This normalization may be a particularly important benefit because it helps couples realize that even though skills can be helpful in preventing and resolving relationship issues, there are no perfect relationships. In addition, as other couples worked through their issues, participants gleaned ideas for solving their own. One said, "Their relationships helped ours;" another said "everyone brought something to the table." Some male participants also enjoyed having other men to talk to, and a few female participants were happy to be around other adults, as they spent most of their day with children. Couples often formed valued friendships with one another, which some felt was missing from their lives. One participant stated, "Most friends go away when you have children." Several couples developed close friendships, even traveling together. 
Incentives were perceived as a bonus, rather than the reason for attending. Sites offered couples incentives such as gift cards, baby clothes, movie tickets, and cash. Most couples expressed gratitude for these incentives and thought they were important. They also appreciated incentives that made them feel special, such as celebrating birthdays and other events or being served dinner at group, which freed them from having to rush dinner beforehand. Some participants admitted that the incentives were their motivation for attending the first session, though not the reason for their continued attendance. In one focus group, couples felt "lured" by the incentives, and were disappointed by what they received (e.g., used baby clothes). Most couples, however, appreciated the incentives, but said they would continue to attend groups even if none were offered.

While most focus group participants had no suggestions for improving the program, some said it should be longer, more widely available, and include more topics. Many suggestions reflected the overall positive experiences of the couples. Generally, couples wanted to expand the program even further. Several wished the program was longer; they wanted the group to meet more than once a week or longer than six months. These couples felt there was not enough time during the scheduled groups to cover everything they wanted. One said, "when there are interesting subjects, time runs out, so we need more hours." Other suggestions were covering more topics, such as dealing with adolescents or in-laws, and addressing the needs of blended families, such as how to communicate with a biological child not living in the household. (These topics are covered in some of the curriculum, though the level of emphasis varies.) Perhaps reflecting their sense of isolation, couples suggested having more outings, and participants who had completed the relationship education groups said they missed the time with other couples. Couples also thought the eligibility requirements should be relaxed so more people would be able to participate and benefit from the program.

Couples typically made attending group sessions a priority, but absences still occurred. Many couples indicated that they did not like missing sessions; that it did not "feel right." The reasons they gave for missing a session were typically unavoidable, such as conflicts with work, illness, or having a baby. Work conflicts were particularly common, since many low-income workers do not have regular hours, and lack of job security made them reluctant to take time off. Some couples also mentioned transportation problems, though sites typically tried to provide transportation to participants. In one focus group, the participants complained that the drivers were often late and would run other errands while transporting them to group. Other, less common, reasons were also given, that indicate group was not always a priority for some respondents. For instance, one participant mentioned football season interfered with attending group, and another said "just being lazy." Typically, however, the reasons given were related to unexpected and difficult to avoid events or circumstances.

\section{Participating Couples Were Able to Recall Specific Relationship Skills and Information Learned in the Sessions}

Participants in a voluntary intervention are unlikely to attend over a long period unless they feel that their time is well spent and learning something worthwhile. Focus group 
participants were asked what kinds of things they learned in the group sessions. In most groups, couples articulated multiple lessons, skills, and topics that were discussed. In one group, for example, the couples agreed that through BSF they learned to think before reacting, to compromise, and to voice their opinions without antagonizing their partner.

Participants thought BSF would have a positive effect on their children because of their improved relationships and insights about parenting. The program seemed to help parents understand the connection between the quality of their relationships and how the child will turn out. One parent commented that she learned "we should be role models for our child." A father said, "I learned that parents should get along so that children can see good parents." Specific examples were given such as "cussing at home will have the child cussing." Some parents felt the program helped to relieve tension between parents and improve the overall atmosphere in the household. One parent summed it up by saying that they learned they should "work on making the home a better environment for our children." Among the key insights they gleaned, participants said they learned to:

- Stop using their child as leverage in an argument

- Always "be there" for their children

- Avoid arguing and fighting in front of their children

Participants cited specific skills they learned and applied in their couple relationships. Unless couples can learn, internalize, and apply the skills gleaned from the group sessions, their relationships are unlikely to improve. To understand the extent to which parents recall what they learned, participants were asked to report on the topics and relationship skills they found particularly useful. Communication was often cited, but other skills were also discussed. Among the many lessons mentioned, couples said they learned to:

- Share responsibilities with their partners, including housework

- Be respectful of their partners

- Pick their battles and compromise

- Help each other heal old traumas

- Trust each other

- Recognize and deal with post-partum depression and stress

- Identify their boiling point

- Watch their tone of voice

- Gain better self understanding 
- Express feelings

- Prevent harmful fights ${ }^{25}$

- Make decisions together

- Mend relationships after adultery

- Make time for intimacy

- Involve fathers in parenting

- Put the family first

- Deal with in-laws and ex-partners

\section{Participants Credit the Group Instruction with Improving Their Relationships}

Focus group participants frequently reported that their relationship skills had improved as a result of the BSF program. They felt they were now more effective communicators, and were more likely to listen and understand their partner. Some talked about learning to value their partner's opinion, rather than trying to change it. Many said the program helped them learn how to talk about their problems calmly and be more tolerant and patient with each other.

Participants talked about how the program helped them learn to handle conflict and control their anger. One man said that prior to BSF he would usually just leave for a few weeks when he argued with his partner-and on one occasion, crashing the car they shared on purpose. A woman reported that prior to participating in the program she "would throw things," but is now learning to control that impulse. A father said the program helped him deal with his anger without punching walls, as he previously had done.

Through improved communication and skills for handling conflict and anger, some couples felt they were better at handling their arguments. One woman credited BSF with helping her voice her opinions without shutting down, and for teaching her partner to stop using vulgar words during disagreements. One man stated that he learned "how not to turn the household into a war zone;" another acknowledged that the program helped him remain calm during arguments.

\footnotetext{
${ }^{25} \mathrm{Harmful}$ fights refers to improperly managed conflicts that damage the relationship.
} 
Some couples were able to reconceptualize their disagreements and saw the opportunity to work together. Several stated they would now dissect their problems and try to work through them, rather than just trying to win an argument. As one parent said, BSF helped them see that "yielding is not losing."

For some, participating in BSF helped them overcome "major" relationship problems. For example, one mother remarked that the program helped her stay in her relationship; through the program she was able to resolve her anger toward her partner. By improving their communication with one another, couples were able to reconnect and work through issues, such as financial problems, which previously had driven them apart.

Several people noted that they discovered things about their partner that they did not previously know, and that helped them feel closer. As one woman said, "it helped me see things from his point of view." Learning about each other's hopes and dreams for the future as well as past traumas and hurts drew couples together and helped them appreciate one another. One father remarked, "it helped me become more caring." Couples felt that the program encouraged them to be more tolerant and patient with their partners, which helped them listen better. These skills also led to greater intimacy and passion.

These benefits not only applied to their couple relationships but other relationships as well. Several mentioned that relationships with their children had improved. As one participant said, "My 15-year old daughter told me I was not the same person because now I can speak to her, listen and give her advice. My daughter said it has given me good results." Others recognized that communicating effectively is important in all relationships. One participant said "these lessons apply to all aspects of our lives."

\section{Many Couples Were Satisfied with the Resources and Assistance Provided by Family Coordinators}

Although most of the focus group time was used to discuss the marriage education groups, a few questions were asked about family coordinators. The amount of contact with family coordinators varied substantially between sites, as expected, but sometimes within sites as well. Couples ranged from having no or very little contact (e.g., two to three phone calls in six months) to weekly visits. Those with more frequent contact tended to be more positive about family coordinators.

Family coordinators provided numerous resources for families. Couples reported that they helped with issues such as employment, education, child care needs, and health and financial problems. Family coordinators in sites with Healthy Family connections also instructed participants on child development. One participant described their family coordinator as "an ear to listen to someone vent." They also reminded couples to attend the group sessions, and in some sites, demonstrated the skills taught during group sessions.

Although a few couples were disappointed with a low level of contact, others were satisfied with their experience. Some couples thought family coordinators were inconsistent and would miss scheduled appointments. Most others, however, found the family 
coordinators helpful and reliable. They indicated they could call on the family coordinators for help with problems that arose and some even described the FCs as being like family.

\section{B. REASONS FOR NONPARTICIPATION}

Attrition from the intervention is an important issue for any evaluation. Although it is rare for all program group members to take part in a voluntary intervention, at least some exposure to the program's services is likely to be necessary to achieve impacts. Earlier in this report we indicated that a substantial proportion of couples assigned to the experimental group-39 percent-do not attend the marriage and relationship skills groups. Some couples apparently are interested in the program and enroll but then do not follow through and participate in the group sessions. In addition to these "nonparticipants," a much smaller proportion of the evaluation sample (18 percent) attends a small number of group sessions and then drops out. These "drop outs" may have different reasons for disengaging from the program compared to those who never attended the group sessions at all.

Couples in both groups-nonparticipants and dropouts-may differ from regular program attendees in their personal lives or in their perception and experiences of BSF. For instance, they may have more obstacles to attendance, or may have disliked something about the program. To understand their views, we conducted brief telephone interviews with individuals who had disengaged from the program.

To form the interview sample, we randomly selected couples at each site who had been assigned to receive the intervention and whose groups had met together at least five times, but either (1) did not attend any group sessions, or (2) attended one or two group sessions but no more. Thirty-six brief interviews were conducted in all, each typically lasting less than ten minutes. Interviews were conducted with one member of the couple, either the mother or the father, thus representing 36 different couples. Those who never attended a group session comprised the bulk of the sample ( 69 percent) compared to dropouts ( 31 percent). All respondents were asked a series of open-ended questions about their participation and experiences with the program. Due to the small sample size and the subjective nature of the questions asked, some caution should be exercised in interpreting the results of this analysis.

\section{Most Nonparticipants Reported Scheduling Issues or Lack of Time}

When asked, nonparticipants gave numerous reasons for their lack of attendance at group sessions, but 72 percent of the reasons could be classified into two categories: scheduling conflicts or lack of time or interest. The remaining reasons involved either a family illness or a relationship issue.

- Thirty-six percent reported a scheduling or transportation issue. Nonparticipants often said that the time for the group sessions conflicted with the work schedule of one of the partners. For example, some had to work evenings or Saturdays when the group was offered. Only one individual indicated a transportation issue; the couple's car broke down and they were 
unable to come to the group sessions. (Most sites provide transportation assistance so it is not surprising that this was an uncommon barrier).

- Another thirty-six percent can be classified as having low interest or lack of time. One participant indicated her partner was attending night school and also working. A few respondents clearly expressed a low level of interest in the program, and one reported that after enrollment they were never contacted again. We classify the latter as low interest since they probably could have contacted the program themselves if they had been more motivated to do so.

- Sixteen percent of the people who never attended group sessions said there was a family illness. Two respondents indicated that their child was not well; in one case the infant was born prematurely and could not be taken out of the home; in the other, a child needed surgery. One respondent reported a complication with her pregnancy and was placed on bed rest. In another case, the partner became ill with a serious virus which spread to the rest of the family.

- Twelve percent reported that an issue in their relationship prevented their attendance at group sessions. In two cases, the respondent indicated that her partner had "changed his mind" about attending the program. Only one person said that she and her partner had had a serious argument and "went their separate ways."

\section{Among Program Dropouts, Most Reported Either a Family Illness or a Scheduling Issue}

Like nonparticipants, many dropouts reported scheduling conflicts, but a higher proportion of dropouts than nonparticipants indicated that a family illness interfered with their attendance.

- Like nonparticipants, one-third of dropouts reported scheduling conflicts. These most often included conflicts that arose because of changing work schedules.

- In contrast to nonparticipants, a higher proportion of dropouts (36 percent) reported that a family illness interrupted their attendance. These most often involved pregnancy complications or a child's illness.

- Two respondents (18 percent of dropouts) indicated that they were too busy or were no longer interested. In one case, a partner said he had already learned the information in school and had been expecting something new. In the other, the husband had to work late and didn't have time. 
- Only one respondent indicated that they dropped out of the group sessions because the relationship ended. This couple had some issues that were too serious to be addressed in the group sessions. They were referred to individual counseling.

Many of these reasons are similar to those offered by regular program attendees for missing sessions. Lives are busy, sometimes chaotic; work schedules change, children get sick. Events interfere with attendance. One difference, however, is the disinterest expressed by a few nonparticipants.

Although some couples who dropped out may have decided BSF was not a good fit for them, others may have cited lack of interest or "no time" to disguise fears or concerns about the group sessions. When asked explicitly, the majority of respondents said they did not have any concerns or fears about the program. None mentioned any worries about sharing personal information with strangers or that the group sessions were only for people with major problems, as those in the focus groups described. This is in stark contrast to the responses of regular attendees in the focus groups. It is possible that regular attendees find it easier to admit to having had these fears, because they apparently were able to work through them. Nonparticipants may also have these fears, but find it easier to cite lack of interest or interfering work schedules for their disengagement.

\section{Nonparticipants and Dropouts Generally Reported Positive Interactions with Program Staff}

There were few reports of couples having a negative experience with staff or with the group sessions. Respondents indicated that the group sessions they did attend were enjoyable and the staff was helpful and repeatedly tried to engage them in the sessions.

Disliking the group sessions was not a major reason for dropping out. Most program dropouts - those who had attended a group session at least once or twicereported being quite pleased with the experience. They found the group sessions fun and helpful for their relationship, and particularly enjoyed the group discussions and support from other couples. Some cited specific skills they had learned or topics that were covered. Only two respondents had relatively negative comments: one said the group was "OK" and the other found the group "too repetitive" and that they had already learned the information in school. For the majority of respondents, the group was a satisfying experience, but schedule conflicts or family illness interfered. These results suggest that it is typically not a negative perception of the group that leads to people dropping out of the program.

Since many regular participants also had schedule conflicts, it is not clear what the difference is between those who eventually return to the group and those who do not. It may be that the nature of the schedule conflict is longer term for nonparticipants and dropouts, such as a permanent change in work schedule or a long-term illness. The groups may also differ in their priorities, with regular attendees being more interested in working on their relationship. 
Interviews with nonparticipants and dropouts confirmed information from sites that staff usually reach out and attempt to reconnect couples who miss group sessions. Most sites have protocols for staff to try to reengage couples. In the interviews, most respondents revealed that staff had made one or more contacts with them when they did not attend group sessions. Some were contacted regularly despite their inactivity in the program. One nonparticipant, for instance, said a staff member called before every session to ask if the couple would be attending. There were however, six participants (17 percent) out of the full sample of 36 who indicated that they never heard from the BSF staff. It is possible the participants simply do not remember the contact-or that one parent is contacted and does not bring it up to their partner-but this could also indicate that some couples fall through the cracks. Following up with nonattendees conveys interest and concern for the couple, and could increase attendance rates. If a couple is never contacted again, it is easier for them to dismiss the program and its services. 



\section{R E F E R E N C E S}

Adler-Baeder, Francesca, Joe Pittman, Laura Lippert, Jackie Pflieger, Brian Higginbotham, Sarah Armstrong, and Amy Long. "Evaluating a Marriage Education Program for LowResource Families: The Family Connections in Alabama Project." Auburn, AL: Auburn University, Department of Human Development and Families Studies, 2004.

Amato, Paul R. "Children of Divorce in the 1990s: An Update of the Amato and Keith (1991) Meta-Analysis.” Journal of Family Psychology, vol. 13, no. 3, 2001, pp. 355-370.

Carlson, Marcia, Sara McLanahan, and Paula England. "Union Formation in Fragile Families." Demography, vol. 41, no. 2, 2004.

Carlson, Marcia, Sara McLanahan, Paula Enmgland, and Barbara Devaney. "What We Know About Unmarried Parents: Implications for Building Strong Families Programs." Washington DC: Mathematica Policy Research, Inc., 2005.

Dion, M. Robin, Sarah A. Avellar, Heather H. Zaveri, and Alan M. Hershey. "Implementing Healthy Marriage Programs for Unmarried Couples with Children: Early Lessons from the Building Strong Families Project." Washington DC: Mathematica Policy Research, Inc., 2006.

Dion, M. Robin, Barbara Devaney, Sheena McConnell, Melissa Ford, Heather Hill, and Pamela Winston. "Helping Unwed Parents Build Strong and Healthy Marriages: A Conceptual Framework for Interventions." Washington, DC: Mathematica Policy Research, Inc., 2003.

Dion, M. Robin, and Debra A. Strong. "Implementing Programs to Strengthen Unwed Parents' Relationships: Lessons from Family Connections in Alabama." Washington, DC: Mathematica Policy Research, Inc., 2004.

Gottman, John, Julia Babcock, Sandra Stith, and Eric McCollum. "Manual for Screening Out Domestic Violence and Suicidality." Seattle, WA: Relationship Research Institute, December 2004. 
Guerney, Bernard G. Relationship Enhancement. San Francisco, CA: Jossey-Bass, Inc., 1977.

Hershey, Alan A., Barbara Devaney, M. Robin Dion, and Sheena McConnell. "Building Strong Families: Guidelines for Developing Programs." Washington, DC: Mathematica Policy Research, Inc., 2004.

Kessler, Ronald C., Peggy R. Barker, Lisa J. Colpe, Joan F. Epstein, Joseph C. Gfroerer, Eva Hiripi, Mary J. Howes, Sharon-Lise T. Normand, Ronald W. Manderscheid, Ellen E. Walters, and Alan M. Zaslavsky. "Screening for Serious Mental Illness in the General Population." Archives of General Psychiatry, vol. 60, 2003, pp. 184-189.

Markman, H.J., M.J. Renick, F. Floyd, S. Stanley, and M. Clements. "Preventing Marital Distress Through Communication and Conflict Management Training: A Four- and Five-Year Follow-Up." Journal of Consulting and Clinical Psychology, vol. 61, 1993, pp. $70-77$.

Martin, J.A., K.D. Kochanek, D.M. Strobino, B. Guyer, and M.F. MacDorman. "Annual Summary of Vital Statistics-2003.” Pediatrics, vol. 115, no. 3, March 2005, pp. 619-634.

McLanahan, Sara, and Gary Sandefur. Growing up with a Single Parent: What Hurts, What Helps. Cambridge, MA: Harvard University Press, 1994.

Miller, S. L., E.W. Nunnally, and D.B. Wackman. "A Communication Training Program for Couples. Social Casework, vol. 57, 1976, pp. 9-18.

Strauss, Murray A., and Emily M. Douglas. "A Short Form of the Revised Conflict Tactics Scales, and Typologies for Severity and Mutuality." Violence and Victims, vol. 19, no. 5, October 2004.

Wilson, Pamela, Mary Ortwein, Carolyn Wiseheart, Akilah Thomas, and Reuben Lawrence. "Trust, Money, Marriage, and Complex Families: Curriculum Modules for Fragile Families.” Washington, DC: Mathematica Policy Research, 2005. 
A P P E N D IX A

S UMMARY OF B SF DEVELOPMENT AN D

I M P L E M E N T A T I O N B Y S I T E 

Table A-1. Summary of BSF Development and Implementation in Atlanta, Georgia

\begin{tabular}{|c|c|c|}
\hline & Atlanta GSU Location & Latin American Association Location \\
\hline \multicolumn{3}{|l|}{ Program Setting } \\
\hline Sponsoring Organization & $\begin{array}{l}\text { Health Policy Center at Georgia State University } \\
\text { (GSU) }\end{array}$ & $\begin{array}{l}\text { Latin American Association (LAA), a community-based } \\
\text { nonprofit }\end{array}$ \\
\hline $\begin{array}{l}\text { Organizational Structure } \\
\text { and Role }\end{array}$ & $\begin{array}{l}\text { GSU is lead agency for site, manages the program } \\
\text { and conducts outreach for both locations; provides } \\
\text { services for English-speaking couples. BSF was } \\
\text { developed from the ground-up at the GSU location. }\end{array}$ & $\begin{array}{l}\text { Delivers BSF services to Spanish-speaking couples. BSF } \\
\text { was added to the services of this multi-program agency. }\end{array}$ \\
\hline Community Context & $\begin{array}{l}\text { GSU's program is located in a large urban downtown } \\
\text { area with a high concentration of African Americans. }\end{array}$ & $\begin{array}{l}\text { LAA is located in a suburban area but serves the } \\
\text { metropolitan area's high concentration of Hispanic families. }\end{array}$ \\
\hline $\begin{array}{l}\text { Approximate Level of } \\
\text { Resources Needed }\end{array}$ & $\$ 8,836$ per couple & $\$ 8,836$ per couple \\
\hline \multicolumn{3}{|l|}{ Recruitment } \\
\hline Source(s) & $\begin{array}{l}\text { Prenatal clinic at major public health hospital in } \\
\text { downtown Atlanta. }\end{array}$ & $\begin{array}{l}\text { Prenatal clinic at major public health hospital in downtown } \\
\text { Atlanta. }\end{array}$ \\
\hline Recruitment Strategies & $\begin{array}{l}\text { Targets pregnant women who come to the clinic with } \\
\text { their partners. Outreach and intake conducted } \\
\text { simultaneously and on the spot, in most cases. }\end{array}$ & $\begin{array}{l}\text { Recruitment of Spanish-speaking couples is done by GSU's } \\
\text { Spanish-speaking outreach/intake workers. }\end{array}$ \\
\hline Enrollment Rate & $\begin{array}{l}388 \text { couples enrolled as of March } 31,2007.34 \\
\text { couples are enrolled per month, on average. }\end{array}$ & $\begin{array}{l}73 \text { couples enrolled as of March } 31,2007.3 \text { couples per } \\
\text { month are enrolled, on average. }\end{array}$ \\
\hline $\begin{array}{l}\text { Enrollee Characteristics at } \\
\text { Baseline }\end{array}$ & $\begin{array}{l}93 \% \text { are African American; } 68 \% \text { have } \mathrm{H} / \mathrm{S} \text { diploma; } \\
52 \% \text { employed; } 76 \% \text { earn less than } \$ 15,000 / \text { year; } \\
67 \% \text { cohabit; } 36 \% \text { MPF; } 63 \% \text { high chance of } \\
\text { marriage; } 86 \% \text { pregnant. }\end{array}$ & $\begin{array}{l}97 \% \text { are Hispanic, Spanish is primary language for } 95 \% \text {; } \\
48 \% \text { have } \mathrm{H} / \mathrm{S} \text { diploma; } 53 \% \text { employed; } 79 \% \text { earn less than } \\
\$ 15,000 / \text { year; } 84 \% \text { cohabit; } 27 \% \text { MPF; } 65 \% \text { high chance of } \\
\text { marriage; } 73 \% \text { pregnant. }\end{array}$ \\
\hline
\end{tabular}


Table A-1 (continued)

\begin{tabular}{|c|c|c|}
\hline & Atlanta GSU Location & Latin American Association Location \\
\hline \multicolumn{3}{|c|}{ Marriage And Relationship Skills Groups } \\
\hline Curriculum Choice & Loving Couples, Loving Children & Loving Couples, Loving Children-Spanish Version \\
\hline Delivery Format(s) & Weekly 2-hour sessions & Weekly 2-hour sessions \\
\hline Incentives for Attendance & $\begin{array}{l}\text { Selected couples receive incentives (gift cards, baby } \\
\text { items) based on attendance }\end{array}$ & $\begin{array}{l}\text { Selected couples receive incentives (gift cards, baby items) } \\
\text { based on attendance }\end{array}$ \\
\hline $\begin{array}{l}\text { Other Practices to } \\
\text { Encourage Attendance }\end{array}$ & $\begin{array}{l}\text { Social activities, meetings } w / \text { group facilitators, } \\
\text { orientation sessions, staff reminders, home visits and } \\
\text { make-up sessions after absences }\end{array}$ & $\begin{array}{l}\text { Meetings w/ FCs and group facilitators; reminders; social } \\
\text { activities; home visits and make-up session after absences; } \\
\text { comfortable setting. }\end{array}$ \\
\hline $\begin{array}{l}\text { Percentage of Program } \\
\text { Group that Initiated } \\
\text { Attendance }\end{array}$ & $79 \%$ & $70 \%$ \\
\hline $\begin{array}{l}\text { Total Average Hours of } \\
\text { Participation by Initiators }\end{array}$ & 22 hours & 29 hours \\
\hline $\begin{array}{l}\text { Percentage of Couples } \\
\text { Completing } 80 \%-100 \% \text { of } \\
\text { Curriculum }\end{array}$ & $23 \%$ & $40 \%$ \\
\hline \multicolumn{3}{|c|}{ Family Coordinator Component } \\
\hline $\begin{array}{l}\text { Philosophy of Case } \\
\text { Management }\end{array}$ & Provide contact and support on an as-needed basis. & $\begin{array}{l}\text { Provide contact and support on a regular basis and also as- } \\
\text { needed. }\end{array}$ \\
\hline Staffing Arrangement & $\begin{array}{l}\text { FC functions split across group facilitators and } \\
\text { intake/outreach staff. }\end{array}$ & $\begin{array}{l}\text { FC functions split across group facilitators and dedicated } \\
\text { Family Coordinators. }\end{array}$ \\
\hline $\begin{array}{l}\text { Encouraging Group } \\
\text { Attendance }\end{array}$ & $\begin{array}{l}\text { Group facilitators contact couples by telephone to } \\
\text { remind them about group, particularly for inconsistent } \\
\text { attendees. }\end{array}$ & $\begin{array}{l}\text { Group facilitators contact couples by telephone to remind } \\
\text { them about group, particularly for inconsistent attendees. }\end{array}$ \\
\hline $\begin{array}{l}\text { Reinforcing Relationship } \\
\text { Skills }\end{array}$ & $\begin{array}{l}\text { Group facilitators reinforce skills during telephone } \\
\text { calls with couples as needed. }\end{array}$ & $\begin{array}{l}\text { FCs reinforce skills through telephone calls and home visits } \\
\text { on a regularly scheduled basis. }\end{array}$ \\
\hline
\end{tabular}


Table A-1 (continued)

\section{Atlanta GSU Location}

$82 \%$ of program group couples were contacted outside of group sessions. Average number of monthly contacts per couple is about 2 . Couples were contacted mostly by telephone ( $84 \%$ of all contacts) and via home visits (3\%).

Parents' Attendance at FC $\quad 90 \%$ of contacts were with both parents. Contacts

\section{Latin American Association Location}

$96 \%$ of program group couples were contacted outside of group sessions. Average number of monthly contacts per couple is about one. Couples were mostly contacted by telephone ( $57 \%$ of all contacts) and through home visits $(40 \%)$.

$22 \%$ of all contacts were with both parents.

\section{Family Support Services Component}

\begin{tabular}{lll}
\hline Method of Assessment & Informal guided discussion. & Informal guided discussion. \\
\hline $\begin{array}{l}\text { Who is Assessed; How } \\
\text { Often; Goal Setting }\end{array}$ & Both parents assessed at enrollment. & Both parents assessed at enrollment. \\
\hline $\begin{array}{l}\text { Percentage of Program } \\
\text { Group Referred for }\end{array}$ & $3 \%$ & $26 \%$ \\
Services & & \\
\hline
\end{tabular}



Table A-2. Summary of BSF Development and Implementation in Baltimore, Maryland

\begin{tabular}{|c|c|}
\hline \multicolumn{2}{|l|}{ Program Setting } \\
\hline Sponsoring Organization & Center for Fathers, Families, and Workforce Development (CFWD), a community-based nonprofit \\
\hline Organizational Structure & $\begin{array}{l}\text { CFWD manages the site and employs all site staff. BSF was added to the services of this multi-program } \\
\text { agency. }\end{array}$ \\
\hline Community Context & $\begin{array}{l}\text { CFWD's program is located in West Baltimore which has a high concentration of low-income, African } \\
\text { Americans. }\end{array}$ \\
\hline $\begin{array}{l}\text { Approximate Level of Resources } \\
\text { Needed }\end{array}$ & $\$ 11,278$ per couple \\
\hline \multicolumn{2}{|l|}{ Recruitment } \\
\hline Source(s) & Six hospitals and clinics throughout the Baltimore area. \\
\hline Recruitment Strategies & $\begin{array}{l}\text { Approach pregnant and postnatal women attending appointments at hospitals and clinics. Receive referrals } \\
\text { from hospitals and clinics. Obtain consent for further contact during street outreach. Outreach and intake } \\
\text { often completed during separate contacts. }\end{array}$ \\
\hline Enrollment Rate & 384 couples enrolled as of March $31,2007.25$ couples are enrolled per month, on average. \\
\hline $\begin{array}{l}\text { Enrollee Characteristics at } \\
\text { Baseline }\end{array}$ & $\begin{array}{l}\text { 95\% are African American; } 60 \% \text { have } \mathrm{H} / \mathrm{S} \text { diploma; } 47 \% \text { employed; } 72 \% \text { earn less than } \$ 15,000 / \text { year; } 67 \% \\
\text { cohabit; } 40 \% \text { MPF; } 53 \% \text { high chance of marriage; } 72 \% \text { pregnant. }\end{array}$ \\
\hline \multicolumn{2}{|c|}{ Marriage and Relationship Skills Groups } \\
\hline Curriculum Choice & Loving Couples, Loving Children \\
\hline Delivery Format(s) & Weekly 2-hour sessions \\
\hline Incentives for Attendance & $\begin{array}{l}\text { Selected couples receive incentives (baby items, gift cards) during a raffle at each session. Couples who } \\
\text { attend the graduation ceremony receive an incentive (gift card), the value of incentive depends on the } \\
\text { couple's attendance record. Couples that attend all group sessions also receive an overnight stay at a local } \\
\text { hotel. }\end{array}$ \\
\hline $\begin{array}{l}\text { Other Practices to Encourage } \\
\text { Attendance }\end{array}$ & $\begin{array}{l}\text { Social activities; meetings with family coordinators; staff reminders; telephone contact or home visits after } \\
\text { group absences; comfortable setting. }\end{array}$ \\
\hline
\end{tabular}


Table A-2 (continued)

Percentage of Program Group that $\quad 61 \%$

Initiated Attendance

Total Average Hours of
Participation by Initiators

Percentage of Couples $\quad 12 \%$

Completing $80 \%-100 \%$ of

Curriculum

\section{Family Coordinator Component}

Philosophy of Case Management Conduct monthly home visits with couples and provide additional ongoing support and contact on an as needed basis.

\begin{tabular}{|c|c|}
\hline Staffing Arrangement & Staff fulfilling FC functions split their time between intake and FC responsibilities. \\
\hline Encouraging Group Attendance & $\begin{array}{l}\text { Intake staff contact couples by telephone to remind them about group. Outreach workers contact all } \\
\text { couples prior to group to inquire about transportation needs. }\end{array}$ \\
\hline Reinforcing Relationship Skills & Intake staff reinforce skills occasionally during home visits (informal approach). \\
\hline Frequency of FC contact & $\begin{array}{l}100 \% \text { of program group couples were contacted outside of group sessions. Average number of monthly } \\
\text { contacts per couple is about } 2 \text {. Couples were contacted mostly by telephone ( } 61 \% \text { of all contacts) and via } \\
\text { home visits }(17 \%) \text {. }\end{array}$ \\
\hline $\begin{array}{l}\text { Parents' Attendance at FC } \\
\text { Contacts }\end{array}$ & $66 \%$ of contacts were with both parents. \\
\hline \multicolumn{2}{|c|}{ Family Support Services Component } \\
\hline Method of Assessment & Intake staff complete a structured assessment tool with couples. \\
\hline $\begin{array}{l}\text { Who is Assessed; How Often; } \\
\text { Goal Setting }\end{array}$ & $\begin{array}{l}\text { Couples complete a family strengthening plan shortly after enrollment in which they identify goals. Intake } \\
\text { staff review and update the plan with couples on a monthly basis during home visits. }\end{array}$ \\
\hline $\begin{array}{l}\text { Percentage of Program Group } \\
\text { Referred for Services }\end{array}$ & $27 \%$ \\
\hline
\end{tabular}


Table A-3. Summary of BSF Development and Implementation In Baton Rouge, Louisiana

\begin{tabular}{|c|c|}
\hline \multicolumn{2}{|l|}{ Program Setting } \\
\hline Sponsoring Organization & Family Road of Greater Baton Rouge, a community-based non-profit \\
\hline Organizational Structure & $\begin{array}{l}\text { Family Road manages the site and employs all site staff. BSF was added to the services of this multi- } \\
\text { program agency. }\end{array}$ \\
\hline Community Context & $\begin{array}{l}\text { Family Road recruits throughout the Greater Baton Rouge community, which is predominantly African } \\
\text { American. }\end{array}$ \\
\hline $\begin{array}{l}\text { Approximate Level of Resources } \\
\text { Needed }\end{array}$ & $\$ 8,852$ per couple \\
\hline \multicolumn{2}{|l|}{ Recruitment } \\
\hline Source(s) & $\begin{array}{l}\text { The Better Beginnings program, which meets at Family Road and links Medicaid-eligible pregnant women to } \\
\text { prenatal and pediatric services. Also community outreach, such as health units, churches, colleges, and } \\
\text { WIC clinics. }\end{array}$ \\
\hline Recruitment Strategies & $\begin{array}{l}\text { BSF is described to pregnant women attending Better Beginnings program at Family Road. To encourage } \\
\text { referrals, staff make presentations at social service programs. Outreach and intake conducted in one } \\
\text { encounter, in many cases. }\end{array}$ \\
\hline Enrollment Rate & 308 couples enrolled as of March $31,2007.23$ couples are enrolled per month, on average. \\
\hline $\begin{array}{l}\text { Enrollee Characteristics at } \\
\text { Baseline }\end{array}$ & $\begin{array}{l}76 \% \text { are African American and } 17 \% \text { are White; } 67 \% \text { have } \mathrm{H} / \mathrm{S} \text { diploma; } 59 \% \text { employed; } 77 \% \text { earn less than } \\
\$ 15,000 / \text { year. } 65 \% \text { cohabit, } 29 \% \text { MPF, } 82 \% \text { high chance of marriage. } 91 \% \text { pregnant. }\end{array}$ \\
\hline \multicolumn{2}{|c|}{ Marriage and Relationship Skills Groups } \\
\hline Curriculum Choice & Loving Couples, Loving Children \\
\hline Delivery Format(s) & Weekly 2-hour sessions \\
\hline Incentives for Attendance & $\begin{array}{l}\text { Couples accumulate points for each attendance, which can be redeemed after reaching specified } \\
\text { attendance milestones. Couples select incentive from list that includes baby items, gift cards, and wedding } \\
\text { assistance. }\end{array}$ \\
\hline $\begin{array}{l}\text { Other Practices to Encourage } \\
\text { Attendance }\end{array}$ & $\begin{array}{l}\text { Meetings with family coordinators; orientation session; staff reminders; ongoing social activities; telephone } \\
\text { contact after group absences; make-up sessions; comfortable setting. }\end{array}$ \\
\hline
\end{tabular}


Table A-3 (continued)

Percentage of Program Group that $\quad 64 \%$

Initiated Attendance

Total Average Hours of
Participation by Initiators

Percentage of Couples $\quad 30 \%$

Completing $80 \%-100 \%$ of

Curriculum

\section{Family Coordinator Component}

Philosophy of Case Management Some couples require greater case management than others. Frequency of FC contact is determined by couples' level of risk.

\begin{tabular}{|c|c|}
\hline Staffing Arrangement & Dedicated family coordinators. \\
\hline Encouraging Group Attendance & Family coordinators contact couples by telephone to remind them about group. \\
\hline Reinforcing Relationship Skills & Family coordinators reinforce skills during telephone contacts and home visits with couples as needed. \\
\hline Frequency of FC contact & $\begin{array}{l}98 \% \text { of program group couples contacted outside of group sessions. Average number of monthly contacts } \\
\text { per couple is about } 2 \text {. Couples contacted mostly by telephone ( } 62 \% \text { of all contacts) and program office visit } \\
(16 \%) \text {. }\end{array}$ \\
\hline $\begin{array}{l}\text { Parents' Attendance at FC } \\
\text { Contacts }\end{array}$ & $32 \%$ of contacts with both parents. \\
\hline \multicolumn{2}{|c|}{ Family Support Services Component } \\
\hline Method of Assessment & $\begin{array}{l}\text { Family coordinators complete a structured assessment tool with couples from which couples are identified } \\
\text { as high- or low-risk. }\end{array}$ \\
\hline $\begin{array}{l}\text { Who is Assessed; How Often; } \\
\text { Goal Setting }\end{array}$ & $\begin{array}{l}\text { Couples complete a family strengthening plan shortly after enrollment in which they identify goals. Intake } \\
\text { staff review and update the plan with couples on a regular basis during home visits. }\end{array}$ \\
\hline $\begin{array}{l}\text { Percentage of Program Group } \\
\text { Referred for Services }\end{array}$ & $25 \%$ \\
\hline
\end{tabular}


Table A-4. Summary of BSF Development and Implementation in Florida

\begin{tabular}{|c|c|c|}
\hline & Broward County, Florida & Orange County, Florida \\
\hline \multicolumn{3}{|l|}{ Program Setting } \\
\hline Sponsoring Organization & $\begin{array}{l}\text { Healthy Families Florida (HFF), a state-level } \\
\text { organization with local sites throughout the state and } \\
\text { run by The Ounce of Prevention Fund of Florida. }\end{array}$ & $\begin{array}{l}\text { Healthy Families Florida, a state-level organization with } \\
\text { local sites throughout the state and run by The Ounce of } \\
\text { Prevention Fund of Florida. }\end{array}$ \\
\hline Organizational Structure & $\begin{array}{l}\text { HFF integrated BSF services into its Healthy Families } \\
\text { Broward agency. The integrated program is known } \\
\text { as Healthy Families Plus. }\end{array}$ & $\begin{array}{l}\text { HFF integrated BSF services into its Healthy Families } \\
\text { Orange agency. The integrated program is known as } \\
\text { Healthy Families Plus. }\end{array}$ \\
\hline Community Context & $\begin{array}{l}\text { Healthy Families Plus (BSF) serves couples in the city } \\
\text { of Fort Lauderdale and surrounding communities, } \\
\text { which is a relatively dispersed area of mixed } \\
\text { race/ethnicities and income levels. }\end{array}$ & $\begin{array}{l}\text { Healthy Families Plus (BSF) serves selected zip codes } \\
\text { within Orange County, including Orlando and surrounding } \\
\text { areas. The service area includes densely populated } \\
\text { communities but covers a fairly large geographic area. }\end{array}$ \\
\hline $\begin{array}{l}\text { Approximate Level of } \\
\text { Resources Needed }\end{array}$ & $\$ 14,169$ per couple & $\$ 14,169$ per couple \\
\hline \multicolumn{3}{|l|}{ Recruitment } \\
\hline Source(s) & Five birthing hospitals throughout the county. & Three birthing hospitals throughout the county. \\
\hline Recruitment Strategies & $\begin{array}{l}\text { Couples prescreened through information provided by } \\
\text { the hospitals. New mothers, and fathers if available, } \\
\text { are approached in the maternity ward. BSF intake is } \\
\text { incorporated into the routine baseline assessment } \\
\text { and intake procedure for Healthy Families. }\end{array}$ & $\begin{array}{l}\text { Couples prescreened through information provided by the } \\
\text { hospitals. New mothers, and fathers if available, are } \\
\text { approached in the maternity ward. BSF intake is } \\
\text { incorporated into the routine baseline assessment and } \\
\text { intake procedure for Healthy Families. }\end{array}$ \\
\hline Enrollment Rate & $\begin{array}{l}235 \text { couples enrolled as of March } 31,2007.22 \\
\text { couples are enrolled per month, on average. }\end{array}$ & $\begin{array}{l}319 \text { couples enrolled as of March } 31,2007.21 \text { couples are } \\
\text { enrolled per month, on average. }\end{array}$ \\
\hline $\begin{array}{l}\text { Enrollee Characteristics at } \\
\text { Baseline }\end{array}$ & $\begin{array}{l}72 \% \text { are African American and } 18 \% \text { are Hispanic; } \\
69 \% \text { have } \mathrm{H} / \mathrm{S} \text { diploma; } 50 \% \text { employed; } 64 \% \text { earn } \\
\text { less than } \$ 15,000 / \text { year; } 66 \% \text { cohabit; } 27 \% \text { MPF; } 49 \% \\
\text { high chance of marriage; } 2 \% \text { pregnant. }\end{array}$ & $\begin{array}{l}60 \% \text { are African American and } 24 \% \text { are Hispanic; } 71 \% \text { have } \\
\mathrm{H} / \mathrm{S} \text { diploma; } 51 \% \text { employed; } 70 \% \text { earn less than } \\
\$ 15,000 / \text { year; } 75 \% \text { cohabit; } 22 \% \mathrm{MPF} ; 62 \% \text { high chance of } \\
\text { marriage; } 0 \% \text { pregnant. }\end{array}$ \\
\hline
\end{tabular}


Table A-4 (continued)

\section{Broward County, Florida}

\section{Orange County, Florida}

\section{Marriage And Relationship Skills Groups}

\begin{tabular}{ll}
\hline Curriculum Choice & Loving Couples, Loving Children \\
\hline Delivery Format(s) & Weekly 2-hour sessions \\
\hline Incentives for Attendance & $\begin{array}{l}\text { Provide incentives to couples after they achieve set } \\
\text { attendance milestones. Incentives include cash or gift } \\
\text { checks to recognize initial and ongoing attendance. }\end{array}$ \\
\hline
\end{tabular}

Loving Couples, Loving Children

Weekly 2-hour or 4-hour sessions

\section{Other Practices to}

Encourage Attendance

Meet with BSF family coordinator (HF home visitor) during parenting-focused home visits; staff reminders; ongoing social activities; telephone contact after group absence; comfortable setting.
$65 \%$
$1 \%$

Provide incentives to couples after they achieve set attendance milestones. Incentives are provided as gift cards to recognize initial and ongoing attendance.

Meet with BSF family coordinator (HF home visitor) during parenting-focused home visits; staff reminders; ongoing social activities; telephone contact after group absence; make-up sessions; comfortable setting.

$\begin{array}{lll}\text { Percentage of Program } \quad 65 \% & 61 \%\end{array}$

Group that Initiated

Attendance

Total Average Hours of
Participation by Initiators

13 hours

16 hours

Percentage of Couples

$3 \%$

Completing $80 \%-100 \%$ of

Curriculum

\section{Family Coordinator Component}

Philosophy of Case

Management

Home visits integrate parenting focus of Healthy Families with the couple and relationship focus of BSF.

\section{Staffing Arrangement A dedicated home visitor jointly provides BSF and} Healthy Families services.

Encouraging Group

Attendance
Home visitors or other staff contact couples by telephone to remind them about group.
Home visits integrate parenting focus of Healthy Families with the couple and relationship focus of BSF.

A dedicated home visitor jointly provides BSF and Healthy Families services.

Home visitors or other staff contact couples by telephone to remind them about group. 
Table A-4 (continued)

\section{Broward County, Florida}

\begin{tabular}{ll}
\hline $\begin{array}{l}\text { Reinforcing Relationship } \\
\text { Skills }\end{array}$ & $\begin{array}{l}\text { Home visitors reinforce skills during home visits with } \\
\text { couples on a regular basis, using special materials } \\
\text { designed for this purpose. }\end{array}$ \\
\hline Frequency of FC contact & $\begin{array}{l}\text { 84\% of program group couples contacted outside of } \\
\text { group sessions. Average number of monthly contacts } \\
\text { per couple is about } 4 . \text { Most contacts made through } \\
\text { home visits }(48 \%) \text { and via telephone }(41 \%) .\end{array}$
\end{tabular}

Parents' Attendance at FC $\quad 20 \%$ of contacts were with both parents. Contacts

\section{Family Support Services Component}

\begin{tabular}{lll} 
Method of Assessment & $\begin{array}{l}\text { Intake workers conduct an in-depth, informally } \\
\text { structured assessment. }\end{array}$ & $\begin{array}{l}\text { Intake workers conduct an in-depth, informally structured } \\
\text { assessment. }\end{array}$ \\
\hline $\begin{array}{l}\text { Who is Assessed; How } \\
\text { Often; Goal Setting }\end{array}$ & $\begin{array}{l}\text { Intake workers assess mothers during intake. } \\
\text { Fathers are included in the assessment, if present, } \\
\text { though the assessment is not targeted to fathers. } \\
\text { Home visitors continue to monitor the needs of } \\
\text { mothers during ongoing visits. }\end{array}$ & $\begin{array}{l}\text { Intake workers assess mothers during intake. Fathers are } \\
\text { included in the assessment, if present, though the } \\
\text { assesment is not targeted to fathers. Home visitors } \\
\text { continue to monitor the needs of mothers during ongoing } \\
\text { visits. }\end{array}$ \\
\hline $\begin{array}{l}\text { Percentage of Program } \\
\text { Group Referred for }\end{array}$ & $62 \%$ & $75 \%$ \\
Services & & 75 \\
\hline
\end{tabular}

Home visitors reinforce skills during home visits with couples on a regular basis, using special materials designed for this purpose.

$91 \%$ of program group couples contacted outside of group sessions. Average number of monthly contacts per couple is about 5 . Most contacts made through home visits (44\%) and via telephone $(33 \%)$.

$28 \%$ of contacts were with both parents.
Services 

Table A-5. Summary of Development and Implementation of BSF in Indiana

\begin{tabular}{|c|c|c|c|}
\hline & Allen County, Indiana & Lake County, Indiana & Marion County, Indiana \\
\hline \multicolumn{4}{|l|}{ Program Setting } \\
\hline Sponsoring Organization & $\begin{array}{l}\text { In Indiana, BSF is sponsored by } \\
\text { Healthy Families Indiana (HFI), a } \\
\text { state-level organization with } \\
\text { program sites throughout the } \\
\text { state, and SCAN, Inc., HFI's } \\
\text { program in Allen County. }\end{array}$ & $\begin{array}{l}\text { In Indiana, BSF is sponsored by } \\
\text { Healthy Families Indiana (HFI), a } \\
\text { state-level organization with } \\
\text { program sites throughout the } \\
\text { state. The HFI program that } \\
\text { administers BSF in Lake County is } \\
\text { administered through contract with } \\
\text { the Villages, an organization that } \\
\text { provides Healthy Families } \\
\text { services throughout the county. }\end{array}$ & $\begin{array}{l}\text { In Indiana, BSF is sponsored by } \\
\text { Healthy Families Indiana (HFI), a } \\
\text { state-level organization with } \\
\text { program sites throughout the } \\
\text { state. Four Healthy Families } \\
\text { locations in Marion County } \\
\text { contract with HFI and SCAN, Inc. } \\
\text { to provide BSF services. Marion } \\
\text { County includes Indianapolis. }\end{array}$ \\
\hline Organizational Structure & $\begin{array}{l}\text { HFI administers BSF in Indiana, in } \\
\text { coordination with SCAN, Inc. In } \\
\text { Allen County, SCAN, Inc. delivers } \\
\text { both Healthy Families and BSF } \\
\text { services, known as Healthy } \\
\text { Couples Healthy Families (HCHF). }\end{array}$ & $\begin{array}{l}\text { HFI administers BSF in Indiana, in } \\
\text { coordination with SCAN, Inc. In } \\
\text { Lake County, BSF is administered } \\
\text { by Healthy Families, which } \\
\text { operates under contract with the } \\
\text { Villages. The intake workers in } \\
\text { Lake County are primarily } \\
\text { employed by another agency, } \\
\text { Mental Health Associates. }\end{array}$ & $\begin{array}{l}\text { HFI administers BSF in Indiana, in } \\
\text { coordination with SCAN, Inc. In } \\
\text { Marion County, BSF is provided } \\
\text { through four Healthy Families } \\
\text { locations throughout the county. }\end{array}$ \\
\hline Community Context & $\begin{array}{l}\text { Couples are recruited from } \\
\text { throughout the Fort Wayne metro } \\
\text { area, which is predominantly } \\
\text { urban. }\end{array}$ & $\begin{array}{l}\text { The service area is both urban } \\
\text { and rural. }\end{array}$ & $\begin{array}{l}\text { Couples are recruited from } \\
\text { throughout the Indianapolis metro } \\
\text { area, the } 12^{\text {th }} \text { largest population in } \\
\text { the country, predominantly urban. }\end{array}$ \\
\hline $\begin{array}{l}\text { Approximate Level of Resources } \\
\text { Needed }\end{array}$ & $\$ 12,095$ on average per couple & $\$ 12,095$ on average per couple & $\$ 12,095$ on average per couple \\
\hline \multicolumn{4}{|l|}{ Recruitment } \\
\hline Source(s) & $\begin{array}{l}\text { Birthing hospitals and area social } \\
\text { service programs }\end{array}$ & Birthing hospitals & $\begin{array}{l}\text { Birthing hospitals and area social } \\
\text { service programs }\end{array}$ \\
\hline
\end{tabular}


Table A-5 (continued)

\begin{tabular}{|c|c|c|c|}
\hline & Allen County, Indiana & Lake County, Indiana & Marion County, Indiana \\
\hline Recruitment Strategies & $\begin{array}{l}\text { Assess mothers in hospital for } \\
\text { Healthy Families. If BSF eligible, } \\
\text { schedule a follow-up home visit to } \\
\text { introduce BSF and complete } \\
\text { intake. Fathers often complete } \\
\text { BSF intake during a separate } \\
\text { home visit. }\end{array}$ & $\begin{array}{l}\text { Assess mothers in hospital for } \\
\text { Healthy Families. Potentially } \\
\text { eligible BSF cases are turned over } \\
\text { to BSF group facilitators for intake. } \\
\text { Group facilitators contact mothers } \\
\text { by telephone to introduce BSF } \\
\text { and schedule an intake home visit. } \\
\text { Dad is asked to be at scheduled } \\
\text { home visit. }\end{array}$ & $\begin{array}{l}\text { Assessment workers receive } \\
\text { Healthy Families referrals from } \\
\text { WIC. Home visits are scheduled } \\
\text { with mothers to complete Healthy } \\
\text { Families assessment. Potentially } \\
\text { eligible BSF cases are turned over } \\
\text { to BSF group facilitators for intake. } \\
\text { Group facilitators contact mothers } \\
\text { by telephone to introduce BSF } \\
\text { and schedule an intake home visit. } \\
\text { Dad is asked to be at scheduled } \\
\text { home visit. }\end{array}$ \\
\hline Enrollment Rate & $\begin{array}{l}59 \text { couples enrolled as of March } \\
31,2007.4 \text { couples are enrolled } \\
\text { per month, on average. }\end{array}$ & $\begin{array}{l}45 \text { couples enrolled as of March } \\
31,2007.4 \text { couples are enrolled } \\
\text { per month, on average. }\end{array}$ & $\begin{array}{l}139 \text { couples enrolled as of March } \\
31,2007.12 \text { couples are enrolled } \\
\text { per month, on average. }\end{array}$ \\
\hline $\begin{array}{l}\text { Enrollee Characteristics at } \\
\text { Baseline }\end{array}$ & $\begin{array}{l}29 \% \text { are African American and } \\
53 \% \text { are White; } 83 \% \text { have } \mathrm{H} / \mathrm{S} \\
\text { diploma; } 53 \% \text { employed; } 76 \% \\
\text { earn less than } \$ 15,000 / \text { year; } 76 \% \\
\text { cohabit; } 28 \% \text { MPF; } 79 \% \text { high } \\
\text { chance of marriage; } 22 \% \\
\text { pregnant. }\end{array}$ & $\begin{array}{l}56 \% \text { are African American and } \\
35 \% \text { are White; } 75 \% \text { have H/S } \\
\text { diploma; } 42 \% \text { employed; } 80 \% \\
\text { earn less than } \$ 15,000 / y e a r ; 72 \% \\
\text { cohabit; } 30 \% \text { MPF; } 73 \% \text { high } \\
\text { chance of marriage; } 64 \% \\
\text { pregnant. }\end{array}$ & $\begin{array}{l}61 \% \text { are African American and } \\
28 \% \text { are White; } 70 \% \text { have H/S } \\
\text { diploma; } 56 \% \text { employed; } 66 \% \\
\text { earn less than } \$ 15,000 / y e a r ; 75 \% \\
\text { cohabit; } 31 \% \text { MPF, } 79 \% \text { high } \\
\text { chance of marriage; } 35 \% \\
\text { pregnant. }\end{array}$ \\
\hline \multicolumn{4}{|c|}{ Marriage and Relationship Skills Groups } \\
\hline Curriculum Choice & Loving Couples, Loving Children & Loving Couples, Loving Children & Loving Couples, Loving Children \\
\hline Delivery Format(s) & Weekly 2-hour sessions & Weekly 2-hour sessions & Weekly 2-hour sessions \\
\hline Incentives for Attendance & $\begin{array}{l}\text { Provide incentives to couples after } \\
\text { they achieve set attendance } \\
\text { milestones. Incentives are gift } \\
\text { cards to recognize initial and } \\
\text { ongoing attendance. }\end{array}$ & $\begin{array}{l}\text { Provide incentives to couples after } \\
\text { they achieve set attendance } \\
\text { milestones. Incentives are gift } \\
\text { cards to recognize initial and } \\
\text { ongoing attendance. }\end{array}$ & $\begin{array}{l}\text { Provide incentives to couples after } \\
\text { they achieve set attendance } \\
\text { milestones. Incentives are gift } \\
\text { cards to recognize initial and } \\
\text { ongoing attendance. }\end{array}$ \\
\hline
\end{tabular}


Table A-5 (continued)

\begin{tabular}{llll}
\hline & \multicolumn{1}{c}{ Allen County, Indiana } & \multicolumn{1}{c}{ Lake County, Indiana } & \multicolumn{1}{c}{ Marion County, Indiana } \\
\hline $\begin{array}{l}\text { Other Practices to Encourage } \\
\text { Attendance }\end{array}$ & $\begin{array}{l}\text { Social activities with other BSF } \\
\text { couples; meet with BSF group } \\
\text { facilitator; parenting-focused home } \\
\text { visits; staff reminders; ongoing } \\
\text { social activities; telephone contact } \\
\text { after group absence; make-up } \\
\text { sessions. }\end{array}$ & $\begin{array}{l}\text { Meet with BSF group facilitator; } \\
\text { parenting-focused home visits; } \\
\text { staff reminders. }\end{array}$ & $\begin{array}{l}\text { Social activities with other BSF } \\
\text { couples; parenting-focused home } \\
\text { visits; staff reminders; ongoing } \\
\text { social activities; telephone contact } \\
\text { after group absence; make-up } \\
\text { sessions; comfortable setting. }\end{array}$ \\
\hline $\begin{array}{l}\text { Percentage of Program Group that } \\
\text { Initiated Attendance }\end{array}$ & $50 \%$ & $50 \%$ & $40 \%$ \\
\hline $\begin{array}{l}\text { Total Average Hours of } \\
\text { Participation by Initiators }\end{array}$ & 26 hours & 19 hours & 28 hours \\
\hline $\begin{array}{l}\text { Percentage of Couples } \\
\text { Completing } 80 \%-100 \% \text { of } \\
\text { Curriculum }\end{array}$ & $20 \%$ & $0 \%$ & $15 \%$ \\
\hline
\end{tabular}

\section{Family Coordinator Component}

Philosophy of Case Management

home visits for Healthy Families.

Limited integration of BSF material

during home visits.

Staffing Arrangement

A dedicated home visitor jointly provides Healthy Families and BSF services. Group facilitators provide some follow-up with couples outside of group sessions.

Encouraging Group Attendance
Home visitors and group

facilitators jointly encourage group attendance during home visits on a regular basis.
Conduct weekly parenting-focused Conduct weekly parenting-focused home visits for Healthy Families. home visits for Healthy Families. Limited integration of BSF material Limited integration of BSF material during home visits. during home visits.

A dedicated home visitor jointly provides Healthy Families and BSF services. Group facilitators provide some follow-up with

A dedicated home visitor jointly provides Healthy Families and BSF services. Group facilitators provide some follow-up with couples outside of group sessions. couples outside of group sessions.

Group facilitators contact couples by telephone to encourage group attendance on a regular basis.
Group facilitators contact couples by telephone to encourage group attendance on a regular basis. 
Table A-5 (continued)

\section{Allen County, Indiana}

Reinforcing Relationship Skills

Home visitors recently trained to reinforce skills during home visits with couples.
Lake County, Indiana

Home visitors recently trained to reinforce skills during home visits with couples.

\section{Marion County, Indiana}

Group facilitators reinforce skills during telephone contact with couples on an as needed basis. Home visitors recently trained to support couples.

Frequency of FC contact

Parents'
Contacts

\section{Family Support Services Component}

$100 \%$ of program group couples contacted outside of group sessions. Average number of monthly contacts per couple is about 8 . Couples were contacted mostly via home visit $(39 \%$ of all contacts) and by telephone (34\%).
$91 \%$ of program group couples contacted outside of group sessions. Average number of monthly contacts per couple is 4 . Couples were contacted mostly by telephone ( $48 \%$ of all contacts) and via home visit (42\%).
$100 \%$ of program group couples contacted outside of group sessions. Average number of monthly contacts per couple is 4 .

Couples were contacted mostly by telephone ( $44 \%$ of all contacts) and via home visit (44\%).

$32 \%$ of contacts with both parents.

$33 \%$ of contacts with both parents.

Method of Assessment

Goal Setting depth, informally structured assessment.

Who is Assessed; How Often; Intake workers assess mothers during intake. Fathers included in the assessment, if present, though the assessment is not targeted to fathers. Home visitors continue to monitor the needs of mothers during ongoing visits.
Intake workers conduct an indepth, informally structured assessment.

Intake workers assess mothers during intake.

64
Intake workers conduct an indepth, informally structured assessment.

Intake workers assess mothers during intake. Home visitors continue to monitor the needs of mothers during ongoing visits. 
Table A-6. Summary of BSF Development and Implementation in Oklahoma City, Oklahoma

\begin{tabular}{|c|c|}
\hline \multicolumn{2}{|l|}{ Program Setting } \\
\hline Sponsoring Organization & $\begin{array}{l}\text { Public Strategies, Inc. operates Oklahoma's BSF program, Family Expectations, as part of its contract with } \\
\text { the Oklahoma Department of Human Services to implement the Oklahoma Marriage Initiative. }\end{array}$ \\
\hline Organizational Structure & $\begin{array}{l}\text { PSI manages and operates all components of Family Expectations, which was developed from the ground } \\
\text { up in Oklahoma. }\end{array}$ \\
\hline Community Context & Family Expectations serves couples throughout Oklahoma City. \\
\hline $\begin{array}{l}\text { Approximate Level of Resources } \\
\text { Needed }\end{array}$ & $\$ 11,149$ per couple \\
\hline \multicolumn{2}{|l|}{ Recruitment } \\
\hline Source(s) & $\begin{array}{l}\text { Wide variety of recruitment sources, including birthing hospitals, prenatal clinics, public health clinics, and } \\
\text { social service programs. Also broad outreach, such as public service announcements and personal } \\
\text { referrals. }\end{array}$ \\
\hline Recruitment Strategies & $\begin{array}{l}\text { Family Expectations often receives referrals from recruitment sources. Outreach workers initiate contact } \\
\text { with potential couples through telephone calls. Staff attempt to conduct the full intake with both members of } \\
\text { the couple simultaneously. All intakes occur at the program office. }\end{array}$ \\
\hline Enrollment Rate & 294 couples enrolled as of March $31,2007.35$ couples are enrolled per month, on average. \\
\hline $\begin{array}{l}\text { Enrollee Characteristics at } \\
\text { Baseline }\end{array}$ & $\begin{array}{l}31 \% \text { are African American and } 41 \% \text { are White; } 70 \% \text { have } \mathrm{H} / \mathrm{S} \text { diploma; } 54 \% \text { employed; } 72 \% \text { earn less than } \\
\$ 15,000 / \text { year; } 79 \% \text { cohabit, } 27 \% \text { MPF; } 73 \% \text { high chance of marriage; } 85 \% \text { pregnant. }\end{array}$ \\
\hline \multicolumn{2}{|c|}{ Marriage and Relationship Skills Groups } \\
\hline Curriculum Choice & Becoming Parents Program for Low-Income, Low-Literacy Couples \\
\hline Delivery Format(s) & $\begin{array}{l}\text { Two formats offered: A weekend format with } 5 \text {-hour sessions that meet weekly for } 6 \text { weeks, and a weekday } \\
\text { format with 3-hour sessions that meet for } 10 \text { weeks. Unmarried BSF couples may meet in groups together } \\
\text { with married couples participating as part of the Supporting Healthy Marriages demonstration. }\end{array}$ \\
\hline Incentives for Attendance & $\begin{array}{l}\text { Couples receive a cash incentive after completing } 6,15 \text {, and } 30 \text { hours of the curriculum. Couples also earn } \\
\text { "Crib Cash" for each group attendance (redeemable at the on-site store). }\end{array}$ \\
\hline
\end{tabular}


Table A-6 (continued)

Other Practices to Encourage

Attendance

Percentage of Program Group that $\quad 80 \%$

Initiated Attendance

Total Average Hours of
Participation by Initiators

Percentage of Couples $\quad 40 \%$

Completing $80 \%-100 \%$ of

Curriculum

\section{Family Coordinator Component}

Philosophy of Case Management

Couples should be expected to come to the program office for regularly scheduled meetings. The frequency of meetings should decrease over time.

$\begin{array}{ll}\text { Staffing Arrangement } & \begin{array}{l}\text { Dedicated FC staff work individually with unmarried couples in BSF, and with married couples who } \\ \text { participate in the Strengthening Healthy Marriages program. }\end{array}\end{array}$

Encouraging Group Attendance

Family coordinators encourage couples to attend group sessions during telephone contact on an as needed basis.

Reinforcing Relationship Skills

Family coordinators reinforce skills during office visits with couples on a regular basis.

Frequency of $\mathrm{FC}$ contact

$100 \%$ of program group couples contacted outside of group sessions. Average number of monthly contacts per couple is about 4 . The majority of all contacts are via telephone $(71 \%)$ and office visits $(25 \%)$.

Parents' Attendance at FC

Contacts

\section{Family Support Services Component}

\section{Method of Assessment}

Who is Assessed; How Often;

Goal Setting

Percentage of Program Group

Referred for Services
Formal assessment of couple's needs using tools developed by the site.

Mothers and fathers assessed soon after enrolling in BSF during a program office visit with the family coordinator.

$61 \%$ 
Table A-7. Summary of BSF Development and Implementation in Texas

\begin{tabular}{|c|c|c|}
\hline & Houston, Texas & San Angelo, Texas \\
\hline \multicolumn{3}{|l|}{ Program Setting } \\
\hline Sponsoring Organization & $\begin{array}{l}\text { Houston transformed its Healthy Families services } \\
\text { into a BSF program, by serving only couples who } \\
\text { meet BSF eligibility requirements. Houston receives } \\
\text { financial support from a state } 1115 \text { waiver and from } \\
\text { an ACF Healthy Marriage Initiative grant. }\end{array}$ & $\begin{array}{l}\text { San Angelo transformed its Healthy Families services into a } \\
\text { BSF program, by serving only couples who meet BSF } \\
\text { eligibility requirements. San Angelo receives financial } \\
\text { support from a state } 1115 \text { waiver. }\end{array}$ \\
\hline Organizational Structure & $\begin{array}{l}\text { Healthy Families Initiatives in Houston manages and } \\
\text { operates all components of BSF. }\end{array}$ & $\begin{array}{l}\text { Healthy Families San Angelo manages and operates all } \\
\text { components of BSF. }\end{array}$ \\
\hline Community Context & $\begin{array}{l}\text { Couples recruited from throughout the Houston metro } \\
\text { area. The majority are Spanish-speaking and } \\
\text { Hispanic. }\end{array}$ & $\begin{array}{l}\text { San Angelo primarily serves English-speaking, Hispanic } \\
\text { couples. }\end{array}$ \\
\hline $\begin{array}{l}\text { Approximate Level of } \\
\text { Resources Needed }\end{array}$ & $\$ 10,112$ per couple & $\$ 12,607$ per couple \\
\hline \multicolumn{3}{|l|}{ Recruitment } \\
\hline Source(s) & $\begin{array}{l}\text { Partnerships with area birthing hospitals and four } \\
\text { public health clinics. }\end{array}$ & The local hospital serves as the primary recruitment source. \\
\hline Recruitment Strategies & $\begin{array}{l}\text { Houston receives referrals from recruitment partners } \\
\text { and then contacts couples by telephone to schedule a } \\
\text { full intake. Recently, Houston began to station } \\
\text { outreach staff at public health clinics to facilitate direct } \\
\text { interaction between the program and potentially } \\
\text { eligible couples. }\end{array}$ & $\begin{array}{l}\text { Outreach staff make initial contact with mothers during their } \\
\text { hospital stay after the child's birth. Full intake is conducted } \\
\text { later with interested couples in their home, ideally with } \\
\text { mothers and fathers simultaneously. }\end{array}$ \\
\hline Enrollment Rate & $\begin{array}{l}220 \text { couples enrolled as of March } 31,2007.14 \\
\text { couples enrolled per month, on average. }\end{array}$ & $\begin{array}{l}219 \text { couples enrolled as of March } 31,2007.13 \text { couples } \\
\text { enrolled per month, on average. }\end{array}$ \\
\hline $\begin{array}{l}\text { Enrollee Characteristics at } \\
\text { Baseline }\end{array}$ & $\begin{array}{l}90 \% \text { are Hispanic; } 58 \% \text { have } \mathrm{H} / \mathrm{S} \text { diploma; } 51 \% \\
\text { employed; } 69 \% \text { earn less than } \$ 15,000 / \text { year. } 83 \% \\
\text { cohabit, } 26 \% \text { MPF, } 69 \% \text { high chance of marriage. } \\
64 \% \text { pregnant. }\end{array}$ & $\begin{array}{l}73 \% \text { are Hispanic and } 21 \% \text { are White; } 64 \% \text { have } \mathrm{H} / \mathrm{S} \\
\text { diploma; } 53 \% \text { employed; } 82 \% \text { earn less than } \$ 15,000 / \text { year; } \\
81 \% \text { cohabit, } 32 \% \text { MPF, } 80 \% \text { high chance of marriage; } 17 \% \\
\text { pregnant. }\end{array}$ \\
\hline
\end{tabular}


Table A-7 (continued)

\section{Houston, Texas}

San Angelo, Texas

\section{Marriage And Relationship Skills Groups}

\begin{tabular}{|c|c|c|}
\hline Curriculum Choice & Love's Cradle & Love's Cradle \\
\hline Delivery Format(s) & $\begin{array}{l}\text { 2-hour, 4-hour, or } 6 \text {-hour sessions. Multiple modules } \\
\text { are presented at the longer sessions. }\end{array}$ & 2-hour weekly sessions \\
\hline Incentives for Attendance & $\begin{array}{l}\text { Couples earn cash incentives that are redeemable } \\
\text { after attaining set attendance milestones. Raffles } \\
\text { also held during sessions. }\end{array}$ & $\begin{array}{l}\text { San Angelo does not regularly offer incentives to couples to } \\
\text { encourage attendance, though they occasionally provide } \\
\text { various gifts to participants such as movie tickets or door } \\
\text { prizes. }\end{array}$ \\
\hline $\begin{array}{l}\text { Other Practices to } \\
\text { Encourage Attendance }\end{array}$ & $\begin{array}{l}\text { Meetings with Family Coordinators and initiation of } \\
\text { parenting-focused home visits; staff reminders; } \\
\text { ongoing social activities; telephone contact after } \\
\text { group absences; couples receive material missed } \\
\text { during absence }\end{array}$ & $\begin{array}{l}\text { Meetings with Family Coordinators and initiation of } \\
\text { parenting-focused home visits; group orientation session; } \\
\text { staff reminders; ongoing social activities; meeting with } \\
\text { current/past participants; telephone contact after group } \\
\text { absences; couples receive material missed during absence; } \\
\text { comfortable setting. }\end{array}$ \\
\hline $\begin{array}{l}\text { Percentage of Program } \\
\text { Group that Initiated } \\
\text { Attendance }\end{array}$ & $43 \%$ & $57 \%$ \\
\hline $\begin{array}{l}\text { Total Average Hours of } \\
\text { Participation by Initiators }\end{array}$ & 20 hours & 25 hours \\
\hline $\begin{array}{l}\text { Percentage of Couples } \\
\text { Completing } 80 \%-100 \% \text { of } \\
\text { Curriculum }\end{array}$ & $3 \%$ & $12 \%$ \\
\hline
\end{tabular}

\section{Family Coordinator Component}

Philosophy of Case

Management

Staffing Arrangement
Conduct weekly home visits that integrate parenting

focus of Healthy Families with the couple and relationship focus of BSF.

Dedicated home visiting staff fulfill the family coordinator role and conduct the parenting-focused home visits.
Conduct weekly home visits that integrate parenting focus of Healthy Families with the couple and relationship focus of BSF.

Dedicated home visiting staff fulfill the family coordinator role and conduct the parenting-focused home visits. 
Table A-7 (continued)

\section{Houston, Texas}

\begin{tabular}{|c|c|c|}
\hline $\begin{array}{l}\text { Encouraging Group } \\
\text { Attendance }\end{array}$ & $\begin{array}{l}\text { Family coordinators encourage couples to attend } \\
\text { group sessions during regularly scheduled home } \\
\text { visits. }\end{array}$ & $\begin{array}{l}\text { Family coordinators encourage couples to attend group } \\
\text { sessions during regularly scheduled home visits. }\end{array}$ \\
\hline $\begin{array}{l}\text { Reinforcing Relationship } \\
\text { Skills }\end{array}$ & $\begin{array}{l}\text { Family coordinators reinforce skills during home visits } \\
\text { with couples on an as needed basis. All FCs are } \\
\text { trained in the Love's Cradle curriculum. }\end{array}$ & $\begin{array}{l}\text { Family coordinators reinforce skills during home visits with } \\
\text { couples on a regular basis. All FCs are trained in the Love's } \\
\text { Cradle curriculum. }\end{array}$ \\
\hline Frequency of FC contact & $\begin{array}{l}100 \% \text { of program group couples were contacted } \\
\text { outside of group sessions. Average number of } \\
\text { monthly contacts per couple is about } 4 \text {. Couples } \\
\text { were contacted mostly via home visits }(53 \%) \text { and by } \\
\text { telephone ( } 43 \% \text { of all contacts). }\end{array}$ & $\begin{array}{l}100 \% \text { of program group couples were contacted outside of } \\
\text { group sessions. Average number of monthly contacts per } \\
\text { couple is about } 5 \text {. Couples were contacted mostly via home } \\
\text { visits }(51 \%) \text { and by telephone ( } 29 \% \text { of all contacts). }\end{array}$ \\
\hline $\begin{array}{l}\text { Parents' Attendance at FC } \\
\text { Contacts }\end{array}$ & $17 \%$ of contacts were with both parents. & $43 \%$ of contacts were with both parents. \\
\hline \multicolumn{3}{|c|}{ Family Support Services Component } \\
\hline Method of Assessment & Informal assessment during home visits. & $\begin{array}{l}\text { Informal assessment during assessment in hospital and } \\
\text { during home visits. }\end{array}$ \\
\hline $\begin{array}{l}\text { Who is Assessed; How } \\
\text { Often; Goal Setting }\end{array}$ & $\begin{array}{l}\text { Mothers and fathers assessed during intake. } \\
\text { Assessments are updated during program } \\
\text { participation through family coordinators monitoring } \\
\text { the couple's needs. }\end{array}$ & $\begin{array}{l}\text { Mothers and fathers assessed shortly after random } \\
\text { assignment. Assessments are updated during program } \\
\text { participation through family coordinators monitoring the } \\
\text { couple's needs. }\end{array}$ \\
\hline $\begin{array}{l}\text { Percentage of Program } \\
\text { Group Referred for } \\
\text { Services }\end{array}$ & $56 \%$ & $40 \%$ \\
\hline
\end{tabular}

